\title{
Nutritional depletion and physical impairment in patients with chronic obstructive pulmonary disease : implications for therapy
}

Citation for published version (APA):

Schols, A. M. W. J. (1991). Nutritional depletion and physical impairment in patients with chronic obstructive pulmonary disease : implications for therapy. [Doctoral Thesis, Maastricht University]. Rijksuniversiteit Limburg. https://doi.org/10.26481/dis.19911018as

Document status and date:

Published: 01/01/1991

DOI:

10.26481/dis.19911018as

Document Version:

Publisher's PDF, also known as Version of record

Please check the document version of this publication:

- A submitted manuscript is the version of the article upon submission and before peer-review. There can be important differences between the submitted version and the official published version of record.

People interested in the research are advised to contact the author for the final version of the publication, or visit the DOI to the publisher's website.

- The final author version and the galley proof are versions of the publication after peer review.

- The final published version features the final layout of the paper including the volume, issue and page numbers.

Link to publication

\footnotetext{
General rights rights.

- You may freely distribute the URL identifying the publication in the public portal. please follow below link for the End User Agreement:

www.umlib.nl/taverne-license

Take down policy

If you believe that this document breaches copyright please contact us at:

repository@maastrichtuniversity.nl

providing details and we will investigate your claim.
}

Copyright and moral rights for the publications made accessible in the public portal are retained by the authors and/or other copyright owners and it is a condition of accessing publications that users recognise and abide by the legal requirements associated with these

- Users may download and print one copy of any publication from the public portal for the purpose of private study or research.

- You may not further distribute the material or use it for any profit-making activity or commercial gain

If the publication is distributed under the terms of Article $25 \mathrm{fa}$ of the Dutch Copyright Act, indicated by the "Taverne" license above, 
Nutritional depletion and physical impairment in patients with chronic obstructive pulmonary disease

Implications for therapy 



\title{
Nutritional depletion and physical impairment in patients with chronic obstructive pulmonary disease
}

\author{
Implications for therapy
}

\section{Proefschrift}

ter verkrijging van de grad van doctor aan de Rijksuniversiteit Limburg te Maastricht, op gezag van de Rector Magnificus, Prof. Mr. M.J. Cohen, volgens het besluit van het College van Dekanen,

in het openbaar te verdedigen

op vrijdag 18 oktober 1991 om 16.00 uur

$$
\text { door }
$$

Anna Maria Wilhelmina Johanna Schols 
Promotor

Prof.Dr. P.B. Soeters

Co-promotor

Dr. E.F.M. Wouters

\section{Beoordelingscommissie}

Prof.Dr. F. ten Hoor, woorzitter

Prof.Dr. M. Decramer, Universitair Ziekenhuis Pellenberg, Leuven

Prof.Dr. C.L.A. van Herwaarden, Katholieke Universiteit Nijmegen

Prof. Dr. A.C. Nieuwenhuijzen Kruseman

Prof. R.M. Rogers M.D., University of Pittsburgh, USA

Prof.Dr. H.J.J. Wellens

CIP Data Koninklijke bibliotheek, Den Haag

Schols, Anra Maria Wilhelmina Johanna

Nutritional depletion and physical impairment in patients

with chronic obstructive pulmonary disease: implications for therapy /

Annemie Schols

Proefschrift Masastricht. - Met lit.opg.- Met samenvatting in het Nederlands.

ISBN 90-9004333-0

Trefw: voeding en gezondheid; CARA patienten.

Omslag: Rita van Gompel

Druk: ARS drukkerij Roermond

A.M.W.J. Schols De studies gepresenteerd in dit proefschrift werden hinancieel ondersteund door Organon International B.. $V$.
an door Nutricia Nederland B. V. De publicatie wan het proefschrift werd mede mogelijk gemaakt door financiële bijdragen van Mijnhardt B.V.
en de Stichting Hornerheide. 
Aam mijn ouders 


\section{Contents}

Chapter 1

Introduction

Part I: Methods

Chapter 2

Body composition by bioelectrical impedance analysis compared to deuterium dilution. and skinfold anthropometry in patients with COPD

Chapter 3

Within-day variation of bioelectrical resistance measurements in patients with COPD

Chapter 4

Measurement of resting energy expenditure in patients with COPD in a clinical setting

Part II: Towards a definition of nutritional depletion

Chapter 5

Prevalence and characteristics of nutritional depletion in patients with COPD eligible for pulmonary rehabilitation

Chapter 6

Body composition and exercise performance in patients with COPD

Part III: Pathogenesis of nutritional depletion in COPD

Chapter 7

Resting energy expenditure in patients with COPD compared to a healthy control group

Chapter 8

Energy balance in patients with COPD

Chapter 9

Transcutaneous oxygen saturation and carbon dioxide tension during meals in patients with COPD 
Chapter 10

The effects of supplemental nutrition alone or combined with anabolic steroids on body composition and physical performance in nutritionally depleted COPD patients

References

Summary

Samenvatting

List of abbreviations

List of publications

Naschrift

Curriculum vitae 



\section{Introduction}

Chronic obstructive pulmonary disease (COPD) is defined as a disorder indicated by tests of abnormal expiratory flow that do not change markedly over periods of several months observation (ATS, 1981). The majority of patients exhibit permanent symptoms. The most important complaint is dyspnea during exertion, and in later stages also at rest. Dyspnea is frequently accompanied by wheezing, cough, sputum and recurrent bronchial infections. These symptoms progressively impair physical performance. Many patients start by avoiding physical activity and doing so enter a downward spiral, which ultimately leads to a point of total disability and inactivity and also to psychosocial distress. Treatment of COPD patients should be directed towards a reversal of this vicious circle. The symptoms indicate that this downward spiral cannot sufficiently be stopped by optimal medical therapy alone, but that a multidisciplinary approach is required.

Reports describing the relation between emaciation and COPD date back to the end of the 19th century (Fowler, 1898). The clinical typology of the emaciated 'pink puffer' and the obese 'blue bloater' introduced by Dormhorst in the early fifties (Dornhorst, 1955) highlighted a characteristically marked range in body appearance in COPD. In the sixties several studies reported that low body weight and weight loss are negatively associated with survival in COPD (Boushy, 1964; Renzetti, 1966; Vandenbergh 1967). There is not much more to be found in the literature until the early eighties, when several studies established the prevalence of nutritional depletion in COPD (Hunter 1981; Driver 1982; Braun, 1984; Fiaccadori, 1988; Schols1, 1989). Prevalence rates ranged from 20 to $70 \%$, depending on the nutritional measures employed and the source of patient population. Therapeutic implications of nutritional depletion in COPD became evident when studies disputed the long-held misconception that the respiratory muscles are spared during undernutrition and dernonstrated that nutritional depletion can cause major alterations in both respiratory muscle mass and function (Thurlbeck, 1978; Arora ${ }^{1+11}, 1982$; Lewis, 1986).

Aim of the study

For the clinical management of nutritional depletion in COPD, acquiring a complete picture of the problem is essential. There is not much information regarding the pathogenesis of nutritional depletion in COPD. Its impact on functional performance has not received much attention either. 
The major part of the work presented in this thesis is devoted to providing a conceptual framework for treating nutritional depletion in patients with stable COPD. In addition, preliminary results are presented of an attempt to improve physical performance in depleted COPD patients.

The thesis is divided into four parts.

Part $I$ is directed towards establishing the methods used in the study. A relatively new technique for assessing body composition in a clinical setting is the bioelectrical impedance method. Chapters 2 and 3 investigate the reliability and reproducibility of this method when fat-free mass in patients with stable COPD is assessed. In chapter 4 a computerized open-circuit ventilated hood is described, constructed with the aim of assessing resting energy expenditure in a clinical setting.

In part II an attempt is made to define nutritional depletion in COPD, on the assumption that nutritional depletion should be reflected by impaired physical performance. Prevalence of nutritional depletion, assessed by several bady composition measures, is related to disease severity and physical impairment in chapter 5 . In chapter 6 a specific investigation is made into which measure of depletion best predicts exercise performance in COPD.

In part III the pathogenesis of nutritional depletion in COPD is dealt with. A major cause of weight loss is an imbalance between energy intake and energy expenditure. In chapter 7 resting energy expenditure in COPD patients is compared with that of a healthy, agematched control group. In chapter 8 energy intake and resting energy expenditure in patients who have recently suffered weight loss are compared with those of stable-weight COPD patients. In the same chapter energy balance is related to disease severity. Chapter 9 systematically deals with the adverse effects of dietary intake on transcutaneous oxygen saturation and carbon dioxide tension.

In part IV the interim analysis is presented of a randomized, placebo-controlled trial investigating the effects of supplemental nutrition, alone or combined with anabolic steroids, on body composition and physical performance of nutritionally depleted COPD patients participating in a pulmonary rehabilitation program. 
Part I: Methods 



\section{Chapter 2}

\section{Body composition by bioelectrical impedance analysis compared to deuterium dilution and skinfold anthropometry in patients with COPD}

\section{Abstract}

Body composition is an important measure of nutritional status in patients with Chronic Obstructive Pulmonary Disease (COPD). We generated a regression model for bioelectrical impedance (bi) using deuterium dilution $\left({ }^{2} \mathrm{H}_{2} \mathrm{O}\right)$ as a reference method in 32 patients with severe COPD, aged (mean \pm SD) $63 \pm 9 \mathrm{y}$. All patients were in stable pulmonary and cardiac condition, without visible signs of edema. Height squared divided by resistance $\left(\mathrm{Ht}^{2} / \mathrm{R}\right)$ correlated well with total body water as measured by ${ }^{2} \mathrm{H}_{2} \mathrm{O}(\mathrm{r}=0.93$, standard error of estimation $(\mathrm{SEE})=1.9 \mathrm{~L})$. The best fitting regression equation to predict total body water consisted of $\mathrm{Ht}^{2} / \mathrm{R}$ and body weight $\left(\mathrm{r}^{2}=0.89, \mathrm{SEE}=1.8 \mathrm{~L}\right)$. The bi predicted total body water was used to estimate bi-fat-free mass (FFM) that was compared with skinfold based FFM predictions (anthr-FFM). Relative to bi-FFM a significant overestimation of $4.4 \pm 0.8 \mathrm{~kg}$ was found by anthr-FFM. Our results suggest that bioelectrical resistance is a useful measure to assess body composition in patients with severe COPD. In comparison with skinfold anthropometry, bi-FFM was found preferable in these elderly patients. 


\section{Introduction}

A negative energy balance commonly occurs in the course of COPD and can ultimately lead to cachexia (Wilson, 1985). Nutritional assessment is therefore important in patients with COPD. Numerous methods are available for the assessment of body composition (Lukaski, 1987). Laboratory methods such as hydrodensitometry, isotope dilution and whole body counting of potassium 40 are established valid techniques for assessing body composition (Lukaski, 1987). However, these methods require procedures which are not well suited for clinical practice. In clinical practice anthropometric methods are commonly applied. A relatively new technique for assessing body composition in the clinical setting is the bioelectrical impedance method. Good correlations of bioelectrical impedance measurements with total body water and fat-free mass determined from hydrodensitometry have been demonstrated in healthy subjects (Lukaski, 1985; Segall, 1985; Kushner 1986; Lukaski, 1986; Jackson, 1988). The method seems promising for clinical use because it is a non invasive measurement, takes only a few minutes and requires no active collaboration of the patients. The analyzer is portable and relatively inexpensive. A high short term reproducibility potentially reduces the inter observer error which is believed to be a major limitation of anthropometry (Jensen, 1983). Concern has been raised however about the validity of impedance measurements for determination of body composition in subjects with abnormal body composition such as in the elderly and in specific disease states (Lukaski, 1985; Cohn, 1985; Katch, 1986). In this study we compare bioelectrical impedance with deuterium dilution and skinfold anthropometry in patients with severe COPD.

\section{Methods}

\section{Parients}

The study group consisted of 24 men and 8 women with severe COPD (table 1) admitted to a pulmonary rehabilitation center. The patients admitted in the study were required to be in stable pulmonary and cardiac condition to exclude a possible confounding effect of excessive fluid shifts. None of the patients had clinical signs of edema or suffered from a lower respiratory tract infection. Maintenance medication in nearly all patients included theophylline, $B_{2}$-agonists and inhaled or oral corticosteroids. Seventeen patients were on maintenance oral diuretic medication. Serum electrolyte concentrations were monitored and within normal range in all patients. Medication was taken at $7 \mathrm{a} . \mathrm{m}$. The patients were informed about the nature and purpose of the study and gave written consent. The study was approved by the ethical comittee of our university. Procedures followed were in accord with the Helsinki declaration from 1977 as revised in 1983. 


\section{Deuterium dilution}

After a fasting baseline urine sample was taken in the early morning ( 6 a.m.) each subject received a weighed 5.00 gram oral dose of deuterium labeled water ( 99.84 atom percentage excess) mixed into $\approx 50 \mathrm{ml}$ watter. The bottle was rinsed once with tap water which was also drunk. Urine samples were collected $3-5,5-6$ and $11-12 \mathrm{~h}$ respectively after the ${ }^{2} \mathrm{H}_{2} \mathrm{O}$ was taken. Deuterium abundances in the urine were measured in duplicate with an isotope ratio mass spectrometer (type Aqua Sira, VG Isogas (Barry, 1985)). The plateau value in the urine after equilibration time and before isotope decay, was reached in nearly all patients in the 5-6 h sample. Isotope excess was \pm 150 ppm. Differences between duplicate measurements were less than 1 ppm indicating a precision of the measurement of at least $99 \%$. Total body water was calculated as the deuterium dilution space divided by 1.04 , correcting for exchange of the deuterium label with nonaquaeous hydrogen of body solids (Schoeller, 1980).

\section{Anthropometry}

Body height $(\mathrm{Ht})$ was measured bare foot standing and determined to the nearest $0.5 \mathrm{~cm}$ (Lameris WM 715, Breukelen, The Netherlands). Body weight was measured with a beam scale without shoes in light clothing to the nearest $0.1 \mathrm{~kg}$ (SECA, FRG). Skinfolds were measured in triplicate to the nearest $0.2 \mathrm{~mm}$ with a Harpenden skinfold caliper according to Durnin and Womersley (1974).

\section{Impedance}

The principle of bioelectrical impedance (bi) is based upon the conductance through body fluids of an electric current $(800 \mu \mathrm{A}, 50 \mathrm{kHz}$ ) (Lukaski, 1987). Conductivity is higher in the fat-free mass which contains all body fluids and electrolytes, than in fat (Pethig, 1979). Theoretically the fat-free mass is linearly related to height ${ }^{2} /$ body impedance or height ${ }^{2} /$ body resistance $\left(\mathrm{Ht}^{2} / \mathrm{R}\right.$ ) if it is assumed that the magnitude of reactance (the imaginary part of impedance) is small relative to resistance (the real part of impedance) (Hoffer, 1969). Resistance (BIA-101, RJL Systems, Detroil, USA) was measured in supine position at the right site as described by Lukaski et al (1986). Resistance measurements and skinfold anthropometry were performed between 9.30-10 a.m. after the patients had emptied their bladder, and at least $2 \mathrm{~h}$ after they had received breakfast and medication (Lukaski, 1987). All measurements were done by the same experienced observer.

\section{Statistics}

Resistance was expressed as a function of the squared height and compared with total body water by linear regression analysis. Height, weight and body mass index $(=$ weight $\left./ \mathrm{Ht}^{2}\left(\mathrm{~kg} / \mathrm{m}^{2}\right)\right)$ and $\mathrm{Ht}^{2} / \mathrm{R}$ were correlated to total body water using the product 


\section{Pant I: Methods}

moment correlation coefficient. Following the simple correlations a linear model was fitted to the data to enable the wariables that contributed to the total body water to be determined using stepwise regression analysis. The bi predicted total body water was used to estimate bi-FFM assuming a hydration factor of 0.73 of the FFM (Sheng, 1979). Percent fat-free mass was derived from the sum of triceps, biceps, suprailiac crest and subscapular skinfolds using the sex and age specific regression equations by Durnin and Womersley (1974). Data were converted to $\mathrm{kg}$ fat-free mass (anthr-FFM) by multiplicating percent fat-free mass by body weight. Differences between bi-FFM and anthr-FFM were tested for signifficance with paired Student"s t-tests (two-tailed). Significance was determined at the $5 \%$ level.

\section{Results}

Table 1 summarizes physical and pulmonary characteristics of the study group. The group represented elderly patients with a severe airflow obstruction. Mean body mass index was $21.2 \mathrm{~kg} / \mathrm{m}^{2}\left(15.7-26.8 \mathrm{~kg} / \mathrm{m}^{2}\right)$ indicating a normall to underweight study group. Figure 1 displays the relationship between $\mathrm{Ht}^{2} / \mathrm{R}$ and total body water.

Table 1: Physical and pulmonary characteristics of the study group.

\begin{tabular}{|c|c|c|c|c|c|c|c|c|c|}
\hline \multirow[b]{2}{*}{ age } & \multirow[b]{2}{*}{$(y)$} & \multicolumn{3}{|c|}{$\begin{array}{l}\text { men } \\
n=24\end{array}$} & \multicolumn{2}{|c|}{$\begin{array}{l}\text { women } \\
n=8\end{array}$} & \multicolumn{3}{|c|}{$\begin{array}{l}\text { men }+ \\
\text { women }\end{array}$} \\
\hline & & 65 & \pm & 10 & $57 \pm$ & 11 & 63 & \pm & 9 \\
\hline height & $(\mathrm{cm})$ & 171 & \pm & 5 & $158 \pm$ & 5 & 168 & \pm & 8 \\
\hline weight & (kg) & 62.7 & \pm & $6.2^{1}$ & $49.7 \pm$ & 5.4 & 59.6 & \pm & 8.1 \\
\hline BMI & $\left(\mathrm{kg} / \mathrm{m}^{2}\right)$ & 21.6 & \pm & 2.5 & $20.1 \pm$ & 2.1 & 21.2 & \pm & 2.5 \\
\hline IVC & (L) & 2.8 & \pm & 0.8 & $1.9 \pm$ & 0.5 & 2.6 & \pm & 0.7 \\
\hline $\mathrm{FEV}$ & (L) & 0.9 & \pm & 0.5 & $0.8 \pm$ & 0.4 & 0.9 & \pm & 0.5 \\
\hline $\mathrm{P}_{\mathrm{i}} \mathrm{O}_{2}$ & $\left(k \mathbb{P}_{d}\right)$ & 8.8 & \pm & 1.8 & $9.1 \pm$ & 1.3 & 8.9 & \pm & 1.6 \\
\hline $\mathrm{P}_{2} \mathrm{CO}_{2}$ & $(\mathrm{kPa})$ & 5.7 & \pm & 1.0 & $5.4 \pm$ & 0.9 & 5.6 & \pm & 1.0 \\
\hline
\end{tabular}

Mean $15 D$

A highly significant correlation coeficient was found with a low standard error of estimation $(r=0.93, S E E=1.9 L, p<0.001)$. The best single predictor of total body water was $\mathrm{Ht}^{2} / \mathrm{R}$ followed by body weight $(r=0.73, \mathrm{SEE}=3.4 \mathrm{~L}), \mathrm{R}(\mathrm{r}=-0.71, \mathrm{SEE}=3.5 \mathrm{~L})$ and height $(r=0.61, \mathrm{SEE}=4.0 \mathrm{~L})$, all were statistically significant with a $p$-value $<0.001$. The body mass index was a poor predictor of total body water $(r=0.39$, $\mathrm{SEE}=4.7 \mathrm{~L}, \mathrm{p}<0.001)$. On stepwise regression analysis the best prediction equation for total body water included $\mathrm{HL}^{2} / \mathrm{R}$ and weight $\left(\mathrm{R}^{2}=0.89, \mathrm{SEE}=1.8 \mathrm{~L}\right.$ ) (table 2). 
Table 2: The selected prediction equation with total body water as the dependent wandale.

\begin{tabular}{lllllll}
$\begin{array}{l}\text { Prediction } \\
\text { variables }\end{array}$ & $\mathrm{r}$ & $\begin{array}{l}\mathrm{R}^{2} \\
\text { model }^{1}\end{array}$ & $\mathrm{~F}$ model $^{2}$ & $\mathrm{dF}$ & Student $^{*} \mathrm{t}^{3}$ & \\
\hline Intercept & 3.32 & & & & & \\
$\mathrm{Hr}^{2} / \mathrm{R}$ & 0.44 & 0.87 & 181.2 & 1.31 & 9.39 & $\mathrm{p}<0.001$ \\
weight & 0.13 & 0.89 & 109.2 & 2.30 & 2.48 & $\mathrm{p}<0.05$ \\
\hline
\end{tabular}

${ }^{\prime} R^{2}=$ (regression sum of squares)/(total sum of squares) for model consisting of current and preceding variables.

${ }^{2}$ Model consisting of current and preceding variables

${ }^{3}$ After adjustment for the remaining wariables.

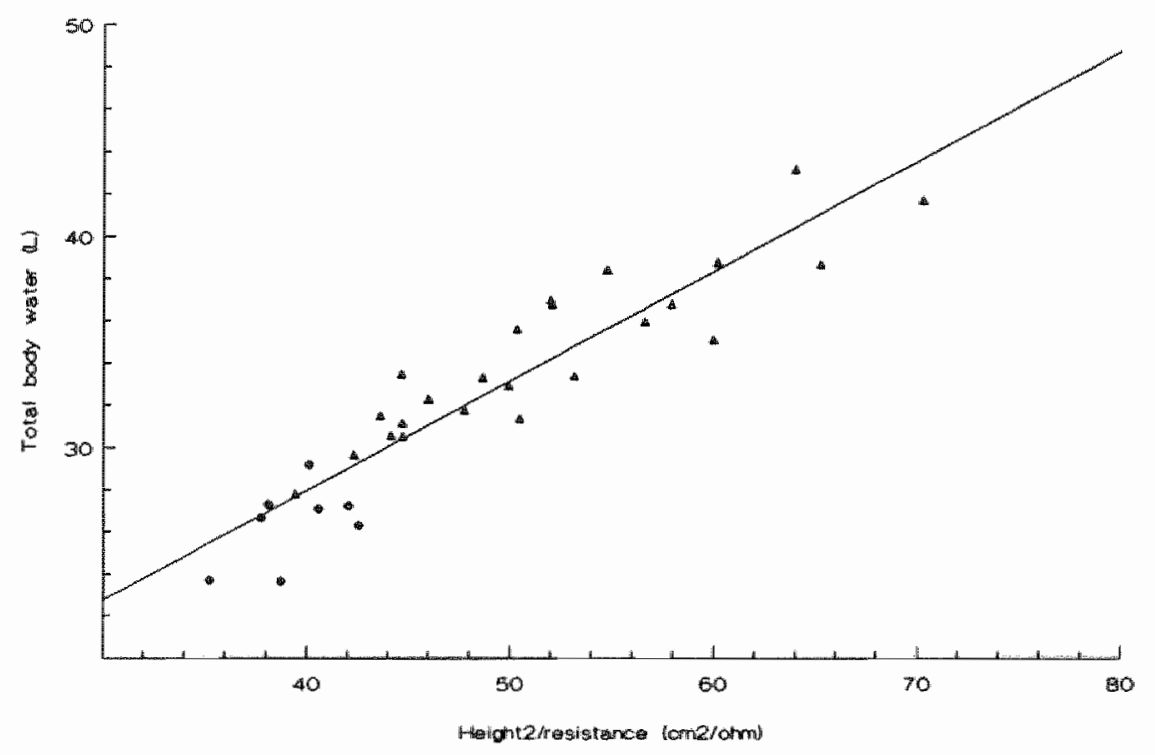

Figure 1: Linear regressions on resistance measurements corrected for height of total body water determined by deuterium dilution. Males (A), females (-)

\section{Discussion}

Several studies have indicated that nutritional status is impaired in a considerable number of patients with COPD. Disturbances in nutritional status in these patients have been characterized by gradual and significant weight loss, a low body weight and substandard values for anthropometric measures (Vandenbergh, 1967; Hunter, 1981; Openbrier, 1983; 


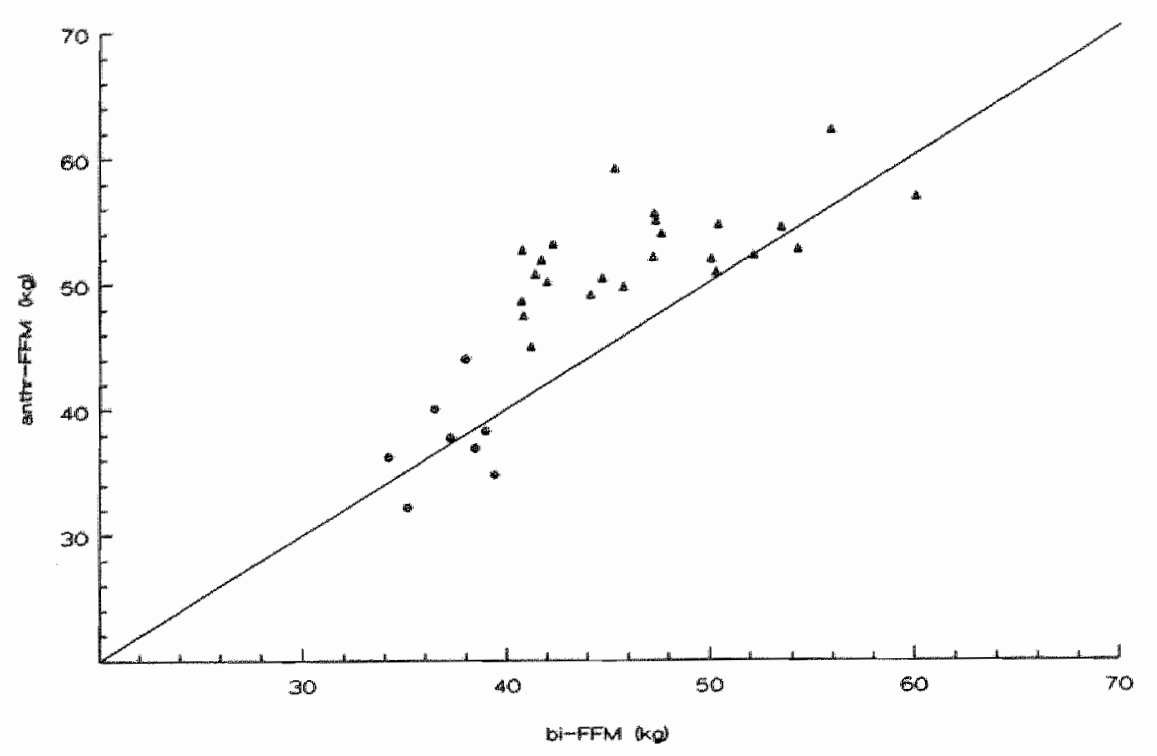

Figure 2: Comparison of predicted fat-free mass by multiple skinfold anthropomatry (anthr-FFM) and bioelectrical impedance (bi-FFM). Males ( $\Delta$ ) and females ( ). Line of idensity is indicated.

Braun, 1984, Fiaccedori, 1988; Schols, 1989). Body weight or body weight corrected for height as a measure of nutritional status is commonly used in clinical studies but has been criticized because it does not take into account differences in body composition between individuals (Edmonds, 1975).

Skinfold anthropometry is commonly used in clinical practice to measure body composition but presents several disadvantages. The method is based on the principle that a constant fraction of lotal body fat is located sub-cutaneously but has been shown to underestimate fat mass in elderly subjects due to a centralization and internalization of body fat which is not reflected by skinfolds (Seidell, 1987; Weits, 1988). The fat mass is calculated from reference tables that are based on regression equations which are population specific. Furthermore the inter observer reproducibility is low (Jensen, 1983). Bioelectrical impedance measurements may provide a means of estimating body composition that takes into account differences in fat distribution and in the ratio fat to fat-free tissue and may thus overcome the problems associated with estimates based on measurements of subcutaneous fat (skinfold thickness) or body size that do not take these differences into account (Lukaski, 1985). 
The development of a new method of assessing thuman body composition is hampered by the lack of convenient, accurate in vivo reference methods. Hydrodensitometry can be an accurate reference method; it is also an indirect estimate but is widely accepted because it has been tested against other independent body composition techniques such as carcassanalysis. Katch and coworkers measured body composition in 11 pulmonary patients by bioelectrical impedance and by hydrodensitometry. The correlation coefficient between percent fat from bioelectrical impedance and percent fat based on densitometry was only 0.65 (Katch, 1986). A disadvantage of using densitometry as a reference method in patients with COPD, is that many patients will be unable or unwilling to undergo the measurement because they are anxious about being totally submersed. Measurement of deuterium dilution space as an index of total body water is generally accepted as an important variable in the assessment of body composition (Lukaski, 1987). The method is more comfortable for the patient requiring only the ingestion of the isotope and the collection of one or more urine, blood or saliva samples afterwards. It seems a particularly appropriate method to compare with bioelectrical impedance because body fluids and electrolytes are responsible for electrical conductance. It is however important to consider the length of time required for tracer equilibration because it depends upon the characteristics of the study sample. In healthy men and women equilibration of deuterium occurs $2 \mathrm{~h}$ after ingestion of the tracer and remains at a constant concentration for the next $3 \mathrm{~h}$ (Lukaski, 1985). In this study group equilibration required $6 \mathrm{~h}$. This is possibly due to water retention in patients with severe COPD.

One of the limitations of deuterium dilution is that the calculation of fat-free mass relies on assumptions of the water content of fat-free mass. In this study we calculated fat-free mass assuming a constant ratio between total body water and fat-free mass of 0.73 (Sheng, 1979). This ratio is regarded questionable in elderly subjects or in patients receiving diuretics due to possible changes in the distribution of intracellular and extracellular water over the body. There is a decrease in body cell mass with age resulting from reductions in total body water, but there are conflicting reports regarding changes in extracellular water with age (Chumlea, 1989). Schoeller concluded in a recent review that the available animal and human studies indicate little or no change in the relationship between total body water and fatwee mass with aging. (Schoeller, 1989). Furthermore it should be stressed that diuretic medication in our patients was given as maintenance therapy and that no patient had visible edema. Alternative approaches to estimating body composition from $B I$ i.e. the estimation of body composution from resistance of body segments, or the assessment of intracellular and extracellular water by measuring reactance, may shed further light on water distribution over the body in COPD patients (Schoeller, 1989; Diaz, 1989). 
We established a good correlation between $\mathrm{HL}^{2} / \mathrm{R}$ and total body water measured by deuterium dilution, corresponding to results by others in healthy younger individuals (Segal, 1985; Kushner, 1986; Lukaski, 1986). None of our patients had clinical signs of edema. Use of diuretics did not increase the measurement error between total body water and $\mathrm{Ht}^{2} / \mathrm{R}$. On stepwise regression analysis only $\mathrm{Ht}^{2} / \mathrm{R}$ and weight were included in the best prediction equation for total body water. After inclusion of $\mathrm{Ht}^{2} / \mathrm{R}$ in the regression model, weight increased the explained variance by only $2 \%$. These findings do not support suggestions by others that in healthy individuals the high correlation reported for bioelectrical impedance is due to the inclusion of height, weight, age or other variables in the prediction equations (Fuller, 1989; Diaz, 1989; Deurenberg, 1989).

When comparing bi-FFM with anthr-FFM we confirmed the suggested overestimation of fat-free mass by skinfold thickness in elderly patients (Seidell, 1987; Weits, 1988). However attempts to predict fat-free mass from total body water and to compare fat-free mass predictions from bi and anthr are open to criticism because no independent reference standard of FFM for these elderly patients is available. To further elucidate the above indicated limitations a research design involving age-matched controls and patients in which total body water prediction equations are independently developed and cross validated is indicated.

We conclude that bioelectrical resistance is a useful measure for the assessment of fat-free mass in patients with severe COPD in slable pulmonary and cardiac condition. The results further suggest that in comparison with skinfold anthropometry, resistance measurements are preferable in elderly patients with COPD. 


\title{
Within-day variation of bioelectrical resistance measure- ments in patients with COPD
}

\begin{abstract}
The relative contribution of a meal, exercise and diuretic therapy on within-day variation of bioelectrical resistance measurements was studied in several groups of patients with severe chronic obstructive pulmonary disease (COPD). All patients were in stable clinical condition. Fasting resistance in the early morning was significantly higher than resistance values during the day (mean $\pm S D): 26 \pm 21$ Ohms). Relative to a non fasting pre-meal. value no significant decrease in resistance was measured within $4 \mathrm{~h}$ after ingestion of a meal. Resistance did not change significantly after a submaximal exercise challenge on the bicycle ergometer. No consistent effect of oral diuretics (40 $\mathrm{mg}$ furosemide) was established within $5 \mathrm{~h}$ after administration. Measurements on two consecutive days at the same time in the nourished state, were highly reproducible: mean change $4 \pm 20$ Ohms). We conclude that in patients with stable COPD within-day variation has only a slight

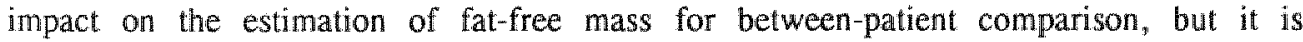
important to take into account during follow-up studies.
\end{abstract}




\section{Introduction}

A relative new technique for assessing body composition in clinical practice, is the tetrapolar bioelectrical impedance method. The principle of the method is based upon the conductivity of an electrical sinusoidal alternating current through body fluids (Lukaski, 1987). In the previous chapter we established a good correlation between bioelectrical resistance and total body water assessed by deuterium dilution in patients with COPD in sitable clinical condition.

Since in biological systems electrical conduction is related to water and ionic distribution in the conductor, it can be deduced that changes in body water and/or ellectrolyte balance influence total body resistance. This may be a drawback to the biloelectrical impedance method in specific conditions such as cardiac and pulmonary disease and during acute illness. In this study the within- and between-day variation of resistance was measured in patients with severe COPD in stable clinical condition. In addition the relative contribution of a meal, exercise and diuretic therapy to the within-day variation in resistance was studied.

\section{Methods}

Several groups of patients admitted to a pulmonary rehabilitation center participated in the study. All patients had severe COPD (forced expiratory volume in 1 s: $\mathrm{FEV}_{1}<50 \%$ of predicted). Patients admitted to the studly had to be in stable clinical condition without clinically detectable signs of edema. Maintenance medication in nearly all patients included theophylline, $B_{2}$-agonists, and inhaled or oral corticosteroids. Medication was taken at 7 a.m. The subjects were fully informed on the nature and purpose of the studies and gave their informed consent.

Body height $(\mathrm{Ht})$ was measured standing bare foot and determined to the nearest $0.5 \mathrm{~cm}$ (Lameris WM 715, Breukelen, The Netherlands). Body weight was measured with a beam scale without shoes in light clothing to the nearest $0.1 \mathrm{~kg}$ (SECA, FRG). Body resistance (R) (RIL-Systems, BIA 101, Detroit, USA) was measured as described by Lukaski (1986). The subjects were measured in a supine position by the same observer. The four electrodes were attached on the dorsal side of the foot and the ankle and on the dorsal side of the thand and the wrist at the right side of the body. The places for fixing the four electrodes were indicated with a sticker to ensure that electrodes were always attached at the same place. Because the technical error of the device is negligeable $(<1$ Ohm) and duplicate measurements in a subject made at the same time never differ by more than $1-2$ Ohms, measurements of resistance in this study are single measurements. 


\section{Sindy 1}

The within day variation in resistance was measured in 24 patients who were not under diuretic medication. The patients were measured at least $2 \mathrm{~h}$ after meal and medication were taken (Lukaski, 1987): (1) at $7 \mathrm{a.m}$. in bed, in the fasting state (2) in the morning at $9.30 \mathrm{a} . \mathrm{m}$. (3) in the afternoon at 2 p.m. and (4) in the evening at 7 p.m.

Srudy 2

The effect of a meal was studied in 10 patients not using diuretic medication. Resistance was measured just before (at $12 \mathrm{a} . \mathrm{m}$.) and $1,2,3$ and $4 \mathrm{~h}$ after ingestion of a warm meal $(625 \pm 100 \mathrm{kcal})$.

\section{Srudy 3}

A possible additional effect of maintenance diuretic therapy was measured in 20 patients within $5 \mathrm{~h}$ after administration of $40 \mathrm{mg}$ furosemide. After a baseline measurement at 7 a.m., just before the medication was taken, resistance was measured at 8 a.m., 9.30 a.m. and $12 \mathrm{a} . \mathrm{m}$. The patients recorded exactly what they ate and drank in this period and urine output was collected and measured between the assessment periods. In the last 8 patients, sodium, potassium and chloride concentrations in plasma and urine were also determined.

\section{Sindy 4}

The effect of exercise on body resistance was determined in 23 patients before and after a submaximal exercise period of $15 \mathrm{~min}$ on a bicycle ergometer. "The work load was adjusted to the patient and represented a relatively streneous exercise challenge.

\section{Study 5}

The within-person between-day variation in resistance was measured on two consecutive days: (a) in 36 patients at $8 \mathrm{a} . \mathrm{m}$. and (b) in 30 patients at $2 \mathrm{p.m}$. In the first group fatfree mass was calculated and expressed as a percentage of body weight, to adjust for possible variations in body weight between 2 days. Thirty patients used oral diuretics.

\section{Statistics}

Fat-free mass was calculated using the following regression equation: $\mathrm{FFM}(\mathrm{kg})=2.38$ $+\left(0.58 \times\right.$ height $^{2} /$ resistance $)+(0.23 \times$ weight $)$. For this formula the standard error of estimation (SEE) $=2.5 \mathrm{~kg}$ and $r^{2}=0.88$. This prediction equation was generated using deuterium dilution as a reference method and assuming a hydration factor of 0.73 (Sheng, 1979) (chapter 2). Analysis of variance was used to calculate the within-person variation of resistance and fat-free mass. Changes of these measures within the individual were tested for significance with paired Student's t-test (two-tailed). Differences between two 
patient groups were tested with the Mann Whitney $U$ test. Significance was determined at the $5 \%$ level. Except in figures, all results are expressed as mean \pm SD.

\section{Results}

Physical characteristics of the study group are listed in table 1 . The group represented elderly patients with severe COPD. Mean body mass index was within the normal range.

Tables 1: Age, weight, height and body mass index (BMI) of subjects participating in several studies.

\begin{tabular}{|c|c|c|c|c|c|c|c|c|c|c|c|c|}
\hline \multirow{2}{*}{$\frac{\text { Study }}{\text { 1. Within-day wariation }}$} & \multirow{2}{*}{ No } & \multicolumn{3}{|c|}{$\begin{array}{l}\text { age } \\
(y)\end{array}$} & \multicolumn{2}{|c|}{$\begin{array}{l}\text { weight } \\
(\mathrm{kg})\end{array}$} & \multicolumn{3}{|c|}{$\begin{array}{c}\text { height } \\
(\mathrm{cm})\end{array}$} & \multicolumn{3}{|c|}{$\begin{array}{l}\mathrm{BMI}^{1} \\
\left(\mathrm{~kg} / \mathrm{m}^{2}\right)\end{array}$} \\
\hline & & 63 & \pm & 7 & 66.0 & \pm 11.4 & 169 & \pm & 9 & 23.3 & \pm & $4.3^{2}$ \\
\hline 2. Effect of imeal & 10 & 67 & \pm & 9 & 66.9 & \pm 10.4 & 171 & \pm & 6 & 22.7 & \pm & 3.3 \\
\hline 3. Effect of exercise & 23 & 62 & \pm & 7 & 68.2 & \pm 11.9 & 172 & \pm & 8 & 22.9 & \pm & 3.1 \\
\hline 4. Effect of diuretics & 20 & 66 & \pm & 6 & 70.1 & \pm 8.3 & 169 & \pm & 4 & 24.5 & \pm & 3.0 \\
\hline \multicolumn{13}{|l|}{ 5. Between day variation } \\
\hline 8 a.m. & 36 & 64 & $\mathbb{E}$ & 8 & 61.0 & \pm 9.9 & 171 & \pm & 8 & 20.9 & \pm & 2.8 \\
\hline 2 p.m. & 30 & 62 & \pm & 6 & 66.6 & \pm 10.0 & 174 & \pm & 6 & 21.9 & \pm & 2.9 \\
\hline
\end{tabular}

1 Body mass index

2Except for No all values are expressed as mean \pm SD

\section{Study I}

Mean value of fasting resistance in the early morning was significantly higher than the other measurements (mean difference $26 \pm 21$ Ohms $(p<0.001)$ (95 percent confidence interval (CI): 16 to 36 Ohms), and consequently calculated fat-free mass was significantly $(\mathrm{p}<0.001)$ lower (figure 1$)(\mathrm{Cr}: 0.7$ to $1.3 \mathrm{~kg}$ ). The other three measurements during the day were not significantly different from each other. Mean within-person within-day variation of these three measurements was $0.3 \pm 0.2 \mathrm{~kg} \mathrm{WFM}$.

\section{Siudy 2}

A small but statistically significant decrease in resistance of $-6 \pm 6$ ohms $(\mathrm{p}<0.01)$ (C): -3 to -9 Ohms) was found between the measurement within $1 \mathrm{~h}$ after ingestion of the meal and 3 th after the meal (figure 2 ).

\section{Study 3}

For the complete group no consistent changes could be established between the fasting early morning resistance and any of the other measurements after treatment with diuretics (mean difference $0 \pm 18$ Ohms (CI: -8 to 8 ohms)). Eight out of 20 patients exhibited a significant decrease in resistance relative to the fasting early moming value until at least 


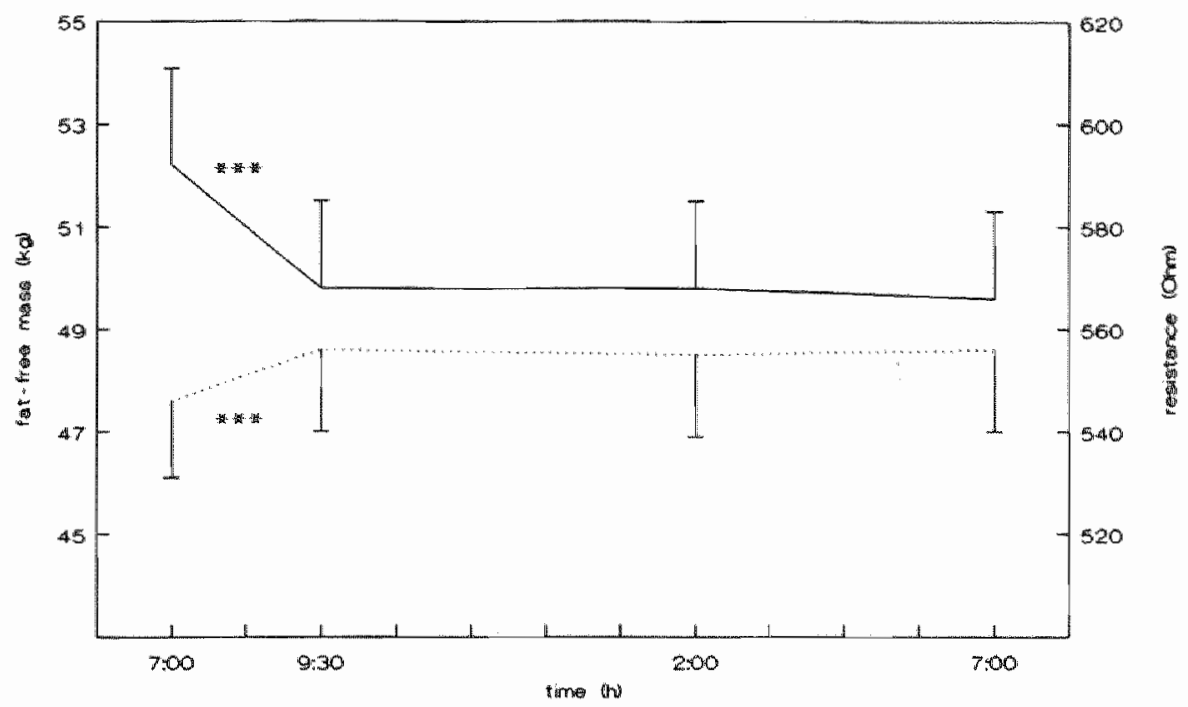

Figure 1: Mean and SEM of resistance (solid lime) and fat-free mass (dotred line) in 24 patients: in fasting state, in the afternoon and in the evering. Asteriks indicate $p<0.001$ vs fasting value.

$2.5 \mathrm{~h}$ after the ingestion of the diuretic. This decrease was comparable to the decrease in resistance in the same time interval in patients not on diuretic therapy. In the other 12 patients the effect of diuretics was to produce either no change at all or an increase in resistance relative to the fasting baseline measurement. Mean values of fat-free mass, fluid intake and fluid output are given in figure 3. The composition of the urine (water, sodium, potassium, chloride) was within the normal range in all measured patients. No differences in fluid balance could be established between patients who exhibited different changes in resistance.

\section{Study 4}

Resistance did not change significantly after the exercise challenge on the bicycle ergometer: mean change: $0 \pm 9$ Ohms.

\section{Study 5}

Measurements on two consecutive days did not result in a significant difference in resistance: mean change [8 a.m.] $5 \pm 24$ Ohms, [ 2 p.m.] $4 \pm 16$ Ohms. When fat-free mass was calculated from the resistance values at $8 \mathrm{a} . \mathrm{m}$., a between-day difference of $0.3 \pm 1.3$ $\mathrm{kg}$ was found. However when fat-free mass was expressed as a percentage of body weight, 


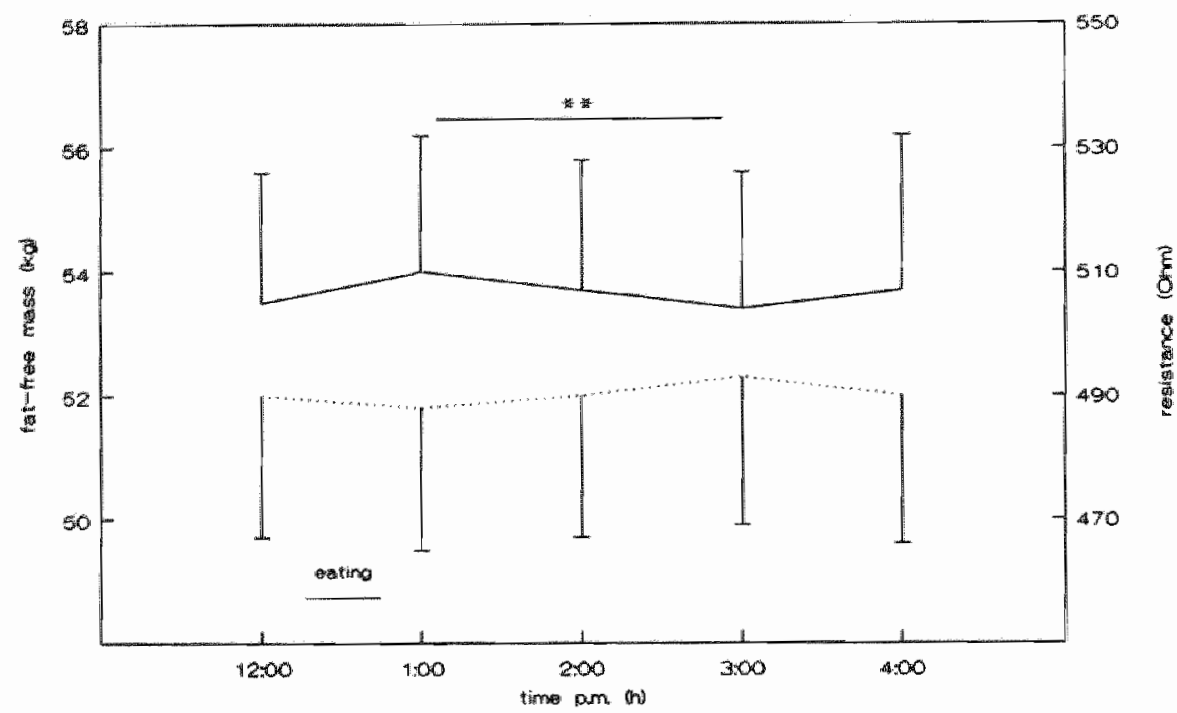

Fignue 2: Mean and SEM of resistance (solid) line and fat-free mass (dotted line) in 10 patients: before and after ingestion of a wam meal. Asteriks indicate $p<0.01$.

mean difference was $0 \pm 1.3 \%$. Reproducibility was not less for patients using oral diuretics.

\section{Discussion}

Although it has been demonstrated that the bioelectrical impedance method correlates well with reference methods of body composition, we questioned the applicability of this method in clinical practice, particularly in patients with COPD. For out-patient screening and followm it is important to consider the sensitivity of the method to diumal changes. We therefore studied the within-day variation of resistance measurements at four different times during the day. Group comparison revealed that only the fasting early morning resistance was significantly higher than the other measurements during the day. This is in contrast with the results by Chumlea (1987) who found no effect of time of the day on impedance measurements. It is not clear however from their results whether subjects were measured in the fasting state in the morning. Among the measuremients during the day, no significant differences could be detected. 


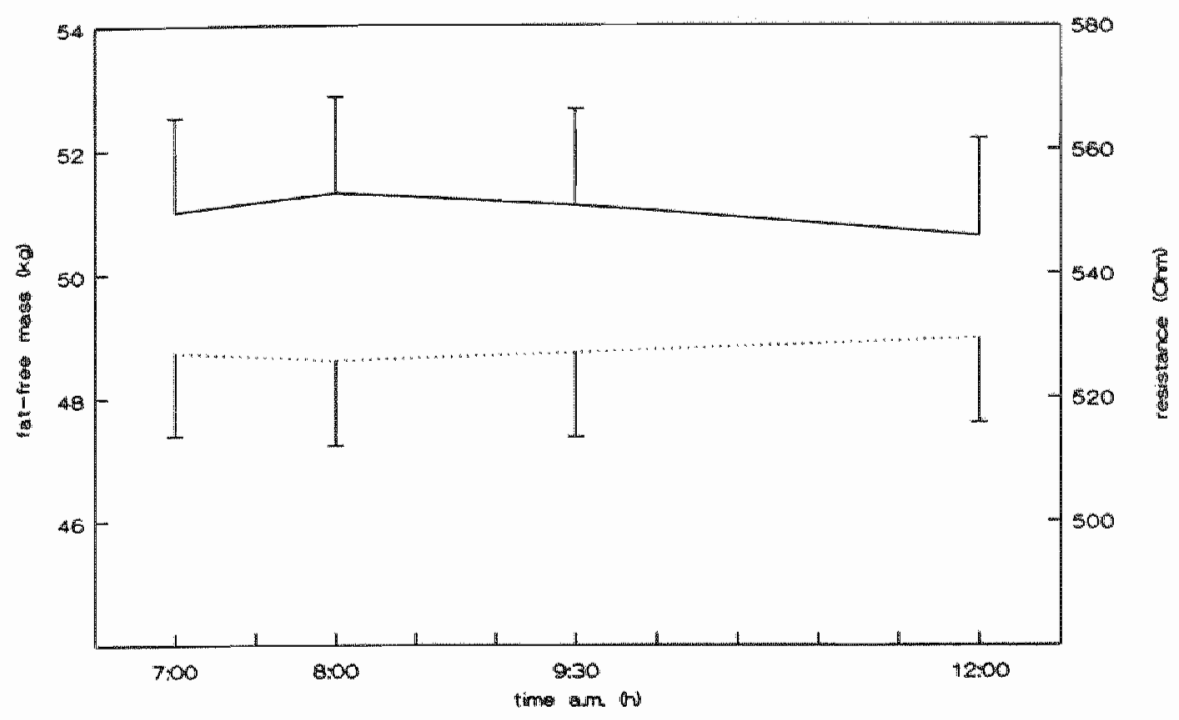

Figure 3: Mean and SEM of resistance (solid line) and fat-fiee mass (dotted line) before ( 7 a.m. in fasting state) and after ingestion of $40 \mathrm{mg}$ furosemide in 20 patients.

$\begin{array}{lrrrrrr} & \rightarrow 7 & ->8 & ->9.30 & ->12 \text { a.m. } \\ \text { fluid input (ml) } & 1 & \pm 3 & 359 \pm 155 & 94 \pm 103 & 112 \pm 96 \\ \text { fluid output (ml) } & 43 \pm 88 & 107 \pm 146 & 338 \pm 168 & 243 \pm 121\end{array}$

These results suggest that differences in resistance measurements occur mainly between the fasting and the nourished state. After eating a meal, minerals and water are absorbed, increasing total body water and electrolytes, causing a decrease in whole body resistance as measured by the impedance method. This was confirmed by Deurenberg (1988) who compared body impedance $1,2,3$, and $4 \mathrm{~h}$ after the ingestion of a liquid formula meal (464 kcal) with a fasting baseline value and found a decrease in impedance by about 13 17 Ohms after $2-4 \mathrm{~h}$.

Immediate meal effects could also explain the observed different patterns of diurnal changes between patients. In accordance with Chumlea (1987) we however could not detect a consistent superimposing effect of a previous meal during the day on the resistance measurement relative to a non-fasting walue just before the meal. Unfortunately we did not adjust fat-free mass for possible body weight changes during the day. 
In healthy individuals a decrease in resistance has been demonstrated after streneous exercise (Deurenberg, 1988). An explanation for this phenomenon is that during exercise the loss of water (sweat, respiration) is relatively larger than the loss of electrolytes, leading to a higher electrolyte density in the body and hence to a lower electrical resistance after exercise. Sweat is hypotonic and the concentration of electrolytes in sweat normally decreases during prolonged exercise (Passmore, 1986). A decrease in resistance can also be explained by an increase in body temperature during exercise leading to an increased specific conductance and consequently to a decreased resistance. The fact that no changes in resistance were detected in this study can thus be explained by a too minimal loss of electrolytes and water, or by the fact that, due to their ventilatory limitation none of our patients reached their sweating threshold. These results suggest that light exercise such as walking or cycling to the hospital for out-patient follow up probably does not have a significant impact on the resistance measurement.

Patients suffering from a cor pulmonale often receive orall diuretics as maintenance medication. We studied the effect of $40 \mathrm{mg}$ furosemide orally administered. Furosemide blocks the reabsorption of sodium chloride ions from the ascending limb of the loop of Henle as well as from the remainder of the diluting segment of the distal tubule. Through this mechanism water reabsorption is prevented and the concentrating ability of the kidney is decreased, causing a strong diuresis. The influence of diuretics on resistance was measured during $5 \mathrm{~h}$ because the diuretic effect of orally administered furosemide begins 20-30 minutes after ingestion of the drug and continues for 4-6 h. One of the main overall effects of furosemide is to produce free water clearance (i.e. hypotonic urine), suggesting that the arguments used in the discussion on exercise will also apply in patients responsive to furosemide i.e. resistance should fall if electrolyte density increases. Diuretics however had no consistent effect on resistance.

Dietary intake, pharmokinetic and pharmacodynamic regulating mechanisms and interaction with other medications may contribute to considerable variations in diuretic effect of the same dose of furosemide (Brater, 1985). Furthermore, patients on long term diuretic therapy may have a delayed diuresis. However no differences in fluid balance could be established between patients who exhibited different changes in resistance. Mean urine output was low, which indicates that the patients were in a steady state on maintenance diuretic medication. Another theoretical possibility may have been different shifts of fluids within the body, e.g. fluid shift from the central part of the body, which has a lower resistance, to the periphery, which has a higher resistance. Possible alternative approaches to estimation from resistance of body segments (Fuller, 1989), may shed further light on the influence on water distribution over the body in COPD. 
Because we established a variation of resistance measurements within one day, we studied the reproducibility of resistance measurements on two different days at the same times. Both in the morning and in the afternoon, the reproducibility was excellent, in agreement with figures given by others in healthy individuals (Lukaski, 1985; Deurenberg, 1988) in the fasting state. This may be partly explained by the fact that the patients stayed in a pulmonary rehabilitation center and had a very regular scheme of daily meals and activities.

In conclusion the studies indicate that the bioelectrical impedance method is a reproducible method for estimating body composition in patients with stable COPD. Standardization of the measurement of resistance is however important since various factors alone or in combination may affect it. The most important determinant of within-day changes in patients with stable COPD seems to be whether the subject is in a fasting or a fed state. These results have only a slight impact on the estimation of body composition for screening purposes or in cross-sectional studies. For example, measuring a subject in a non-fasting state can result in a resistance lower by about 20 Ohms. This may cause an overestimation of $1.5 \mathrm{~kg}$ or $2.3 \%$ fat-free mass in a male subject (height: $180 \mathrm{~cm}$, weight: $70 \mathrm{~kg}$ ). It is however important to take these changes into account during follow-up or when diuretic therapy is introduced or altered. Finally it should be stressed that these results refer only to COPD patients in a stable clinical condition. Further studies are required to assess the applicability of resistance measurements in conditions of superimposed acute disease. 



\title{
Chapter 4
}

\section{Measurement of resting energy expenditure in patients with COPD in a clinical setting}

\begin{abstract}
There is a growing tendency to estimate energy requirements by means of the assessment of resting energy expenditure (REE) by indirect calorimetry. In this study a computerized open-circuit ventilated hood system is described, constructed for assessing REE in a clinical setting. Measurement error of the device, tested by ethanol combustion was $+2 \%$ for $\mathrm{VO}_{2}$ and $\mathrm{VCO}_{2}$ and $<1 \%$ for the respiratory quotient. To assess the within-patient variability of REE measurements performed in a daily clinical routine, we studied the following aspects of the measurements in several groups of COPD patients: (1) reproducibility, (2) the influence of routine physical activities prior to the measurement, (3) measurement duration and (4) the difference between measurements using a hood or a mouth piece. Reproducibility of measurements with a 2 month interval in 12 weight stable

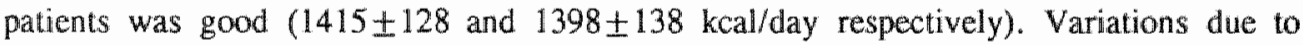
limited activities and different measurement durations (between 10 and 30 minutes) were not significant. Variations between measurements with a mouth piece and ventilated hood were larger in patients than in healthy controls but for both groups no systematic difference was established. REE can be reliably assessed with a wentilated hood system in stable COPD patients on an outpatient basis, providing a short rest is taken prior to the measurement.
\end{abstract}




\section{Introduction}

The maintenance of body functions requires a constant expenditure of energy. Energy is expended for active transport processes, to maintain chemical and electrical gradients across cellular membranes, for the synthetic processes and for muscular contraction. 24 Hour energy expenditure is composed of four components: the sleeping metabolic rate, energy cost of arousal, the thermic effect of food and the energy cost of activity (Ravus$\sin , 1986$ ). Resting or basal energy expenditure, which comprises the sleeping metabolic rate and the energy cost of arousal, can be defined as the minimum rate of energy expenditure in an awake, relaxed person, lying on a bed, after an overnight fast (Ravussin, 1989). Resting energy expenditure (REE) is the major determinant of total energy expenditure amounting to about $70 \%$ in sedentary persons.

In the past, estimation of resting energy requirements of patients was mostly based on prediction formulae such as the Harris-Benedict equations (Harris, 1919). At present there is a growing tendency to estimate energy requirements using the assessment of REE by indirect calorimetry. Measurement of REE may be particularly valuable in patients with chronic obstructive pulmonary disease (COPD), for two reasons: (1) nutritional depletion is a common problem in these patients and (2) several studies have demonstrated an increased REE in patients with COPD (Donahoe, 1990).

Determination of REE by using the principles of indirect calorimetry has been facilitated by the availability of a number of gas exchange measurement devices (Kemper, 1989). In this study a computerized open-circuit ventilated hood is described, constructed for assessing REE in patients in a clinical setting.

Although resting metabolic rate is generally assumed to be relatively constant, few data exist with regard to the within-patient variability of REE measurements performed in a daily clinical routine. In this study we therefore addressed the following questions: (I) Is the REE measurement reproducible in stable COPD patients? If, indeed, the measurement is reproducible, it would imply that one measurement can be used to calcullate a patients" energy requirements. (2) What is the influence of physical activity on the REE measurement? If REE is still increased a few hours after normal daily physical activities, it implies that REE cannot be measured on an outpatient basis. (3) Is there a difference in REE measurements using a ventilated hood or a mouth piece? Brief measurements of energy expenditure with a mouth piece and nose clips are an acceptable alternative to continuous measurement of gas exchange with a ventilated hood in healthy subjects who are adjusted to the technique (Segal, 1987). Since many COPD patients suffer from severe dyspnea, we studied whether in patients with advanced COPD the two methods would give different results. 


\section{Methods}

\section{The ventilated hood system}

The principle of a ventilated hood system is that a stream of air is forced to pass across the face of a subject and mixes with the expired air which is collected by a transparant plexiglas hood, placed over the subject's head. The rate of energy expended can be calculated by determining the amount of air flowing through the hood and by measuring the oxygen $\left(\mathrm{O}_{2}\right)$ and the carbon dioxide $\left(\mathrm{CO}_{2}\right)$ concentrations in the incoming and outcoming air. Figure 1 gives a schematic representation of the system.

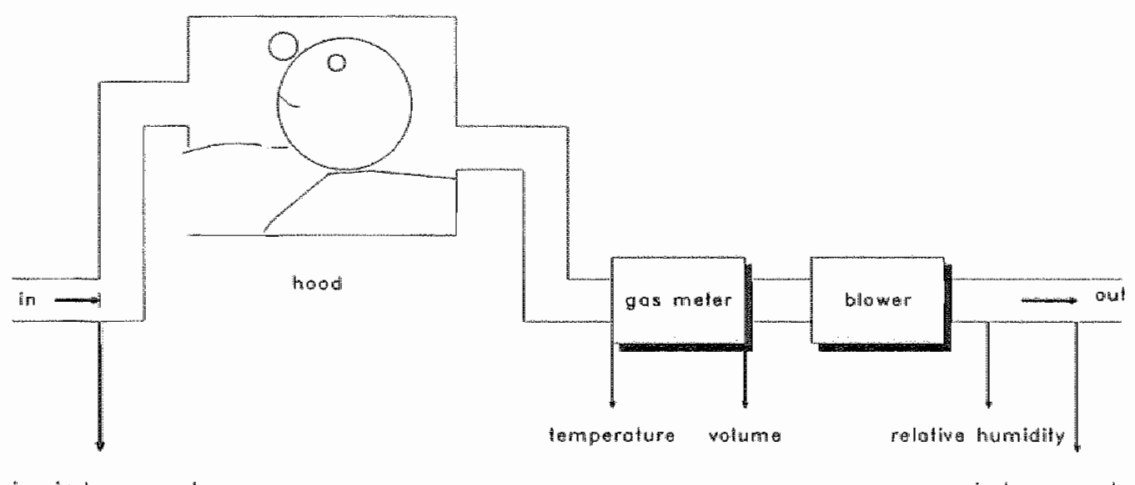

inspiratory somple

Figure 1: Schematic representation of the ventilated hood system.

Room air is drawn through the hood by negative pressure created by a pump downstram (Mijnhardt, Bunnik, The Netherlands). Airflow through the hood is measured in the outlet airstream by a dry gas meter (G6, Meterfabriek Schlumberger, The Netherlands). The dry gasmeter used is calibrated with a Blakeslee piston pump with mercury seals. A humidity sensor (Vaisala, Humicap, HMD20U, Helsinki, Finland) a temperature sensor (P Schoffelen analog devices AD590) and an ambient pressure sensor (Mijnhardt, CX103 board) are incorporated. Gas temperature is measured in the gas meter and relative humidity after the gas meter. Flow readings of the gas meter are converted to STPD (standard temperature pressure dry) conditions. Downstream to the flow measurement a small quantity $(0.1 \mathrm{~L} / \mathrm{min})$ of air is continuously withdrawn for gas analysis. Before gas analysis the sample is dried (Perma pure mini dryer MD, Inacom instruments BV, Veenendaal, The Netherlands) and sample pressure is stabilized for analysis. Through a system of computer-driven solenoidvalves (Kühnke, West Germany) sample gas is 
obtained from either the ventilated hood, calibration gases or room air upstream of the canopy. Gas analysis is performed with a paramagnetic $\mathrm{O}_{2}$ analyzer (Mijnhardt Oxygen module, Bunnik, The Netherlands) with full-scale range of $100 \%$, modified to $0-25 \%$, and an infrared $\mathrm{CO}_{2}$ analyzer (Mijnhardt, $\mathrm{CX} 103$ module) with a modified full scale range of $1 \%$. The $\mathrm{O}_{2}$ and $\mathrm{CO}_{2}$ analyzers are accurate to $0.05 \%$ and $0.04 \%$ absolute respectively. Accuracy is improved by linearizing the $\mathrm{CO}_{2}$ analyzer data and by digitally filtering data in the computer. Both analyzers then are within $0.01 \%$ absolute accuracy. Analyzers are calibrated using two dry calibration gases. Zero settings are performed by passing $100 \%$ nitrogen through the analyzers $(0.1 \mathrm{~L} / \mathrm{min})$. The span of the $\mathrm{O}_{2}$ and $\mathrm{CO}_{2}$ analyzers is set by passing a special gas mixture $\left(0.8 \pm 0.008 \% \mathrm{CO}_{2}\right.$ and $19.0 \pm 0.005 \% \mathrm{O}_{2}$ in $\left.\mathrm{N}_{2}\right)$ through the analyzer. The equipment is calibrated with both calibration gases at the start and end of every experiment. Canopy gas is sampled continuously and data are produced every 10 seconds. Flow rates between $25-50 \mathrm{~L} / \mathrm{min}$ depending on body size are used. The flow through the canopy is adjusted to keep $\mathrm{CO}_{2}$ readings in the range of $0.40-0.80 \%$ i.e. as near to the calibration gas $\mathrm{CO}_{2}$ content as possible, for maximum accuracy. The hood has a volume of 30 liter. The $\mathrm{CO}_{2}$ concentration increases during exhaling and is mixed with air in the canopy. The flow is directed over the face of the subject through an air inlet in front and an air outlet at the top of the hood, to remove exhaled $\mathrm{CO}_{2}$ immediately and avoid $\mathrm{CO}_{2}$ build up in the canopy. Mixing furthermore takes place in the tubes and in the gas meter. Flow adjustments are made before the experiment is started. The flow is kept constant throughout the experiment.

A microcomputer (Apple IIe) controls the system and performs the calculations. Output voltage signals of the $\mathrm{O}_{2}$ and $\mathrm{CO}_{2}$ analyzers, the humidity, pressure and temperature sensor's are measured and digitized by a data-acquisition interface (Applied engineering) using a 16 channel, 12-bit $\mathrm{AD}$ converter. The gasmeter pulse output is digitally counted in the computer giving a continuous flow measurement. Concentration of $\mathrm{O}_{2}$ and $\mathrm{CO}_{2}$ in samples of canopy gas is measured continuously every $10 \mathrm{~s}$ a filtered value is recorded. The computer calculates and prints the values of $\mathrm{O}_{2}$ consumed, $\mathrm{CO}_{2}$ produced, the respiratory quotient (RQ) and the rate of $\mathrm{EE}$ over the whole experimental period.

Energy expenditure is calculated using the abbreviated Weir formula (1949). This formula deletes the factor necessary to adjust for incomplete protein oxydation.

\section{Patienss}

The study group consisted of COPD patients in stable clinical condition admitted to a pulmonary rehabilitation center. The healthy volunteers consisted of hospital staff members. A description of the study groups for the different studies is given in table 1 . 
Table 1: Description of the stuty groups

\begin{tabular}{|c|c|c|c|c|c|c|c|c|}
\hline study & $\begin{array}{l}\text { 1. effect } A D L \\
\text { 2. length of mer }\end{array}$ & surement & 3. re & oducibilit & 4. $\mathrm{h}$ & ood or mo & th prec & \\
\hline & patients & controls & & ients & & atients & & ontrols \\
\hline No & $=12$ & $=14$ & n & $=\mathbb{1 2}$ & $\mathrm{n}$ & $=12$ & $\mathrm{n}$ & $=6$ \\
\hline age & \pm 6 & \pm 8 & 65 & \pm 9 & 63 & \pm 7 & 31 & \pm 16 \\
\hline weight (kg) & $65.7 \pm 11.0^{1}$ & $65.5 \pm 10$ & 64.7 & \pm 14.3 & 61.7 & \pm 8.8 & 73.0 & \pm 10.4 \\
\hline height $(\mathrm{cm})$ & $170.0 \pm 7.0$ & $172.0 \pm 8.1$ & 168.0 & \pm 7.8 & 168.0 & \pm 8.0 & 177.0 & \pm 8.2 \\
\hline IVC $(\%)$ & \pm 16 & & 70 & \pm 20 & 80 & \pm 20 & & \\
\hline $\mathrm{FEV}_{1}(\%)$ & \pm 10 & & 34 & \pm 16 & 31 & \pm 7 & & \\
\hline $\mathrm{P}_{\mathrm{a}} \mathrm{O}_{2} \quad(\mathrm{kPa})$ & $8.2 \pm 1.5$ & & 8.11 & \pm 1.4 & 8.1 & \pm 1.1 & & \\
\hline $\mathrm{P}_{1} \mathrm{CO}_{2} \quad(\mathrm{kPa})$ & $5.5 \pm 0.6$ & & 5.8 & \pm 0.9 & 5.3 & $\pm \quad 0.8$ & & \\
\hline
\end{tabular}

${ }^{2}$ Except for No all values are expressed as mean $上 S D$

\section{Variability and accuracy of the method}

The precision of the gas analyzers and the calibration procedure was measured throughout the study period by ethanol (Merck 983, Darmstadt, West Germany) combustion tests of different durations ranging from 5 minutes to 60 minutes. To oxydize $1 \mathrm{~g}$ of ethanol $1.460 \mathrm{~L}$ of $\mathrm{O}_{2}$ is needed and $0.972 \mathrm{~L}$ of $\mathrm{CO}_{2}$ is produced $(\mathrm{RQ}=0.666)$. When a known quantity of ethanol is combusted, the volumes of $\mathrm{O}_{2}$ consumed and $\mathrm{CO}_{2}$ produced, involved in the oxydation process can be calculated. These calculated values are compared to the observed values. To calculate the variability of the method the ethanol combustions were extrapolated to an ethanol combustion rate needed for the average sedentary individual with a REE of $1600 \mathrm{kcal} /$ day. This corresponds to an ethanol combustion of 229 gram assuming an energetic equivalent of ethanol oxydation of 7 kcal. For the oxydation of $229 \mathrm{~g}$ of ethanol $334 \mathrm{~L} \mathrm{O}_{2}$ are needed and $222 \mathrm{~L} \mathrm{CO}_{2}$ are produced.

Unless described differently in the experiments, measurements were performed in the early morning (between $8.30-9.30 \mathrm{a} . \mathrm{m}$.), in a fasting state (for at least $10 \mathrm{~h}$ ) approximately $2 \mathrm{~h}$ after the patients had received their maintenance medication. The patients were lying comfortable in semi recumbent position. The upper body was elevated according to the individual preferences. The patients were asked to remain completely quiet and did not watch television or listen to the radio. The investigators ensured that the subjects did not move or sleep. After initiating the measurements, time was allowed ( \pm 7 minutes) to adjust to the hood and to stabilize EE. 
Study 1: Effect of activities of daily living (ADL).

The effect of ADL prior to the measurement was tested in 12 patients on two consecutive days. On the first day the patients were allowed to dress, wash and walk to the metabolic ward. After lying down for 20 minutes, energy expenditure was measured during a 30 minute period. On the second day, the patients remained in bed until the investigator took them by a wheel chair to the metabolic ward. The two measurements were done while the patients were maintained in the same position since it has been shown that resting metabolic rate may vary at different body positions (Christensen, 1983).

\section{Study 2: Length of measurement}

To assess the possibility to perform short term experiments, measurements of different duration were compared. REE was calculated in the same group of patients and in 14 healthy controls (age $31 \pm 8$ y) after $5,10,15,20,25$ and 30 minutes respectively.

\section{Study 3: Reproducibility of the measurement}

Reproducibility of REE measurements during a 2 month interval was established in 12 patients whose bodly weight remained stable throughout this period.

\section{Study 4: Ventilated hood or mouth piece}

Paired measurements using both a ventilated hood and a mouth piece were performed in 12 patients and 6 controls. Ethanol combustion tests were performed prior to every combined measurement. Subjects were randomly measured with hood or mouth piece first. All patients were remeasured by the second system within 5 minutes so that the subject's position and environment remained unchanged throughout both measurements. The patient's expired air was collected via a mouth piece attached to a douglas bag. The initial $5 \mathrm{~min}$ of gas collection was discarded to allow for adjustment to the mouth piece. The remaining 7-10 min of gas collection was analyzed. Since REE is primarily determined by $\mathrm{VO}_{2}$ (Weir, 1949), and to exclude differences in accuracy of different gas analyzers, the $\mathrm{O}_{2}$ analyzer of the ventilated hood system was used to measure REE in both conditions. $\mathrm{No}_{\mathrm{VCO}_{2}}$ measurements could be performed since the $\mathrm{VCO}_{2}$ of the exhaled air from the douglas bag was outside the span of the $\mathrm{CO}_{2}$ analyzer of the ventilated hood.

\section{Statistics}

Comparisons between measurements under different circumstances were made using the statistical analysis of Bland \& Altman (1986). As emphasized by these authors methods that yield estimates with a high correlation coefficient may not necessarily show a high degree of agreement. Therefore in this analysis the differences in REE under different circunstances are plotted against the means of the two methods. This is then used to calculate the overall mean bias (mean difference) between the two methods, the associated 
limits of agreement ( \pm 2 standard deviations of the differences between methods) and the extent to which the mean bias changes with an increase in the mean of two measurements.

\section{Results}

Ethanol combustion tests revealed an overestimation for $\mathrm{VO}_{2}$ (mean $\pm \mathrm{SD}$ ) $(102.2 \pm 2.7 \%$ ) and for $\mathrm{VCO}_{2}(102.2 \pm 2.1 \%)$. RQ was $100.4 \pm 1.7 \%$. The measurements were tolerated well. In only one patient the measurement had to be stopped, bocause he had claustrophobia feelings.

\section{Study 1}

No significant differences were established between measurements performed after a complete rest and measurements done after light physical activities, when a short rest was inserted prior to the measurement. This did not only apply for calculated energy expenditure: $(1406 \pm 238 \mathrm{kcal}$ and $1431 \pm 259 \mathrm{kcal} / \mathrm{day})$ (figure 2) but also for respiratory quotient $(\mathrm{RQ}=0.82 \pm 0.05)$.

\section{Study 2}

Calculated REE did not differ significantly between measurements of $5,10,15,20,25$ and 30 min duration respectively (table 2 ).

Table 2: Resting evergy expenditure (nuean 4 SDj in kcal/day in 12 patients and 14 controls after different measurement durations

\begin{tabular}{lll}
\hline Time $(\mathrm{min})$ & Patients & Controls \\
\hline 05 & $1.420 \pm 242$ & $1510 \pm 227$ \\
10 & $1410 \pm 226$ & $1505 \pm 224$ \\
15 & $1410 \pm 237$ & $1514 \pm 225$ \\
20 & $1414 \pm 239$ & $1521 \pm 229$ \\
25 & $1428 \pm 243$ & $1531 \pm 229$ \\
30 & $1436 \pm 245$ & $1535 \pm 231$ \\
\hline
\end{tabular}

\section{Sindy 3}

The reproducibility after a 2 months interval was very good (figure 3). Average REE in the 12 weight stable patients $(64.7 \pm 14.3 \mathrm{~kg}$ and $65.0 \pm 14.9 \mathrm{~kg}$ ) after 2 months (1415 $128 \mathrm{kcal} / \mathrm{day})$ was not significantly different from the baseline value at admission to the center $(1398 \pm 138 \mathrm{kcal} / \mathrm{day})$. 


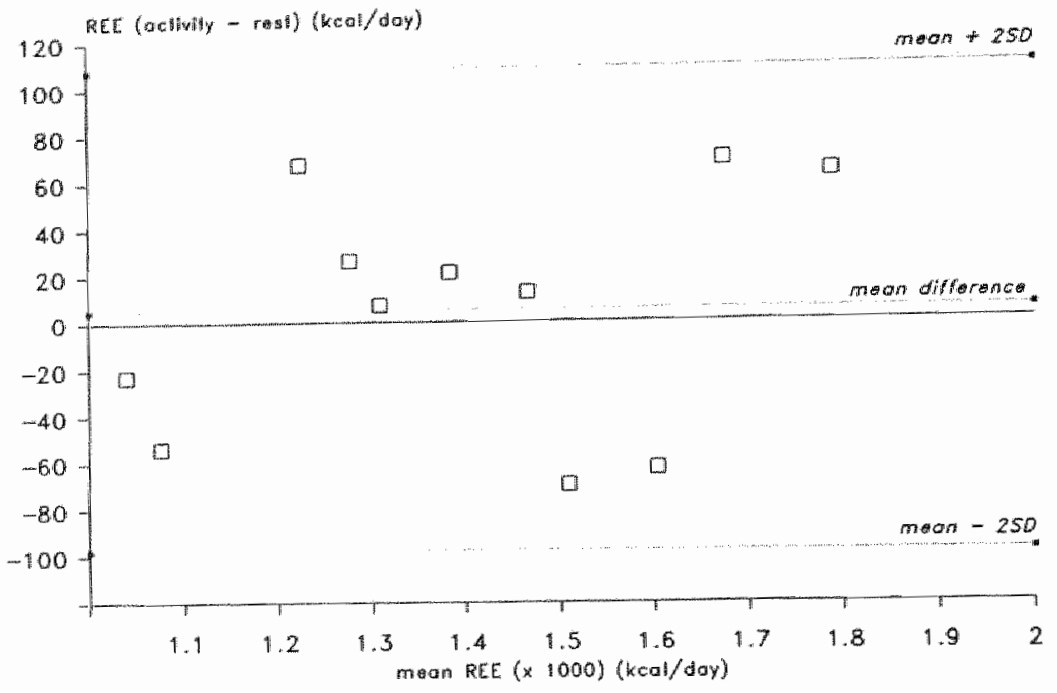

Figure 2: Difference against mean resting energy expenditure measured at complete rest and affer light physical activities.

\section{Study 4}

The difference between measurements with mouth piece and ventilated hood was larger in patients than in controls, but no systematic difference could be established between both devices in either group. The difference between calculated $\mathrm{REE}$ using only $\mathrm{VO}_{2}$ measurements or $\mathrm{VO}_{2}$ and $\mathrm{VCO}_{2}$ measurements amounted to $-16 \mathrm{kcal} / \mathrm{day}$, or $-1.9 \%$ (range -3 $0.3 \%$.

\section{Discussion}

The ventilated hood system appears to be a confortable method to measure REE in patients suffering from severe COPD. The ethanol combustion tests revealed that when properly maintained, calibrated and interfaced to the patients, the device is very accurate.

Standard measurements were performed in the early morning after an overnight fast, at least two hours after the patients received their maintenance medication. Drug treatment in the majority of patients includes B-2 agonists and theophylline, both potentially capable of increasing metabolic rate (Dullo, 1986; Vaisman, 1987). The precise influence of these drugs was not measured because withdrawing treatment might exacerbate the condition. 


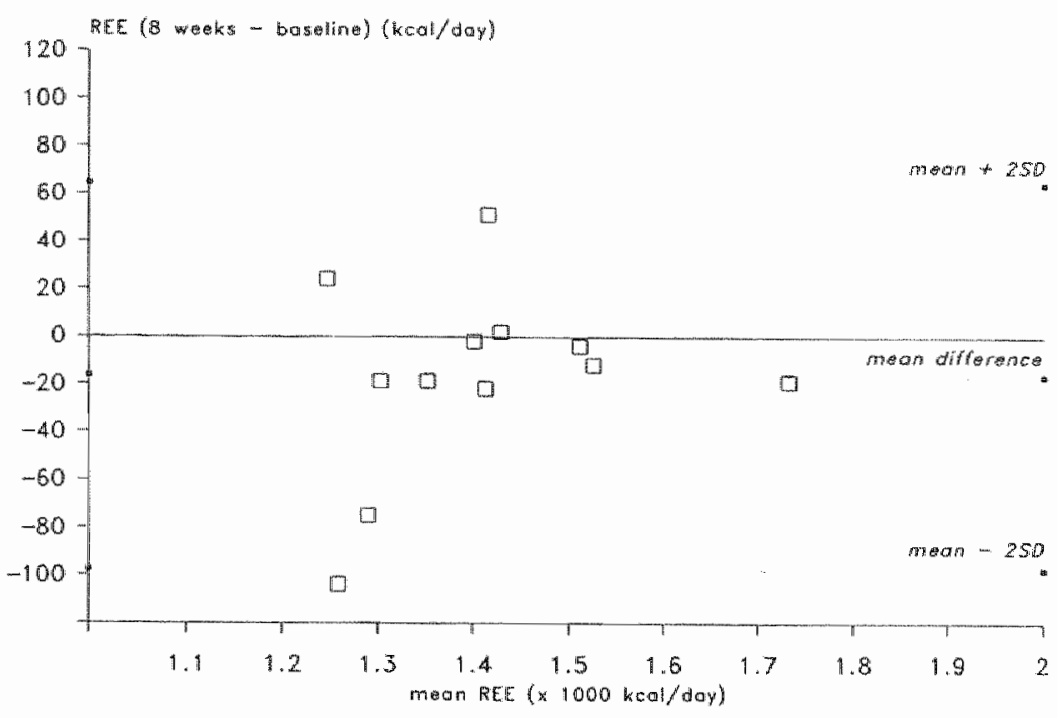

Figure 3: Difference against mean of repeated resting energy expenditure measurements with an intenal of 8 wks.

On the other hand bronchodliating treatment itself may reduce the work of breathing. As suggested by others (Lanigan, 1990) the obtained REE is thus reflective of the "best case" ventilatory conditions.

A considerable number of patients was dyspneic at rest or suffered from severe exercise impairment. Washing, dressing and shaving are activities which require frequent use of respiratory muscles. In patients with a severe airflow obstruction oxygen consumption of the respiratory muscles may increase to $40 \%$ of total $\mathrm{VO}_{2}$ (Bye, 1983). Nevertheless in agreement with findings in patients not suffering from COPD (Fredrix, 1990) we found that limited physical activity had no measurable effect on REE when a short rest is taken prior to the assessment.

Since subjects can breathe spontaneously in a ventilated canopy, it is possible to perform measurements requiring longer duration in a supine position with minimal discomfort (Jequier, 1987). For a reliable assessment of REE, it is however not necessary to perform long experiments or to strictly standardize the actual duration of the measurement, provided that a period is used (in our studies: 7 minutes) to adjust to the hood. Based on the experiments and to obtain an optimum beween sample frequency and acceptability of 


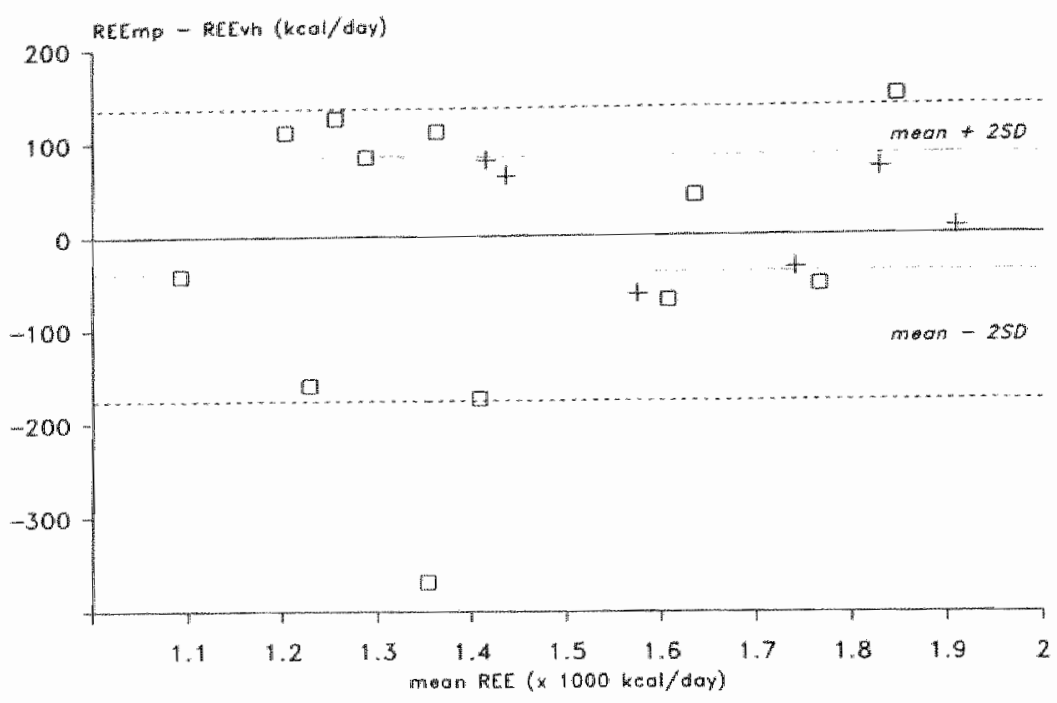

Figure 4: Difference against mean resing energy expendinure based on VO $\mathrm{O}_{2}$ measured using a mouth piece and a ventilated hood respectively. $(\square /-)$ patients, $(+/ . .$,$) controls.$

the measurement, we changed the duration of our standard REE experiments from 30 to 15 minutes. Reproducibility of 2 measurements with the ventilated hood performed under the same standard conditions with an interval of 2 months was excellent and comparable to findings in healthy subjects (Garby, 1986; Soares, 1986; Murgatroyed, 1987).

A disadvantage of mouth pieces and tace masks excluding full face masks with diluted air stream, is that it is nearly impossible to prevent air leaks (Jequier, 1987). These are climinated with a ventilated hood system since the hood is at a pressure slightly below barometric. Futhermore the discomfort associated with masks, nose clips and mouth pieces can alter breathing pattorn, create anxiety and prevent the achievement of the resting state (Segal, 1987). On the other hand a hood may create claustrophobia feelings. Although in some patients measurements with mouth piece and ventilated hood varied substantially, no systematic difference was established in patients or controls.

The following implications for the clinical measurement of resting energy expenditure can be derived from these results. REE measurements using a ventilated hood are highly reproducible suggesting that one measurement suffices to characterize resting metabolic rate at a certain time point in patients with stable COPD. Since it seems justified to 
neglect variations in light physical activities, REE in patients with severe COPD can be measured on an outpatient basis providing a rest is taken prior to the measurement. Since the assessment of REE by indirect calorimetry has been facilitated by modern technology it opens possibilities for the future as a routine test to aid in determining caloric requirements and/or to mark energy metabolism. Ethanol combustion is a useful test to determine the accuracy of the device, and should be performed regularly. 

Part II: Towards a definition of nutritional depletion 



\section{Chapter 5}

\section{Prevalence and characteristics of nutritional depletion in patients with COPD eligible for pulmonary rehabilitation}

\section{Abstract}

Prevalence and characteristics of nutritional depletion were assessed by body composition measurements in 255 COPD patients in stable clinical condition admitted to a pulmonary rehabilitation center. Depletion of body weight, fat-free mass (using bioelectrical resistance measurements) and muscle mass (from creatinine height index (CHI) and midarm muscle circumference) was most pronounced ( $40-50 \%)$ in patients suffering from chronic hypoxemia, and in normoxemic patients with severe airflow obstruction (FEV $<$ $35 \%$ ), but occurred furthermore in $\pm 25 \%$ of patients with moderate airflow obstruction. Classification of the patients in 4 groups by body weight and fat-free mass (both expressed as percent of ideal body weight), revealed that depletion of fat-free mass may occur in normal weight COPD patients (group 3). These patients exhibit also a decreased $\mathrm{CHI}$ $(61 \pm 21 \%)$ (mean $\pm S D$ ) and suffer from physical impairment (12 minute walking distance (WD): $532 \pm 152$ meters) even to a greater degree than underweight patients with a relative preservation of fat-free mass (group 2) ( $\mathrm{CHI}=73 \pm 16 \%$; $\mathrm{WD}=744 \pm 233$ meters). No systematic differences were established between the 4 groups in serum protein concentrations, or in medication use. We conclude that fat-free mass is a better indicator of body mass depletion than body weight. Classification of COPD patients by body weight and fat-free mass may have consequences for planning and interpretation of intervention strategies, particularly in group $2+3$ patients. 


\section{Introduction}

It is generally acknowledged that a substantial proportion of COPD patients are malnourished and that malnutrition contributes to the deterioration of clinical condition. There is a large body of literature on nutritional assessment, which is poorly standardized. This is caused by several factors: (1) Malnutrition is not well defined. (2) Most measures used can be influenced by a chronic negative energy balance, but also by coinciding disease (Forse, 1980; Bleiberg-Daniel, 1985; O'Keefe, 1988). As a result in western medical practice 'undernutrition' or 'malnutrition' is indiscriminately used regardless if the clinical condition results from lack of food or from disease. It may therefore be more appropriate not to call patients undernourished but rather 'depleted'. In addition we advocate the use of measures that reflect function rather than measures that cannot directly and logically be related to biological function. One such 'logical' measure is fat-free mass or better body cell mass (BCM). Body cell mass reflects the quantity of actively metabolizing (liver, gut, immune system) and contracting (muscle) tissue (Forse, 1980).

There is not yet a direct measure of the $\mathrm{BCM}$ available in clinical practice, but it is generally acknowledged that in the absence of excessive fluid shifts, a useful estimate is given by the fat-free mass (FFM). Numerous methods are available for the assessment of FFM, most of which are cumbersome and unfit for clinical use (deuterium dilution, anthropometry, creatinine height index requiring $24 \mathrm{~h}$ urine collection, densitometry, whole body counting of potassium 40) (Lukaski, 1987). In recent years bioelectrical resistance was introduced allowing quick, easy and reliable assessment of fat-free mass (Lukaski, 1985). In chapter 2 we validated this method by comparing the results with deuterium dilution as reference method for the measurement of total body water, and with anthropometry. It appeared that measurement of resistance in addition to body weight and height, gave a reliable estimation of fat-free mass in patients with stable COPD. In this study we assessed the relationship between depletion of fat-free mass and functional performance. We specifically tried to assess which measure of depletion best predicts physical impairment in COPD.

\section{Methods}

The study group consisted of patients with moderate to severe COPD, consecutively admitted to an intensive pulmonary rehabilitation program. All patients were referred to the rehabilitation center by their pulmonary physician in a stable clinical condition. Prior to entering the program, a careful evaluation of the patient was performed including nutritional assessment. Patients exhibiting an increase in forced expiratory volume in one second $\left(F E V_{1}\right)>10 \%$ of baseline after inhalation of a $\mathbb{B}_{2}$-agonist, or patients suffering from cancer, unstable cardiac condition, active gastrointestinal abnormalities, recent 
surgery or severe endocrine disorders were excluded from the study. The final study group consisted of 255 patients.

\section{Lung, function}

$\mathrm{FEV}_{1}$ and inspiratory vital capacity (IVC) were measured with a wet spirometer; the highest value of at least three spirometric manoeuvres was used. FEV and IVC were expressed as a percentage of the reference value (Quanjer, 1983). Arterial blood gases were drawn by puncture of the brachial artery at rest while breathing room air. Arterial oxygen tension $\left(\mathrm{P}_{\mathrm{a}} \mathrm{O}_{2}\right)$ and carbon dioxide tension $\left(\mathrm{P}_{\mathrm{a}} \mathrm{CO}_{2}\right)$ were analyzed on a blood gas analyzer (Radiometer, ABL 330, Copenhagen, Denmark). Respiratory muscle strength was determined by measuring maximal inspiratory and expiratory mouth pressures, according to the technique described by Black and Hyatt (Black, 1969). The best of three determinations was used in subsequent calculations.

\section{Nutritional assessment}

Body height (Ht) was measured bare foot standing and determined to the nearest $0.5 \mathrm{~cm}$. Body weight was measured with a beam scale without shoes in light clothing to the nearest $0.1 \mathrm{~kg}$. Frame size (small, medium, large) was calculated from wrist circumference. Body weight was expressed as a percentage of ideal body weight (PIBW). Ideal body weight was determined as the midpoint of the weight range for a given height and frame size from the 1983 metropolitan life insurance tables. Mid upper arm circumference (MAC) of the right arm was taken with a flexible measuring tape (Bishop, 1981). Skinfolds were measured in triplicate with a skinfold caliper (Durnin, 1967). All anthropometric measurements were performed by the same research assistent. Arm muscle circumference (MMC) was derived by computation as follows: $M M C=M A C$ (cm) - ( $\pi$ x triceps skinfold (mm)). Actual MMC values were compared with standard values for age and sex (Bishop, 1981; Falciglia, 1988) and the data expressed as a percentage of standard (PIMMC). Body fat content was estimated from the sum of skinfold thicknesses at four sites: bicipital, tricipital, subscapular and suprailiac using the 'Durnin' tables (1974). Fat-free mass was measured by the bioelectrical impedance method. Resistance (BIA 101, RJL Systems, Detroit, USA) was measured in supine position at the right side as described by Lukaski (1985). Fatufree mass was calculated from $\mathrm{Ht}^{2} / \mathrm{resistance} \mathrm{and}^{\circ}$ body weight using a patient specific regression equation (chapter 3). Since no data are available on ideal fat-free mass, fat-free mass was expressed as a percentage of ideal body weight (FFMPIBW). Skeletal muscle mass was estimated from the creatinine height index which was calculated by dividing the 24 hour urinary creatinine excretion of the patient by a reference value based on ideal body weight (Jensen, 1983). The results of 15 patients were discarded because of obviously poor urine collections. Serum concentrations of albumin, prealbumin and transferrin were analyzed by radial immunodiffusion on an automated system (Cobas Mira, Hofmann la Roche, Switzerland). 


\section{Exercise performance}

Exercise performance was evaluated with a 12 minute walking test, performed in a level enclosed corridor according to the method described by McGavin (1976). Corridor walking can be considered as a useful method to evaluate exercise tolerance in COPD patients (Swerts, 1990). All tests were performed in the early afternoon and no encouragement was given. As learning effects have been noticed to occur quickly with repeated walking tests (Beaumont, 1985), the patients performed one practice test. Patients with cardiovascular, neurological, and locomotor diseases or suffering from chronic hypoxemia, were excluded from exercise testing.

Other relevant data regarding disease history, pattern and duration of weight loss and medication were obtained from a standardized medical questionnaire completed by the 2 pulmonary physicians of the center. All measurements were performed approximately one week after admission, when medication was optimalized, and theophylline levels in a therapeutical range $(8-15 \mathrm{mg} / \mathrm{L})$ were obtained.

\section{Statistics}

Patients were classified by airflow obstruction and $\mathrm{P}_{\mathrm{a}} \mathrm{O}_{2}$ to relate nutritional measures to severity of disease. As cut off points for $\mathrm{FEV}_{1}$ the values $35 \%$ and $50 \%$ were taken corresponding to earlier studies (Schols ${ }^{\text {fl }}, 1989$; Wilson, 1989). Chronic hypoxemia was defined as a resting $\mathrm{P}_{\mathrm{a}} \mathrm{O}_{2}<7.3 \mathrm{kPa}$ according to the criteria of the American Thoracic Society (1987). A second classification was performed according to body composition. Patients were stratified by FFMPIBW and PIBW in 4 groups. PIBW $=90 \%$ was taken as stratification value since PIBW $<90 \%$ is a commonly employed clinical definition of nutritional depletion (Wilson, 1989). FFMPIBW was related to PIBW and sex by multiple linear regression analysis. The value corresponding to $\mathrm{PIBW}=90 \%$ was taken as stratification value for FFMPIBW. Statistical analysis was performed using one way analysis of variance followed by pairwise multiple comparisons. The Mann-Whitney-U test was used where appropriate. Frequency data were compared using the Chi-square test. Significance was determined at the $5 \%$ level. All values are expressed as mean $\pm S D$.

\section{Results}

A description of the study group is given in table 1. The group represented elderly patients with moderate to severe COPD, the majority of whom were males $(80 \%)$. Sex differences were established in $\mathrm{FEV}_{1}$, respiratory muscle strength and 12 minute walking distance. Maintenance medication in the majority of patients included theophylline, $B_{2}$ agonists and inhaled or oral corticosteroids. 135 Patients used diuretics. 
Toble 1: Description of the study group

\begin{tabular}{|c|c|c|c|c|c|c|}
\hline \multirow[b]{2}{*}{ age } & \multirow[b]{2}{*}{$y$} & \multicolumn{2}{|r|}{$\begin{array}{l}\text { males } \\
\mathbf{n}=203\end{array}$} & \multirow[b]{2}{*}{ \pm} & \multicolumn{2}{|c|}{$\begin{array}{l}\text { females } \\
\mathrm{n}=52\end{array}$} \\
\hline & & 65 & \pm 8 & & 62 & \pm 9 \\
\hline IVC & $\%$ pred & 67 & \pm 18 & & 71 & \pm 20 \\
\hline $\mathrm{FEV}_{\mathrm{I}}$ & ofpred & 33 & \pm 14 & $\frac{2}{\xi}$ & 41 & \pm 17 \\
\hline $\mathrm{P}_{\mathrm{a}} \mathrm{O}_{2}$ & $\mathrm{kPa}$ & 8.8 & $\pm 1.7^{1}$ & & 9.1 & \pm 1.6 \\
\hline $\mathrm{P}_{3} \mathrm{CO}_{2}$ & $k P_{a}$ & 5.5 & $\pm \quad 0.9$ & & 5.3 & $\pm \quad 0.8$ \\
\hline $\mathbb{P}_{\mathrm{j}}-\max$ & $\mathrm{kPa}$ & 5.3 & \pm 2.3 & $\#$ & 3.4 & $\pm \quad 1.5$ \\
\hline$P_{n}=\max$ & $\mathrm{kPa}$ & 7.7 & $\pm \quad 3.3$ & $\#$ & 4.4 & \pm 2.0 \\
\hline$W^{2}$ & $\mathrm{~m}$ & 666 & \pm 263 & * & 575 & \pm 245 \\
\hline \multicolumn{2}{|c|}{ Medication } & \multicolumn{5}{|c|}{$\begin{array}{l}\text { total group } \\
\qquad \mathbf{n}=253\end{array}$} \\
\hline \multicolumn{2}{|c|}{ theophylline } & \multicolumn{5}{|c|}{225} \\
\hline \multicolumn{2}{|c|}{$B_{2}$-sympathomimetics } & \multicolumn{5}{|c|}{234} \\
\hline \multicolumn{2}{|c|}{ ipratropiumbromide } & \multicolumn{5}{|c|}{226} \\
\hline \multicolumn{2}{|c|}{ corticosteroids oral } & \multicolumn{5}{|c|}{187} \\
\hline \multicolumn{2}{|c|}{ corticosteroids inhalation } & \multicolumn{5}{|c|}{152} \\
\hline \multicolumn{2}{|c|}{ diuretios } & \multicolumn{5}{|c|}{135} \\
\hline \multicolumn{2}{|c|}{ digoxine } & \multicolumn{5}{|c|}{51} \\
\hline
\end{tabular}

'mean $\pm \mathrm{SD}$; ${ }^{2}$ walking distance; * $\mathrm{p}<0.05 ;+\mathrm{p}<0.005 ;$; $\mathrm{p}<0.001$

Mean values of nutritional measures, categorized by disease severity as well as the percentage of low values in each sub-group are shown in table 2 . Depletion of body mass was most pronounced in patients suffering from chronic hypoxemia, 40-50\% of whom exhibited sub-normal values for body composition measures and serum albumin concentration. In normoxemic patients PIBW $(\mathrm{p}<0.001)$, FFMPIBW $(p<0.01)$, PIMMC $(p<0.001)$, CHI $(p<0.001)$ and albumin $(p<0.01)$ were positively associated to $\mathrm{FEV}_{1}$, but no significant differences were established between $35 \% \leq F E V_{\|} \leq 50 \%$ and $\mathrm{FEV}_{1}>$ $50 \%$. A minority of patients had sub-normal walues for prealbumin and transferrin (12\% and $9 \%$ respectively) whereas in $12 \%$ supra-normal prealbumin levels $(>0.40 \mathrm{~g} / \mathrm{L})$ were found.

Results of the regression analysis are shown in table 3. FFMPIBW $=67 \%$ (malesi and FFMPIBW $=63 \%$ (females) corresponded to PIBW $=90 \%$. Mean values of nutritional and functional measures obtained after categorizing the study group by body composition in 4 sub-groups are shown in table 4 . Females of group 2 and 3 were not statistically compared to other groups, since the number of females in these groups was too small. 
Part II: Towords a definition of nutritional deptetion

Table 2: Nutritional measures categarized by disease severity.

\begin{tabular}{|c|c|c|c|c|c|c|c|c|c|c|c|c|}
\hline \multirow[b]{2}{*}{ weight lossi } & \multicolumn{2}{|c|}{$\begin{array}{l}\mathrm{P}_{\mathrm{N}} \mathrm{O}_{2}<7.3 \mathrm{kP} \\
(\mathrm{n}=48)\end{array}$} & \multicolumn{3}{|c|}{$\begin{array}{l}\mathrm{FEV}_{i}<35 \% \\
(\mathrm{n}=112)\end{array}$} & \multicolumn{3}{|c|}{$\begin{array}{l}35 \% \leq F E V_{1} \leq 50 \% \\
(\mathrm{n}=56)\end{array}$} & \multicolumn{4}{|c|}{$\begin{array}{l}\mathrm{FEV}_{1}>50 \% \\
(\mathrm{n}=37)\end{array}$} \\
\hline & $\mathrm{n}$ & $=9$ & $\mathbf{n}$ & $=$ & 27 & $\mathrm{n}$ & $=$ & 10 & $\mathbf{n}$ & $=$ & 9 & \\
\hline PIBW & 90.6 & $\pm 12.0^{\mathrm{g}}$ & 95.4 & \pm & 14.1 & 102.0 & \pm & 16.6 & 107.2 & \pm & 15.7 & \\
\hline$<90 \%$ & & & & & & $\%$ & & $27 \%$ & & & & $11 \%$ \\
\hline FFMPIBW & 67.8 & \pm 8.2 & 69.9 & \pm & 9.2 & 73.5 & \pm & 10.5 & 73.6 & \pm & 8.4 & \\
\hline$<67 / 63^{3} \%$ & & & & & & $\%$ & & $25 \%$ & & & & $24 \%$ \\
\hline PIMMC & 84.1 & \pm 11.1 & 90.0 & \pm & 11.4 & 96.3 & \pm & 12.9 & 97.7 & \pm & 11.9 & \\
\hline$<90 \%$ & & & & & & $\%$ & & $32 \%$ & & & & $30 \%$ \\
\hline $\mathrm{CHI}$ & 60.7 & \pm 15.6 & 68.3 & 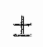 & 20.0 & 80.0 & \pm & 17.9 & 83.5 & \pm & 26.3 & \\
\hline$<60 \%$ & & & & & & & & $18 \%$ & & & & $16 \%$ \\
\hline ALB & 35.3 & \pm 2.3 & 35.7 & \pm & 2.2 & 36.9 & \pm & 1.9 & 35.7 & \pm & 2.1 & \\
\hline$<35 \mathrm{~g} / \mathrm{L}$ & & & & & & $\%$ & & $15 \%$ & & & & $27 \%$ \\
\hline PALB & 0.27 & \pm 0.10 & 0.30 & \pm & 0.08 & 0.30 & \pm & 0.08 & 0.29 & \pm & 0.08 & \\
\hline$<0.20 \mathrm{~g} / \mathrm{L}$ & & & & & & $\%$ & & $4 \%$ & & & & $14 \%$ \\
\hline $\begin{array}{l}\text { TRF } \\
<2.0 \mathrm{~g} / \mathrm{L}\end{array}$ & 2.5 & \pm 0.4 & 2.5 & \pm & 0.5 & $\%$ & \pm & $\begin{array}{l}0.5 \\
4 \%\end{array}$ & 2.5 & 上 & 0.6 & $16 \%$ \\
\hline
\end{tabular}

'Excejt for weight loss, all walues are expressed as mean $\pm \mathrm{SD} ;{ }^{2}$ proportion of patients (in \%) with submormall values; ${ }^{3}$ males/females.

Table 3: The selected prediction equation with fat-free mass (FFMPIBW) as the dependent variable.

\begin{tabular}{|c|c|c|c|c|c|}
\hline $\begin{array}{l}\text { Prediction } \\
\text { variables }\end{array}$ & $\mathbf{r}$ & $\begin{array}{l}\mathbb{R}^{2} \\
\text { model }^{1}\end{array}$ & F model ${ }^{2}$ & $\mathrm{dF}$ & Student's $t^{3}$ \\
\hline
\end{tabular}

\begin{tabular}{|c|c|c|c|c|c|c|}
\hline Intercept & 31.5 & & & & & \\
\hline PIBW & 0.45 & 0.63 & 417 & 1.254 & 21.95 & $p<0.001$ \\
\hline $\operatorname{sex} x^{4}$ & -4.67 & 0.67 & 253 & 2.253 & -5.82 & $p<0.001$ \\
\hline
\end{tabular}

${ }^{1} \mathrm{R}^{2}=$ (regression sum of squares)/(total sum of squares) for modell consisting of current and preceding
variables.

${ }^{2}$ Model consisiting of current and preceding variables

${ }^{3}$ After adjustment for the remaining variables.

${ }^{4}$ males $=1$, females $=2$

Below nomnal body weight (group $I+2)$

A decreased body weight and fat-free mass in group 1 was reflected in significantly lower values for PIMMC, $C H I$ and 12 minute walking distance $(\mathrm{p}<0.05)$ than group 2 . Respiratory muscle strength was also lower, but statistical significance was not reached. Sub-cutaneous fat mass was not different between the 2 groups. $36 / 66$ Patients in group 1 
relative to $7 / 23$ patients in group 2 recalled recent weight loss $\left(x^{2}=3.97, p<0.05\right)$.

Normal body weight (group $3+4$ )

A decreased fat-free mass in group 3 was reflected in a lower PIMMC and in a decreased CHI, more than would be expected from the difference in PIBW with group 4. Depletion of fat-free mass coincided in these normal weight patients with a decreased respiratory muscle strength $\left(\mathrm{P}_{\mathrm{i}}\right.$-max: $\left.\mathrm{p}<0.01\right)$ and decreased exercise performance $(\mathrm{p}<0.05)$. No significant difference in sub-cutaneous fat mass was established between both groups.

Table 3: Nutritional measures, lung function and physical perfomance, categorized by body compasition (PIBW and FFMPIBW) in 4 groups.

\begin{tabular}{|c|c|c|c|c|c|c|c|c|c|c|c|c|c|}
\hline \multirow{2}{*}{$\begin{array}{l}\text { group } \\
\mathrm{n}=\mathrm{m} / \mathrm{f} \\
\text { PIBW } \\
\text { FFMPIBW } \\
\text { PIBW }\end{array}$} & \multirow{2}{*}{$\begin{array}{l}(\%) \\
(\%) \\
(\%)\end{array}$} & \multicolumn{4}{|c|}{$\begin{array}{l}1 \\
\mathrm{n}=52 / 14 \\
<90 \\
<63 / 67\end{array}$} & \multicolumn{4}{|c|}{$\begin{array}{l}2 \\
\mathbf{n}=16 / 7 \\
<90 \\
\geq 63 / 67\end{array}$} & \multicolumn{2}{|c|}{$\begin{array}{l}\quad 3 \\
\mathrm{n}=20 / 4 \\
\geq 90 \\
<63 / 67\end{array}$} & \multicolumn{2}{|c|}{$\begin{aligned} & 4 \\
& n=113 / 25 \\
& \geq 90 \\
& \geq 63 / 67\end{aligned}$} \\
\hline & & 81.1 & \pm & 6.64 & \# & 85.9 & \pm & 3.94 & H & 95.8 & \pm 5.34 & 107.6 & $\pm 12.9^{2}$ \\
\hline FFMPIBW & $(\%)$ & 60.4 & \pm & 4.2 .4 & \# & 70.6 & \pm & 3.64 & H & 64.3 & \pm 3.5 H & 76.4 & \pm 6.4 \\
\hline $\mathrm{FM}$ & (\%) & 14.6 & \pm & 4.0 & H & 14.0 & \pm & $4.0 \dagger$ & \# & 18.7 & \pm 6.1 & 20.8 & \pm 5.1 \\
\hline FM I & $(\%)$ & 24.3 & \pm & 4.5 & 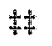 & 23.4 & \pm & $3.7 \$$ & +4 & 31.2 & \pm 1.1 & 30.7 & \pm 6.5 \\
\hline PIMMC & (\%) & 81.0 & \pm & 8.94 & \#施 & 87.2 & \pm & 10.1 & H & 90.3 & $\pm 9.4 \%$ & 96.9 & \pm 12.1 \\
\hline $\mathrm{CHI}$ & $(\%)$ & 60.5 & \pm & $15.9 \neq$ & \# & 73.3 & \pm & $16.3^{\text {* }}$ & & 60.9 & \pm 21.4 & 78.5 & \pm 21.3 \\
\hline ALB & $(\mathrm{g} / \mathrm{L})$ & 35.4 & \pm & 2.2 & $* *$ & 35.9 & \pm & 2.4 & & 35.2 & \pm 2.5 & 36.2 & \pm 2.1 \\
\hline PALB & $(\mathrm{g} / \mathrm{L})$ & 0.29 & \pm & $0.09^{\circ}$ & & 0.24 & \pm & $0.08+$ & 形和 & 0.29 & \pm 0.07 & 0.30 & \pm 0.08 \\
\hline TRF & $(\mathrm{g} / \mathrm{L})$ & 2.5 & \pm & 0.5 & & 2.4 & \pm & 0.6 & & 2.6 & \pm 0.6 & 2.6 & \pm 0.5 \\
\hline IVC & (\%) & 67 & \pm & 20 & & 67 & \pm & 17 & & 65 & \pm 20 & 68 & \pm 18 \\
\hline $\mathrm{FEV}_{1}$ & $(\%)$ & 30 & \pm & 15 & Hat & 30 & \pm & 7 & *** & 32 & \pm 13 & 38 & \pm 16 \\
\hline $\mathrm{P}_{4} \mathrm{O}_{2}$ & $(\mathrm{kPa})$ & 8.6 & \pm & 1.6 & *** & 8.4 & \pm & 1.7 & $* *$ & 8.7 & \pm 1.8 & 9.1 & \pm 1.6 \\
\hline $\mathbb{P}_{2} \mathrm{CO}_{2}$ & $(\mathrm{kPa})$ & 5.5 & \pm & 0.8 & & 5.7 & \pm & 1.3 & & 5.4 & \pm 0.9 & 5.3 & \pm 0.8 \\
\hline $\mathbb{P}_{i}-\max m$ & $(\mathrm{kPa})$ & 4.6 & \pm & 2.2 & \# & 5.2 & \pm & 1.9 & & 4.4 & 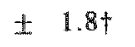 & 5.8 & \pm 2.3 \\
\hline $\mathbb{P}_{\text {; }}$-max & $(\mathrm{kPa})$ & 2.8 & \pm & 1.2 & 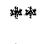 & 3.1 & \pm & 1.9 & & 2.8 & \pm 1.0 & 3.7 & $\pm \quad 1.5$ \\
\hline $\mathbb{P}_{\mathrm{e}}-\max \mathrm{m}$ & (kPa) & 6.7 & \pm & 2.8 & 楼 & 8.0 & \pm & 2.8 & & 7.1 & \pm 3.3 & 8.3 & \pm 3.5 \\
\hline $\mathbb{P}_{\text {-max } f}$ & $\left(k P_{a}\right)$ & 3.8 & \pm & 2.2 & & 4.3 & \pm & 2.0 & & 3.8 & \pm 2.0 & 4.8 & \pm 1.8 \\
\hline$W D^{3}$ & (m) & a & $=$ & $37 / 11^{1}$ & $+t$ & $\mathrm{n}$ & $=$ & 13.6 & & n & $=13 / 4^{*}$ & n & $=102 / 19$ \\
\hline $\mathrm{m}$ & & 568 & \pm & $239 *$ & $+\uparrow$ & 744 & \pm & $233 \uparrow$ & & 532 & $\pm 152^{\text {㗊 }}$ & 709 & $\pm \quad 27$ \\
\hline f & & 544 & \pm & 136 & & 651 & \pm & 297 & & $\$ 23$ & $\pm \quad 292$ & 567 & \pm 283 \\
\hline
\end{tabular}

$\mathrm{m}=$ males $/ \mathrm{f}=$ females; ${ }^{2}$ values are expressed as mean $\pm \mathrm{SD} ;{ }^{3}$ WD $=$ walking distance

$* p<0.05$ compared to adjacent group; ** $p<0.05$ compared to group 4

$\uparrow p<0.01$ compared to adjacemt group; $\dagger \dagger p<0.01$ compared to growp 4

$\ddagger \mathrm{p}<0.005$ compared to adjacent group; $\$ \mathrm{p}<0.005$ compared to group 4

$\# \mathrm{p}<0.001$ compared to adjacent group; $\mathrm{p}<0.001$ compared to group 4 
Below normal body weight or fat-free mass (group $2+3$ )

Despite a significant difference in PIBW and in sub-cutaneous fat mass $(\mathrm{p}<0.001)$, no difference in PIMMC was found between the groups. CHI and 12 minute walking distance were significantly lower $(p<0.05)$ in group 3 . Even more striking was the finding that the CHI in group 2 was only slightly lower $(73.3 \%$ vs $78.5 \%, p<0.05)$ than reference group 4 , whereas no difference in 12 minute walking distance could be established between both groups.

Serum proteins were not systematically different between the 4 groups. Since a substantial number of patients were on oral corticosteroid and/or diuretic therapy, a possible confounding effect of medication on nutritional measures and physical performance was studied. Patients that received corticosteroids were compared with patients who had not received oral corticosteroids for at least 3 months prior to admission. No differences were found between the two groups in body composition, respiratory muscle strength and walking distance. Prealbumin concentrations were significantly higher $(0.30 \pm 0.09$ and $0.27 \pm 0.07 \mathrm{~g} / \mathrm{L}$ respectively, $\mathrm{p}<0.05)$ and albumin concentrations lower $(35.7 \pm 2.3$ and $36.3 \pm 2.0 \mathrm{~g} / \mathrm{L}$ respectively, $\mathrm{p}<0.05$ ) in patients using oral corticosteroids. Independent of body composition, CHI was significantly lower in patients using diuretic medication $(66 \pm 22 \%$ and $77 \pm 19 \%$ respectively, $p<0.001)$. Consumption of medication was equally distributed among the 4 body composition groups.

\section{Discussion}

Only limited information is available with respect to the relationship between nutritional measures and disease severity in COPD. Several investigators reported a compromised nutritional status but most of the patient groups were small and suffered from severe airflow obstruction. The study by Wilson (1989) is of interest, who analyzed 779 male patients with stable COPD $\left(\mathrm{P}_{\mathrm{n}} \mathrm{O}_{2}>7.3 \mathrm{kPa}\right)$, participating in the $\mathrm{NIH}$-intermittent positivepressure breathing trial. PIBW $<90 \%$ was found in approximately $25 \%$ of the patients: $51 \%$ in the more obstructed group (FEV $<35 \%$ ) and $20 \%$ in the less obstructive patients. Our results in patients admitted to a pulmonary rehabilitation center, are in agreement with these findings. In addition we established a high prevalence of nutritional depletion in patients suffering from chronic hypoxemia.

Another purpose of this study was to characterize nutritional status by body composition rather than by PIBW alone. Characterization of the patients by body composition in 4 groups, revealed that depletion of fat-free mass may occur in a substantial proportion of normal weight COPD patients. Such patients have a relatively abundant fat mass and suffer from physical impairment even to a greater degree than underweight patients with a relative preservation of fat-free mass. The degree of impairment was similar in under- 
weight and normal weight patients exhibiting fat-free mass depletion. This classification was supported by the CHI which has received widespread clinical acceptance as biochemical indicator of muscle mass (Heymsfield, 1983). CHI was strikingly lower in the two groups exhibiting a depleted fat-free mass.

We recognize that these findings were less significant for females. This may be due to the small number of females included in the study, particularly in group 2 and group 3 , or to the fact that the discrepancy between PIBW and FFMPIBW was less pronounced in females than in males.

Fat-free mass was assessed using the relatively new bioelectrical impedance technique. In a previous study (chapter 2) we compared this method with deuterium dilution space as an index of total body water, which is generally considered as an important variable in the assessment of body composition. We established a good correlation between height ${ }^{2} /$ resis- $^{-}$ tance and total body water measured by deuterium dilution corresponding to results by others obtained in healthy younger individuals. One of the limitations of deuterium dilution is that the calculation of fat-free mass relies on assumptions of the water content of FFM (Sheng, 1979) which may be different in the elderly, in patients or in extremely thin or obese subjects due to possible changes in the distribution of intracellular and extracellular water in the body. BCM decreases with age resulting in reduced total body water, but there are conflicting reports regarding changes in extracellular water with age (Chumlea, 1989). Schoeller concluded in a recent review that the available animal and human studies indicate little or no change in the relationship between total body water and fat-free mass with aging (Schoeller, 1989). The degree of disease related extra cellular water expansion is also assumed to be minor since all patients were in a stable clinical condition. We recognize that a substantial number of patients was hypoxemic and used diuretics. However only patients with a compensated cor pulmonale, not suffering from edema, were included. In chapter 3 we investigated the effect of maintenance diuretic treatment on the within-day variation of resistance. No consistent effect was established of $40 \mathrm{mg}$ furosemide within $5 \mathrm{~h}$ after oral administration.

Serum values of albumin, prealbumin and transferrin were either in the normal range or moderately decreased. The reason for the use of albumin as a nutritional indicator was based on the observation that prolonged starvation is associated with a discrete reduction in albumin concentration. The magnitude of the drop is modest which may indicate that loss of skeletal muscle serves to furnish amino acids for the maintenance of more vital proteins such as albumin (Munro, 1964). In our experience a sudden drop in albumin is related to sudden clinical deterioration (Soeters "1990), probably representing a reduction in net albumin synthesis rates and 3rd space losses with expansion of the extravascular distribution volume (Forse, 1980). Albumin behaves in this respect as a negative acute 
phase protein. This was also demonstrated by Fiaccedori (1988) who found substantially lower serum albumin concentrations, independent of body composition in patients suffering from acute respiratory failure compared to COPD outpatients. Although prealbumin is generally considered to be a more sensitive indicator of short term nutritional depletion and repletion than albumin because of its very short half life (Tuten, 1985), not only few low senum prealbumin concentrations were found, but a substantial number of patients had elevated values. In agreement with other studies (Morton, 1988) we demonstrated that this may be partly due to long term corticosteroid mediation. The fact that transferrin was also not very discriminative is not surprising since iron status in patients with COPD probably does not reflect iron store deficits but is rather an adjustment of the body to hypoxemia (Hunter, 1981).

Our results indicate that somatic wasting has detrimental effects on respiratory muscle function. This was confirmed in autopsy studies which demonstrated that diaphragm muscle mass is substantially reduced in depleted patients without and with COPD (Thurlbeck, 1978; Arora II , 1982). Other studies have also shown decreased respiratory muscle strength in depleted patients not suffering from COPD compared to their non depleted counterparts (Kelly, 1984; Rochester, 1986). In COPD respiratory muscle strength may be further reduced due to mechanical factors affecting the effectiveness of the respiratory muscles (Rochester, 1985). Hyperinflation causes shortening of inspiratory muscles so that the fibers are not at their optimal length tension ratio (Derenne, 1978).

Impairment of muscle function secondary to nutritional depletion may modify clinical and functional status in several ways. Rochester and Braun suggested from their results (Rochester, 1985) that inspiratory muscle weakness may contribute to hypercapnia, since it modifies the pattern of breathing towards smaller tidal volumes and higher respiratory rates. Several studies established a lasuar maximnd wevise power output in underweight patients with COPD compared to normal or overweight patients with equivalent degrees of expiratory airflow limitation (Renzi, 1985; Wilson, 1989; Gray-McDonald, 1989). In an earlier study using a 12 minute walking test we also found a positive association between creatinine height index and submaximal exercise performance ( $\left.S c h o l s{ }^{11}, 1989\right)$.

Subjective estimates of breathlessness have been found to be congruent with these physiological findings. Killian et al (1988) compared the intensity of breathlessness, inspiratory with a Borg scale, at comparable levels of activity in patients with varying inspiratory muscle strength and with varying degrees of airflow obstruction. The intensity
of breathlessness at a given comparable intensity of activity increased as and at each level of $\mathrm{FEV}_{1}$, as respiratory muscle strength declined. 
We conclude that nutritional depletion commonly occurs in COPD patients eligible for pulmonary rehabilitation. On the assumption that depletion is reflected in physical impairment, the results suggest that FFM is a better indicator of body cell mass depletion than body weight. Loss of FFM in the absence of loss of body weight, can remain unrecognized and still have detrimental consequences. Stratification of COPD patients by body weight and fat-free mass may have consequences for planning and interpretation of intervention strategies, particularly in group 2 and 3 patients. 


\title{
Chapter 6
}

\section{Body composition and exercise performance in patients with COPD}

\begin{abstract}
Patients with COPD can be severely disabled by dyspnea and exercise impairment. To investigate whether nutritional depletion may limit exercise performance we studied 54 patients with COPD (FEV $<50 \%$ and $\left.\mathrm{P}_{\mathrm{a}} \mathrm{O}_{2}>7.3 \mathrm{kPa}\right)_{\text {, }}$ in stable clinical condition admitted to a pulmonary rehabilitation center. Fat-free mass was assessed anthropometrically (using skinfold measurements at four sites (anthr)) and by bioelectrical impedance. In addition the creatinine height index and arm muscle circumference were assessed. Twelve minute walking distance amounted to $845 \pm 178$ (mean \pm SD) $\mathrm{m}$. No association was established between walking distance and spirometric measures. A good correlation was found between walking distance and fat-free mass in the total group (bi: $r=0.73$, anthr: $r=0.65$ ) and in a sub-group of 23 lean patients (body weight $<90 \%$ of ideal weight) (bi: $r=0.66$, anthr: $r=0.46$ ). Body weight correlated with walking distance only in the total group $(r=0.61)$. On stepwise regression analysis, fat-free mass assessed using the bioelectrical impedance method, maximal inspiratory mouth pressure and $\mathrm{P}_{a} \mathrm{O}_{2}$ explained $60 \%$ of the variation in 12 minute walking distance. We conclude that fat-free mass, independent of airflow obstruction is an important determinant of exercise performance in patients with severe COPD.
\end{abstract}




\section{Exercise performance}

Exercise performance was evaluated with a 12 minute walking test, performed in a level enclosed corridor according to the method described by McGavin (1976). Corridor walking can be considered as a useful method to evaluate exercise tolerance in COPD patients (Swerts, 1990). All tests were performed in the early afternoon and no encouragement was given. As learning effects have been noticed to occur quickly with repeated walk tests (Swerts, 1990; Beaumont 1985), the patients performed one practice test. Walking distance was measured after 2,6 and 12 minutes walking. Patients who were not able to walk continuously for 12 minutes, were excluded from analysis.

\section{Statistics}

Descriptive statistics are given as mean $\pm S D$. Body composition measures were correlated mutually, with lung function measures and with 12 minute walking distance by means of the product moment correlation coefficient. After the simple correlations had been completed a linear model was fitted to the data to enable the variables that contributed to the 12 minute walking distance to be determined by stepwise regression analysis.

Table 1: Description of the study group.

\begin{tabular}{|c|c|c|c|}
\hline age & $(y)$ & 66 & \pm 6 \\
\hline \multirow[t]{2}{*}{ inspiratory vital capaciry } & (L) & 2.5 & $\pm \quad 0.7^{1}$ \\
\hline & $(\%)$ & 67 & \pm 19 \\
\hline \multirow[t]{2}{*}{$\mathrm{FEV}_{1}$} & (L) & 0.9 & \pm 0.3 \\
\hline & $(\%)$ & 33 & \pm 9 \\
\hline $\mathrm{P}_{4} \mathrm{O}_{2}$ & $(\mathrm{kPa})$ & 9.7 & $\pm \quad 1.4$ \\
\hline $\mathrm{P}_{2} \mathrm{CO}_{2}$ & $(\mathrm{kPa})$ & 5.3 & \pm 0.6 \\
\hline$P_{i} \cdot \max$ & (kPa) & 5.8 & \pm 2.3 \\
\hline$P_{0}-\operatorname{manx}$ & $(\mathrm{kPa})$ & 8.0 & $\pm \quad 3.9$ \\
\hline PIBW & $(\%)$ & 95.4 & \pm 13.4 \\
\hline FFMPIB W.bi & $(\%)$ & 70.7 & \pm 8.5 \\
\hline FFMPIBW-snthr & $(\%)$ & 75.9 & $\pm \quad 9.5$ \\
\hline creatinine height index & (\%) & 73.7 & \pm 19.4 \\
\hline aron muscle circumference & $(\%)$ & 90.2 & \pm 9.2 \\
\hline
\end{tabular}

1 meanysD

\section{Results}

Characteristics of the study group are summarized in table 1. The group consisted of 54 patients with COPD, the majority of whom were male $(80 \%)$. Age of the patients was Normally distributed, ranging from 50-79 y. Most patients were normal to underweight 
according to body weight expressed as a percentage of ideal weight (range 69.3- $120.0 \%$ ). Fat-free mass values by bioelectrical impedance (FFM-bi) were significantly lower than by skinfold anthropometry (FFM-anthr) $(\mathrm{p}<0.001)$. Highly significant correlations were obtained between the independent measures of body composition (table 2). A good correlation $(r=0.86)$ was found between the two measures of FFM which was slightly higher than the correlation between FFMPIBW and PIBW. CHI correlated slightly better with FFMPIBW-bi than with FFMPIBW-anthr or PIBW. Arm muscle circumference correlated less with the other measures except for body weight.

Respiratory muscle strength correlated significantly with PIBW $(\mathrm{p}<0.005)$, FFMPIBW $(p=0.01)$ and creatinine height index $(p<0.01)$. No significant associations were established between any of the nutritional measures and IVC, FEV 1 or arterial blood gases. The mean 12 minute walking distance was $845 \pm 178$ meters. The mean increase between the practice test and the study was $119 \mathrm{~m}(95 \%$ confidence interval +76 and $+162 \mathrm{~m}$. Walking speed $(\mathrm{km} / \mathrm{h})$ at 2, 6 and 12 minutes walking was compared between the low performance group (walking distance being more than one SD below the mean walking distance) and the other patients (figure 1).

Table 2: Mutual correlation coefficients of the body composition measures.

\begin{tabular}{lcccc}
\hline & FFMPIBW-bi & FFMPIBW-anthr & CHI & MMC \\
& & & & \\
PIBW & $0.79^{1}$ & 0.81 & 0.49 & 0.69 \\
FFMPIBW-bi & & 0.86 & 0.54 & 0.51 \\
FFMPIBW-anthr & & & 0.46 & 0.41 \\
CHI & & & 0.44 \\
\hline
\end{tabular}

"All walues are statistically significant with a p-walue $<0.001$

Mean walking speed at 2 minutes walking was $4.6 \mathrm{~km} / \mathrm{h}$ for the normal to high performance groups and did not change throughout the test. Mean walking speed for the low performance group was $3.2 \mathrm{~km} / \mathrm{h}$ at 2 minutes and then decreased significanlly during the remainder of the test $(p<0.05)$. The mean increase in heart rate at the end of the test was $28 \pm 15$ beats per minute and did not differ between groups. Twelve minute walking distance showed significant correlations with all body composition measures. A good correlation was found between walking distance and fat-free mass determined by the bioelectrical impedance method (table 3 ). Among the lung function measurements only $\mathbf{P}_{\mathrm{i}}$ $\max , \mathrm{P}_{\mathrm{e}}$-max and $\mathrm{P}_{\mathrm{a}} \mathrm{O}_{2}$ were significantly correlated with walking distance. In a sub group of underweight patients (body weight $<90 \%$ of ideal weight, $n=23$; table 3 ) the correlation with body weight disappeared but the correlation between fat-free mass and 12 minute walking distance remained highly significant. 
Part II: Towards a definitioni of nutritional depletion

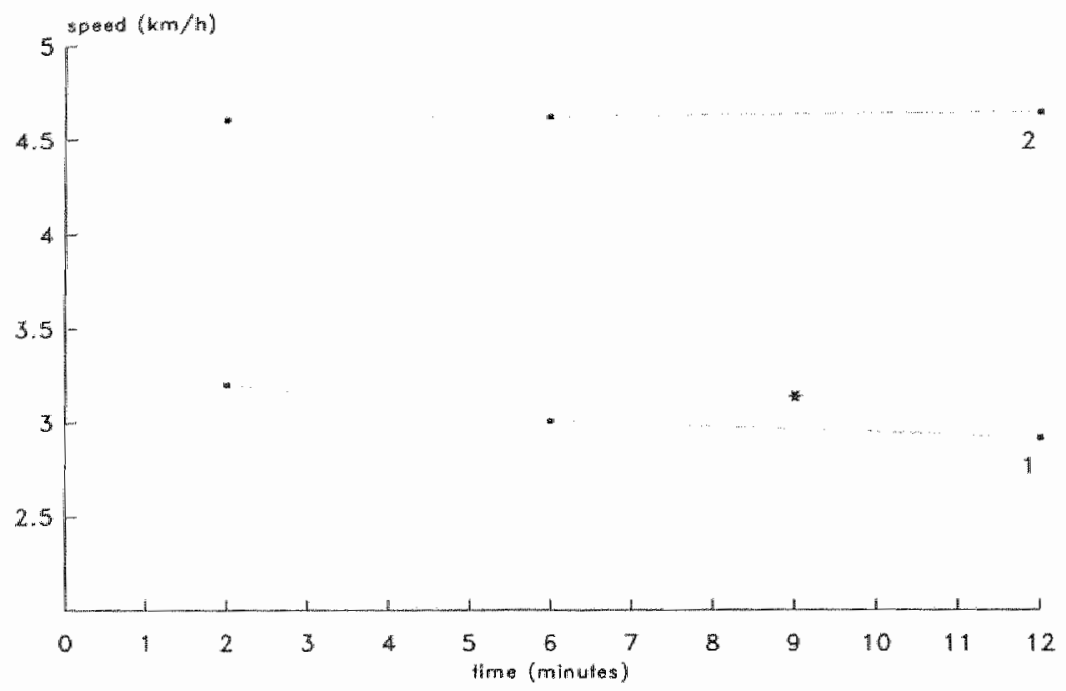

Figure 1: Mean walking speed after 2, 6, and 12 min. for the low performest (=walking distance more than I SD below wean walking distance) compared with the ather patients.

Table 3: Correlation coefficients for lung function and body composition measures with 12 minute walking distance.

$$
\begin{array}{ll}
\text { total group } & \text { sub group } \\
(n=54) & (n=23)
\end{array}
$$

\begin{tabular}{|c|c|c|c|}
\hline IVC & (C) & 0.22 & 0.04 \\
\hline FEV & (L) & 0.06 & 0.05 \\
\hline $\mathrm{P}_{2} \mathrm{O}_{2}$ & $(\mathrm{kPa})$ & $0.20 *$ & 0.05 \\
\hline $\mathrm{P}_{4} \mathrm{CO}_{2}$ & $\left(k P_{\text {fit }}\right)$ & 0.07 & 0.10 \\
\hline$P_{1}-\max$ & $(\mathrm{kPa})$ & 0.41 & 0.27 \\
\hline$P_{n}-\max$ & $(\mathrm{kPa})$ & 0.38 & 0.21 \\
\hline PIBW & $(\%)$ & $0.61 \%$ & 0.18 \\
\hline FFMPIBW-bi & $(\%)$ & $0.73 \#$ & 0.66 \\
\hline FFMPIBW-anthr & $(\%)$ & $0.65 \#$ & $0.46 *$ \\
\hline CHI & $(\%)$ & 0.39 & 0.21 \\
\hline $\mathrm{MMC}$ & $(\%)$ & 0.37 \# & 0.07 \\
\hline
\end{tabular}


In the multiple regression model inclusion of FFM-bi, $\mathrm{P}_{\mathrm{i}}$-max and $\mathrm{P}_{\mathrm{a}} \mathrm{O}_{2}$ explained $60 \%$ of the variation in walking distance (table 4). Although walking distance differed significantIy between men and women, gender was not significant on the stepwise regression analysis.

Table 4: The selected prediction equation with walking distance as dependent variable.

\begin{tabular}{|c|c|c|c|c|c|c|}
\hline $\begin{array}{l}\text { prediction } \\
\text { Variables }\end{array}$ & $\begin{array}{l}\text { regression } \\
\text { coefficient }\end{array}$ & $\begin{array}{l}\mathrm{R}^{2} \\
\text { model } l^{\mathrm{B}}\end{array}$ & F model ${ }^{2}$ & Df & Student"s $t^{3}$ & \\
\hline intercept. & .514 .52 & & & & & \\
\hline FFMPIBW-bi & 13.80 & 0.52 & 58.0 & 1.53 & 7.08 & $p<0.001$ \\
\hline Pit - max & 1.94 & 0.56 & 33.5 & 2.52 & 2.52 & $p<0.01$ \\
\hline $\mathrm{P}_{2} \mathrm{O}_{2}$ & 27.54 & 0.60 & 26.6 & 3.51 & 2.45 & $p<0.05$ \\
\hline
\end{tabular}

\section{Discussion}

The few studies available report conflicting results on the relationship between mutritional status and exercise performance. Studies measuring maximal exercise performance by cycle ergometry have established a positive association between $\mathrm{VO}_{2}$-max and body weight as a percentage of ideal weight. Contrary to other studies (Efthimiou 1988; GrayMcDonald, 1989; Schols, 1989 II) we found a significant positive association between sub maximal exercise performance measured with a walking test and body weight. Differences in outcome of these studies might be related to several factors including the type of exercise test, the selection of paticnts and the nutritional measures studied.

In contrast to other studies (Efthimiou, 1988; Gray McDonald, 1989) we used a 12 minute walking test which may be more discriminative than a 6 minute walk. Figure 1 demonstrates that in patients with the poorest performest walking speed decreased between 6 and 12 minutes. Nevertheless the positive association with body weight remained significant when we used 6 in stead of 12 minute walking distance. Obesity (Swinburn, 1989) may be a reason why the walking distance of 'normal' (mean $\pm S D$ ) $(118 \pm 17 \%)$ weight patients did not differ from that of underweight patients in the study by Efthimiou.

Although we found a good correlation between body weight and walking distance, the correlation coeffient between fat-free mass and walking distance was substantially better. 


\section{Part II. Towards a definition of nutritional depletion}

This is not surprising since fat-free mass in clinically stable patients mainly consists of metabolic active tisue, whereas body weight also comprises inactive fat. The increased value of fat-free mass over body weight however was most pronounced in the sub group of underweight patients. This indicates that only when fat-free mass drops to very low levels, it is critical for physical performance.

We compared fat-free mass with commonly used clinical measures of body composition. There was a reasonable correlation belween creatinine height index and fat-free mass although urinary creatinine excretion suffers from a substantial day to day variation which detracts from this measurement of muscle mass (Schols, 1989 ). Arm muscle circumference added little to the estimation of muscle mass. It correlated less well with $\mathrm{CHI}$ or fat-free mass than with body weight. A disadvantage of skinfold anthropometry is that the method is based on the assumption that a proportionate fraction of total body fat is located. sub-cutaneously. It has been shown however that fat mass is underestimated in elderly subjects due to a centrallization and internalization of body fat which is not reflected by skinfolds (Seidell, 1987; Weits, 1988). This variability may be reflected more in arm muscle circumference, which is based on only 1 skinfold, rather than in FFM-anthr which is based on skinfold measurements at 4 sites.

In spite of these problems, stepwise regression analysis revealed that fat-free mass estimated from bioelectrical impedance contributed the major part of the explained variation in 12 minute walking distance in addition to $\mathrm{P}_{\mathrm{i}}-\max$ and $\mathrm{P}_{4} \mathrm{O}_{2}$.

Muscle wasting is an obvious part of depletion of fat-free mass. In general, strength of skeletal muscle is related to muscle mass and muscle fiber contractility. The respiratory muscles like other striated muscles contain a mixture of type I or slow-twitch (oxygen dependent, fatigue resistant) fibers and type II or fast-twitch fibers, dependent on oxidative (IIa) or glycolytic (IIb) energy stores (Faulkner, 1979). Slow twitch fibers are recruited during slow intensity contractions. As the intensity of contraction increases, fast twitch latigue resistant and later fast twitch fatiguable fibers are recruited. Prolonged undernutrition is associated with proportionate reductions in diaphragmatic mass as a result of decreases in the cross sectional area of the muscle fiber in various animal models (Kelsen, 1985; Lewis, 1986; Siech, 1989). The reduction in muscle bulk results in a decrease in muscle force output, while the mechanical effectiveness of the residual myofibrillar material remains unaffected. The effects of undernutrition on fast fibers are of greater magnitude than on slow fibers: greater atrophy of fast fibers ensures that a greater percentage of the total muscle cross sectional area will be composed of slow oxidative fibers whose resistance to fatigue is greater than that of fast fibers. Therefore the tension of the respiratory muscles generated during basal activities may be well preserved, but the maximum power output of the diaphragm in wasted individuals will be 
impaired as progressively greater numbers of fast fibers are recruited. Atrophy of type 2 fibers as part of diminished fat-free mass has been suggested as the underlying cause of the correlation between body weight and $\mathrm{VO}_{2}$-max (Gray-McDonald, 1989).

The relation between 12 minute walking distance and nutritional depletion is more difficult to explain since it is likely that fast fibers will be recruited less during sub maximal exercise than during maximal exercise. Three additional mechanisms are postulated. Firstly atrophy of fast-twitch fibers with reduction of maximum force output predisposes the diaphragm to fatigue since this is related to the level of force generated during breathing, expressed as a percentage of the maximum force achievable. A second mechanism is suggested by the study by Lopes and colleagues (1982) who found increased muscle fatiguability and slowing of relaxation of the adductor pollicis muscle in undernourished patients with gastrointestinal disease. Since this increase occured without change in local blood flow, the slower muscle relaxation rate and increase in muscle fatiguability were explained by a decrease in local energy stores of the limb muscles. Efthimiou et al. (1989) demonstrated similar changes as well as reduced strength in the sternomastoid muscle in underweight patients with COPD. Donahoe et al. (1989) found an increase in oxygen consumption of the ventilatory muscles for a given level of ventilation in underweight patients with COPD. The increased oxygen consumption of the ventilatory pump could therefore be a third exercise limiting factor in these patients by decreasing the proportion of total available oxygen for the exercising limb muscles.

We conclude that muscle mass is an important determinant of exercise performance in patients with severe COPD, independent of the degree of airflow obstruction. In spite of the fact that the type 1 fibers are relatively spared in the wasting process associated with nutritional depletion, several other mechanisms can explain increased fatiguability of skeletal muscle resulting in exercise limitation in these patients. Further studies are needed to confirm these pathophysiological changes in depleted patients with COPD. 

Part III: Pathogenesis of nutritional depletion in COPD 



\title{
Chapter 7
}

\section{Resting energy expenditure in patients with COPD compared to a healthy control group}

\begin{abstract}
Resting energy expenditure (REE) was measured in 68 patients with stable chronic obstructive pulmonary disease (COPD) and in 34 weight stable, age matched $(65 \pm 8$ y) $(\mathrm{x} \pm \mathrm{SD}$ ) healthy controls. Fat-free mass determined by bioclectrical resistance, explained $84 \%$ of the variation in REE in the control group, but only $34 \%$ in the COPD patients. REE could not reliably be predicted from regression equations either developed in healthy subjects or in COPD patients. REE adjusted for fat-free mass was significantly higher in weight losing $(n=34)$ compared to weight stable $(n=34)$ patients $(1675 \pm 191 \mathrm{kcal} /$ day and $1588 \pm 159 \mathrm{kcal} / \mathrm{day})$. Pulmonary function was more compromised in weight losing patients. Adjusted REE in weight stable patients was significantly higher than in the healthy control group (1499 $\pm 99 \mathrm{kcal} / \mathrm{day})$. We conclude that in patients with COPD other factors in addition to fat free mass are important determinants of REE. A disease related increase in REE dewclops which may contribute to weight loss in COPD in combination with a lack of an adaptive response to undernutrition in weight losing patients.
\end{abstract}




\section{Introduction}

Weight loss is a common phenomenon in patients with chronic obstructive pulmonary disease (Wilson, 1985) and can ultimately lead to cachexia. A major cause of weight loss is an imbalance between energy intake and energy expenditure. In this study we focus on resting energy expenditure (REE) as the major component of total energy expenditure in sedentary persons (Ravussin, 1981) and in COPD patients (Hugli, 1990).

An increased REE has been reported in patients with COPD. (Braun, 1984; Goldstein, 1987; Fitting, 1989; Wilson, 1990; Lanigan, 1990). However the available literature is contradictory with respect to the prevalence of hypermetabolism in COPD. This controversy may be due to a limited number of patients in the studies, absence of an appropriate healthy control group or missing data concerning body composition of the patients. In this study we compared REE normalized for fat-free mass, in COPD patients with recent significant weight loss with weight stable COPD patients and with a healthy, weight stable, age-matched control group.

\section{Subjects and methods}

\section{Patients}

The patient group consisted of 68 COPD patients, aged between 51 and 86 years, admitted to a pulmonary rehabilitation center for physical training (table 1). Patients exhibiting an increase in $\mathrm{FEV}_{1}>10 \%$ of baseline after inhalation of a $\mathbb{B}_{2}$-agonist, or patients suffering from cancer, unstable cardiac condition, active gastrointestinal abnormalities, recent surgery, severe endocrine disorders or obesity (body mass index (BMI) $\geq 30$ $\mathrm{kg} / \mathrm{m}^{2}$ ) were excluded from the study. To exclude a possible confounding effect of acute exacerbation of their disease, only patients in a stable pulmonary and cardiac condition were studied. None of the patients was suffering from a respiratory tract infection or had clinical signs of edema.

\section{Controls}

Controls were 34 healthy men and women between the age of 51 and 82 years, living in the same area as the patients. All volunteers had stable weights, a $\mathrm{BMI}<30 \mathrm{~kg} / \mathrm{m}^{2}$ and no evidence of physical or mental disease. They underwent a medical examination to exclude disorders which might affect their metabolic rate such as anaemia high blood pressure, thyroid dysfunction, heart failure, infectious disease or COPD. All subjects had normal blood pressures, pulse rates and body temperatures. 
Resting energy expenditure (REE)

Resting energy expenditure was measured by indirect calorimetry using a ventillated hood system, which is described in more detail in chapter 4 . The hood consisted of clear plexiglas and had a volume of 30 liters. Gas anallyses were performed using a paramagnetic oxygen analyzer (Mijnhardt Oxygen module, Bunnik, the Netherlands) and an infrared carbondioxide analyzer (Mijnhardt UG51, Bunnik, The Netherlands). Dry gases were measured and the results converted to standard temperature and pressure. Flow through the canopy was kept constant during the measurements and was adjusted to body weight of the subject ranging from 30 to $45 \mathrm{~L} / \mathrm{min}$. System control and calculations were performed on a microcomputer. The system was calibrated at the start and at the end of the experiment.

Measurements in patients were done within one week after admission to the rehabilitation center when medication was optimalized and therapeutic serum theophylline levels (8-15 $\mathrm{mg} / \mathrm{L}$ ) were attained. REE was measured in the early morning, after an overnight fast and a period of at least 30 minutes bed rest ${ } 2 \mathrm{~h}$ after the patients had received their maintenance medication. Measurements in controls were performed similarly, but on an out patient basis. Fredrix (1990) showed that variations due to limited physicall activities including a short travel from home to the hospital do not significantly influence the measurement of REE. Gas exchange data were collected over a 20 to 30 minutes period of steady state. Reproducibility of measurements on two consecutive days was good: the standard error of measurement of a single determination of REE was $56 \mathrm{kcal}$ resulting in a within-patient coefficient of variation of $3.3 \%$ (Fredrix, 1990). The abbreviated Weir equation (1949) was used to callculate REE.

\section{Bioelectrical resistance.}

Body height was measured bare foot standing and determined to the nearest $0.5 \mathrm{~cm}$. Body weight was measured with a beam scale without shoes in light clothing to the nearest 0.1 $\mathrm{kg}$. Falt-free mass (FFM) was measured using the bioelectrical impedance (bi) method. Resistance (BIA-101, RJL Systems, Detroit) was measured in the supine position at the right site as described by Lukaski (1985). In chapter 2 we established a good correlation between $\mathrm{Ht}^{2} /$ resistance and tolal body water (TBW) assessed by deuterium dilution in 32 normal to underweight COPD patients in stable clinical condition and used bi-predicted TBW to estimate bi-FFM, assuming a hydration factor of 0.73 (chapter 3). To assess whether the same prediction equation could be applied to the control group, height/resistance was related to TBW in 17 controls (figure 1 ).

\section{Lung function}

$\mathrm{FEV}_{1}$ and inspiratory vital capacity (IVC) were measured with a wet spirometer; the highest value of at least three spirometric manoeuvres being used. FEV and IVC were 
expressed as a percentage of the reference value (Quanjer, 1983). Arterial blood gases were drawn by puncture of the brachial artery at rest while breathing room air. Arteriall oxygen tension $\left(\mathrm{P}_{\mathrm{a}} \mathrm{O}_{2}\right)$ and carbon dioxide tension $\left(\mathrm{P}_{\mathrm{a}} \mathrm{CO}_{2}\right)$ were analyzed on a blood gas analyzer (Radiometer, ABL 330, Copenhagen, Denmark). Respiratory muscle strength was determined by measuring maximal inspiratory $\left(\mathbf{P}_{\mathrm{i}}-\mathrm{max}\right)$ and expiratory $\left(\mathrm{P}_{\mathrm{e}}-\mathrm{max}\right)$ mouth pressures, according to the technique described by Black and Hyatt (1969). The best of three determinations was used in subsequent calculations. No pulmonary function tests were performed in the control group.

Other relevant data regarding disease history, pattern and duration of weight loss, smoking behavior and medication were obtained by an interview with the pulmonary physician using a standardized medical questionnaire.

\section{Statistics}

Weight loss was calculated as the difference between reported stable weight minus actual weight. Weight loss was considered significant when the decrease in body weight within the previous 6 months amounted to $10 \%$ or more of usual stable body weight. The other patients and the control group had been weight stable for at least 1 year prior to admission.

The linear regression of TBW on height ${ }^{2} /$ resistance in 32 patients and 17 controls was graphically displayed (figure 1a) and slope and intercept of the two lines were compared using a small sample t-test as described by Kleinbaum and Kupper (1988). The equation generated in the controls was cross validated in the 32 patients and the residual TBW scores were plotted versus the mean TBW ((measured +predicted)/2) (figure $1 \mathrm{~b}$ ).

REE was adjusted for fat-free mass to normalize data for group comparison. The adjusted REE was calculated as the group $(n=102)$ mean REE plus measured REE minus predicted REE. The group mean REE is the mean REE in absolute terms; the measured REE is the REE measured in each subject; the predicted REE is the calculated REE obtained by using the individual fat-free mass in the linear regression equation of REE on FFM generated in the control group. Furthermore REE was expressed as a percentage of predicted REE. Predicted REE was calculated using the equations by Harris-Benedict (REE/HB) (Harris, 1919), and the COPD specific equations by Moore (REE-Moore) (1988). Subjects with a measured REE above $110 \%$ of that predicted by the HB formula were considered hypermetabolic. This definition of hypermetabolism was based on Boothby's (1936) finding that $95 \%$ of normal individuals exhibit a measured REE within $10 \%$ of predicted. 
Statistical analysis was performed using one way analysis of variance followed by the Tukey pairwise multiple comparison procedure. The Mann-Whitney U test was used where appropriate. Frequency data were compared using the Chi-square test. Results are expressed as mean \pm SD. Significance was determined at the $5 \%$ level.

\section{Results}

The patients represented elderly subjects with COPD (mean $\pm S D: 65 \pm 7$ y) and a marked airflow obstruction (FEV: $33 \pm 14 \%)$. Weight losing patients exhibited significantly lower values of weight, fat-free mass, $\mathrm{FEV}_{1}, \mathrm{P}_{\mathrm{a}} \mathrm{O}_{2}$ and respiratory muscle strength than weight stable patients (table 1). No difference in FFM was found between weight stable patients and the healthy controls. Percent fat mass was significantly higher $(p<0.05)$ in the control group, which consisted of more females than the patient groups. Slope and intercept of the regressions of TBW on height $t^{2} /$ resistance were not significantly different between patients and controls (figure 1a). The residual plot as a function of mean TBW (figure 1b) revealed no hint of any systematic trends for the equation generated in the controls and applied to the patients. We therefore decided to use the same prediction equation for FFM that we generated in the COPD patients (chapter 2) also in the control group.

FFM explained $84 \%$ of the inter-individual variation in REE in the healthy control group, with a standard error of estimation (SEE) of $1.01 \mathrm{kcal} / \mathrm{day}$. Addition of sex or fat mass as variables did not significantly increase the explained variation in REE. In COPD patients FFM explained only $34 \%$ (SEE $=164 \mathrm{kcal} / \mathrm{dlay}$ ) of the variation in REE. REE in absolute terms and normalized REE values are shown in table 2 . The within group coefficient of variation in REE/HB was substantially larger in patients $(14 \%)$ than in controls $(5 \%)$. $42 / 68$ patients $(62 \%)$ and $5 / 34$ controls $(15 \%)$ were considered hypermetabolic $(p<-$ $0.001)$. Measured REE was not different from the Moore equations in the weight losing group, but significantly lower in weight stable patients and controls $(p<0.001)$. Adjusted metabolic rate in the weight losing group was higher than in the weight stable patients $(p<0.05)$. Adjusted metabolic rate in weight stable patients was significantly higher than in stable weight controls $(p<0.01)$ (table 2 ). Figure 2 graphically displays the relation between adjusted metabolic rate and FFM for the 3 groups. Adjusted REE was higher $(p<0.05)$ in smokers $(R E E=1649 \pm 169 \mathrm{kcal} / \mathrm{day}, \mathrm{n}=30)$ than in non/ex smokers (REE $=1561 \pm 164 \mathrm{kcal} / \mathrm{day}, \mathrm{n}=72$ ). Smoking did not explain the observed differences between patients and the control group. However the difference in adjusted REE disappeared when the non-smoking COPD sub groups were compared (weight loss: $1636 \pm 174, \mathrm{n}=22$; weight stable: $1573 \pm 175, \mathrm{n}=26 ; \mathrm{NS}$ ). Maintenance medication in nearly all patients included theophylline, $B-2$ agonists and inhaled or oral corticosteroids and was not different between the groups. 
Table 1: Description of the studly group.

\begin{tabular}{|c|c|c|c|c|c|c|c|c|c|}
\hline & & \multicolumn{5}{|c|}{ Patients } & \multirow{2}{*}{\multicolumn{3}{|c|}{$\begin{array}{l}\text { Controle } \\
\text { subjects } \\
\mathbf{n}=34\end{array}$}} \\
\hline & & \multicolumn{2}{|c|}{$\begin{array}{l}\text { weight losing } \\
\text { nil }=34\end{array}$} & \multicolumn{3}{|c|}{$\begin{array}{c}\text { weight stable } \\
n=34\end{array}$} & & & \\
\hline $\operatorname{sex}$ & $\mathrm{M} / \mathrm{F}$ & \multicolumn{2}{|c|}{$27 / 7$} & \multicolumn{3}{|c|}{$26 / 8$} & \multicolumn{3}{|c|}{$18 / 16$} \\
\hline age & (y) & 65 & \pm 8 & 65 & \pm & 5 & 65 & \pm & 8 \\
\hline height & $(\mathrm{cm})$ & 171 & \pm 7 & 171 & \pm & 8 & 167 & \pm & 9 \\
\hline weight & $(\mathrm{kg})$ & 57.2 & $\pm 10.3^{1}$ & 67.8 & $t$ & $7.3 H$ & 71.1 & \pm & 10.3 \\
\hline FFM & $(\mathrm{kg})$ & 43.4 & \pm 7.5 & 48.8 & \pm & $6.7 \%$ & 49.5 & \pm & 8.9 \\
\hline fat malss & $(\%)$ & 24 & \pm 6 & 28. & \pm & $5 \neq$ & 31 & \pm & $5 \$$ \\
\hline IVC & (\%pred) & 65 & \pm 19 & 77 & \pm & $18+$ & & & \\
\hline FEV, & (\%pred) & 31 & it 13 & 39 & \pm & $14 *$ & & & \\
\hline $\mathrm{P}_{\mathrm{i}} \mathrm{O}_{2}$ & $\left(\mathrm{kP}_{\mathbb{Q}}\right)$ & 8.4 & \pm 1.7 & 9.3 & \pm & $1.6^{\circ}$ & & & \\
\hline $\mathrm{PaCO}_{2}$ & $(\mathrm{kPa})$ & 5.7 & \pm 0.7 & 5.5 & \pm & 0.8 & & & \\
\hline $\mathbf{P}_{7} \sim \operatorname{mat} x$ & $(\mathrm{kPa})$ & 4.2 & \pm 1.9 & 5.3 & \pm & $2.1^{*}$ & & & \\
\hline $\mathrm{P}_{\mathrm{e}}-\max$ & $\left(k P_{i a}\right)$ & 5.4 & \pm 2.6 & 6.9 & \pm & $2.6^{*}$ & & & \\
\hline
\end{tabular}

'Except for sex, all wallues are expressed as mean $\pm S D$.

$* p<0.05 ;+p<0.01 ; p<0.005 ; p<0.00 \%$ significantly different from weight losing patients.

$\$ p<0.05$ significantly different from weight stable patients.

Table 2: $24 \mathrm{H}$ resting energy expenditure (REE) expressed in absolute terms and compared to predicted REE in the 3 sub groups.

$\begin{array}{cccc} & \text { Patients } & \text { Controle subjects } \\ \text { total group } & \text { weight losing } & \text { weight stable } & \text { weight stable } \\ (n=68) & (n=34) & (n=34) & (n=34)\end{array}$

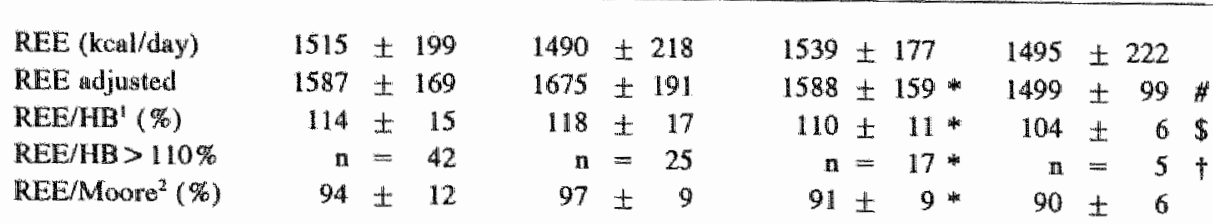

All values are expressed as mean $\mathrm{S} \mathrm{SD} ;{ }^{1} \mathrm{HB}=$ Harris-Benedict equations; ${ }^{2}$ Moore $=$ Moore equations. $p<0.05$ significantly different from weight losing patients.

$\$ p<0.05 ; p<0.01 ; p<0.001$ significantly different from weight-stable patients. 

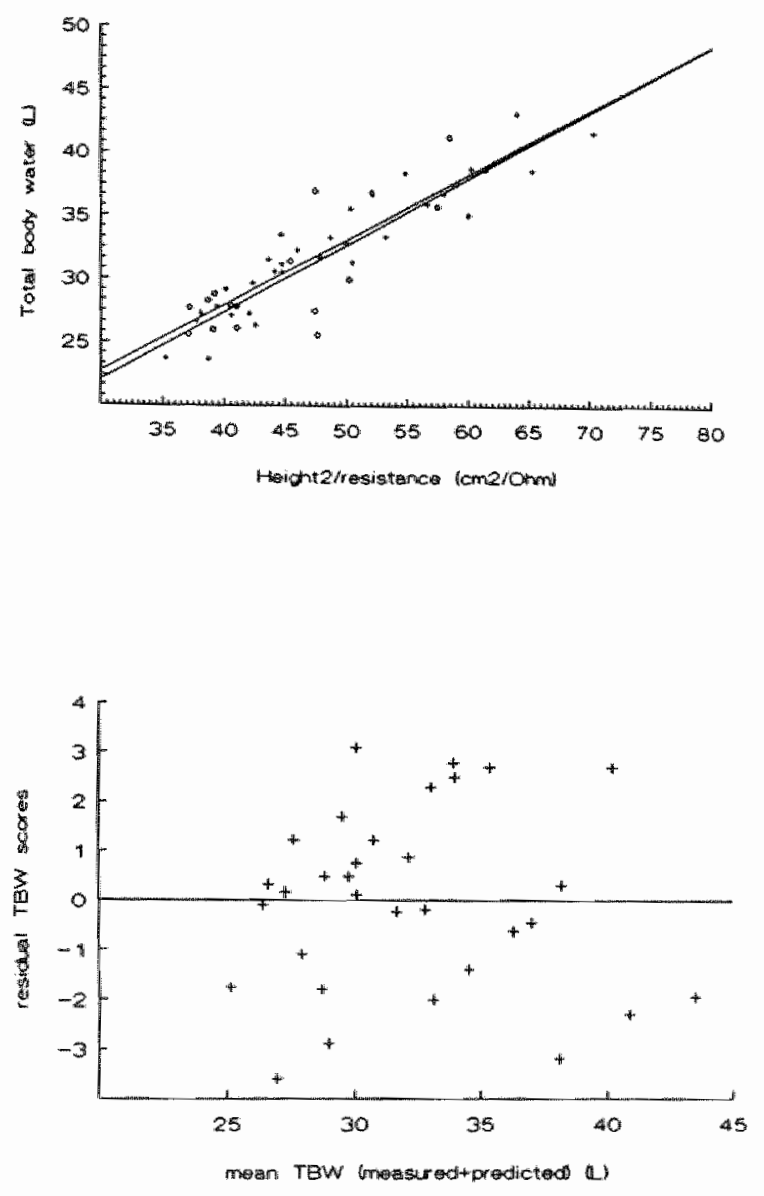

Figure la: Lineat regressions on resistance measurements corrected for height squared of total body water (TBW) determined by deuterium dilution.

COPD patients: $y=7.2+\left(0.52 \times \mathrm{Ht}^{2} /\right.$ resistance $) ; r^{2}=0.86 ; \mathrm{SEE}=1.89 \mathrm{~L}$ control group: $y=6.1+\left(0.53 \times \mathrm{Ht} / \mathrm{r}_{\mathrm{resistance}}\right) ; \mathrm{r}^{2}=0.72 ; \mathrm{SEE}=2.84 \mathrm{~L}$

Figure 16: COPD patients: Residual TBW scores plorted versus mean TBW. 
Pan II: Pathogenests
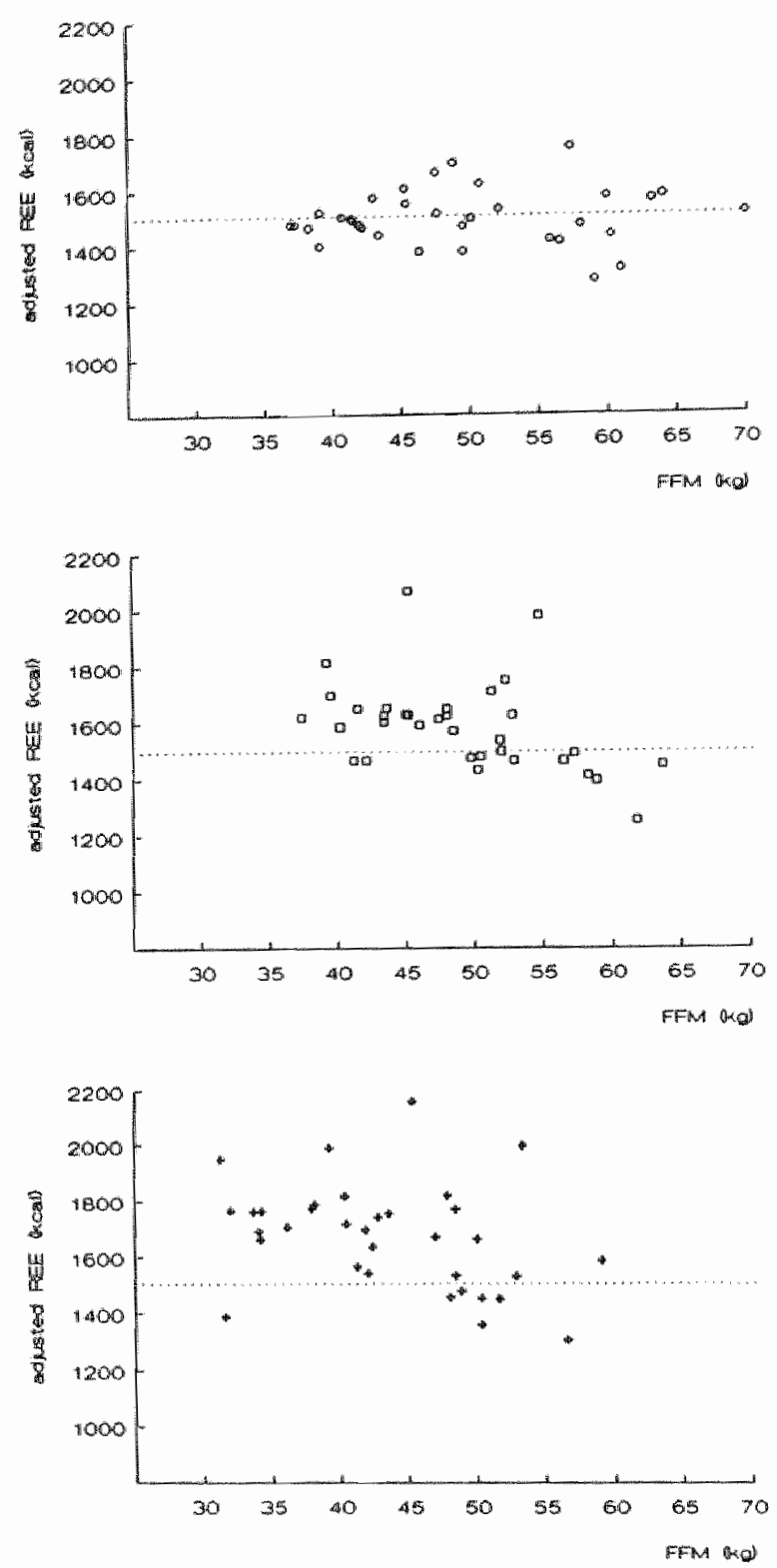

Figure 2: Adjusted REE agaitst fot free mass (FFM) in healthy controts (upper pantel), weight stable COPD patiens (middel ponel) and COPD patients whth recent werght loss (lower panel). 


\section{Discussion}

The most common approach to predict REE for an individual, is to apply a formula such as the equations of Harris and Benedict. The HB equations are based on the subject's age, height, weight and sex. Several studies in healthy individuals showed that inter-individual differences in REE tend to disappear when these factors are considered (Benedict, 1915; Boothby, 1936).

The HB equations however underestimate REE in patients with COPD. Measured REE in the patient group was significantly elevated compared to predicted REE. The prediction equations by Moore (1988), particularly designed for COPD patients were also invalid, because they overestimated REE in most patients. Furthermore a large interindividual variation in resting metabolic rate in patients was found when measured REE was expressed as percent of predicted REE. These results demonstrate that REE in COPD needs to be measured rather than predicted.

Part of the differences between REE of patients and controls may be caused by differences in 'metabolically active' tissue between patients and controls, which the HB equations do not take into account. The size of the 'metabolic active' mass is usually estimated by a measure of the amount of fat-free mass in the body. In this study we used the relatively new bioelectrical impedance technique (Lukaski, 1985). In an earlier study we established a good correlation between height ${ }^{2} /$ resistance and TBW assessed by deuterium dilution in clinically stable COPD patients (chapter 2) and used TBW to estimate FFM This prediction equation for FFM was applied to the control group since no systematic differences were established in the linear regressions of TBW on height $/ 2$ resistance in a sample of patients and controls. One of the limitations of deuterium dilution is that the calculation of FFM relies on assumptions of the water content of FFM (Sheng, 1979). In this study we assumed a constant ratio between TBW and FFM of 0.73 . This ratio may be different in elderly subjects or in patients due to alterations in the distribution of intracellular and extracellular water over the body (Schoeller, 1989). However since the control group was age matched and since all patients were in a stable clinical condition, we assumed no differences in hydration between patients and controls.

REE adjusted for FFM remained significantly higher in COPD patients compared to the healthy controls. These findings suggest that in patients with COPD other factors in addition to fat-free mass are important determinants of REE.

The observed differences in FEV, and respiratory muscle strength between weight losing and weight stable patients support recent data by others that the increased resting metabolic rate in patients with COPD may be caused by an increased oxygen consumption 
of the respiratory muscles secondary to an increased resistive load and impaired efficiency of the respiratory muscles (Donahoe, 1989).

Other factors which may increase metabolic rate are smoking and drug therapy. Smoking has been suggested to influence metabolic rate by stimulation of the sympathetic nervous system (Hofstetter, 1986). Indeed we found significant differences in adjusted REE. between smoking and non-smoking subjects. The results further indicate that smoking may have confounded the difference in adjusted REE between the patient sub groups. Smoking however did not explain the observed differences in adjusted metabolic rate between sub groups of patients and the control group.

Our patients were in a stable clinical condition but their drug treatment included $B_{2^{-}}$ agonists and theophylline, both potentially capable of increasing metabolic rate (Dullo, 1986; Vaisman, 1987). We did not measure the influence of these drugs because discontinuation of treatment might have exacerbated the condition. On the other hand bronchodilating treatment itself may reduce the work of breathing. As suggested by others (Lanigan, 1990) the obtained REE probably reflects the 'best case" ventilatory conditions. However further studies are indicated to dissociate the impact of the disease and drug therapy, for instance by treating a control group with similar drug therapy.

Adjusted REE was higher in weight losing compared to weight stable patients. This finding is in contrast with the decrease in resting metabolic rate which normally occurs during starvation and weight loss in healthy individuals or patients Brennan, 1977; Goldstein, 1987). It is also in contradiction with the formulated hypothesis that weight loss is and adaptive mechanism to decrease oxygen consumption in severe COPD. This theory has sound physiological basis from studies of semistarvation in normal humans in whom both weight loss and decreased total oxygen consumption exceeding the decrease in body mass (Keys, 1950) suggest an adaptive proces.

We conclude that a disease related increase in REE develops in a substantial number of patients with severe COPD. Increased REE may contribute to weight loss in COPD in combination with a failure of an adaptive response to undemutrition in weight losing patients. The results in weight stable patients further indicate that resting metabolic rate may be an important and early marker of alterations in energy metabolism in COPD. 


\title{
Chapter 8
}

\section{Energy balance in patients with COPD}

\begin{abstract}
The contribution of resting energy expenditure and dietary intake to weight loss was determined in 80 patients with stable COPD. Dietary intake was assessed using the diet history method. Resting energy expenditure was measured with a ventilated hood system. Resting energy expenditure in absolute terms was not significantly different between patients with recent continued weight loss $(n=39)$ and stable weight patients. Dietary intake in absolute terms as well as dietary intake expressed as a ratio of measured resting energy expenditure were significantly lower in the weight losing patients. Classification of the patients in three sub groups by severity of disease: (1) FEV $>35 \%$ (2) FEV $\leq 35 \%$ and (3) $\mathrm{P}_{\mathrm{a}} \mathrm{O}_{2}<7.3 \mathrm{kPa}$, revealed a higher prevalence of weight loss in the more compromised groups, and a significantly decreased dietary intake in the hypoxemic patients. These results indicate that a failure of an adaptive response to undernutrition and an inadequate dietary intake for energy expenditure are two contributing factors to weight loss in COPD.
\end{abstract}




\section{Introduction}

For many years it has been recognized that part of the patients with chronic obstructive pulmonary disease (COPD) exhibit a gradual and significant weight loss during the natural course of their illness. At present the cause of progressive weight loss in patients with COPD is not well understood. Several potential mechanisms have been hypothesized, including an impaired gastrointestinal function, a decreased dietary intake, an adaptive mechanism to decrease oxygen consumption, a hypermetabolic state, a limited cardiac output and decreased capillary bed, and psychosocial factors (Wilson, 1985). These factors can be roughly divided into two groups: those involving energy input and those involving energy output. The airm of this study was to determine the contribution of increased energy expenditure and decreased dietary intake to weight loss in patients with stable COPD.

\section{Methods}

\section{Patients}

COPD patients admitted to a pulmonary rehabilitation center for general physical training, were studied. Patients exhibiting an increase in $\mathrm{FEV}_{1}>10 \%$ after inhalation of a $\mathrm{B}_{2}$ agonist, or patients suffering from cancer, unstable cardiac condition, active gastrointestinal abnormalities, recent surgery, severe endocrine disorders, or obesity (body weight $>120 \%$ of ideal weight) were excluded from the study. To preclude a possible confounding effect of acute exacerbation of their disease, only patients with stable COPD were studied.

\section{Lung function}

FEV, and inspiratory vital capacity (IVC) were measured with a wet spirometer; the highest value of at least three spirometric manoeuvres was used. $\mathrm{FEV}_{1}$ and $\mathrm{IVC}$ were expressed as a percentage of the reference value (Quanjer, 1983). Arterial blood gases were drawn by puncture of the brachial artery at rest while breathing room air. Arterial oxygen tension $\left(\mathrm{P}_{\mathrm{k}} \mathrm{O}_{2}\right)$ and carbon dioxide tension $\left(\mathrm{P}_{4} \mathrm{CO}_{2}\right)$ were analyzed on a blood gas analyzer (Radiometer, ABL 330, Copenhagen, Denmark). Inspiratory muscle strength ( $P_{i}-$ max) was assessed by determining maximal inspiratory mouth pressures according to the technique described by Black and Hyatt (1969). The best of three determinations was used in subsequent calculations.

\section{Resting energy expenditure}

Resting energy expenditure (REE) was measured by indirect calorimetry using a ventilated hood system, which is described in more detail in chapter 4 . The hood consisted of clear plexiglas and had a volume of $30 \mathrm{~L}$. Gas analyses were performed using a paramag- 
metic oxygen analyzer (Servomex Oxygen module, Bunnik, The Netherlands) and an infrared carbon dioxide analyzer (Mijnhardt, CX103). Dry gases were measured and the results converted to standard temperature and pressure. Flow through the canopy was kept constant during measurements and was adjusted to the body weight of the patient. System control and calculations were performed on a microcomputer. The system was calibrated at the start and at the end of the experiment. The measurements were done in the early moming at complete rest, in a supine position, after an ovemight fast. Gas exchange data were collected every 10 seconds over a 20 minutes period at steady state.

\section{Dietary intake}

Dietary intake of the period before admission, was estimated with the diet history method with cross-check (Black, 1982). All interviews were performed by the same trained dietician within the first week after admission to the center and coded for computer nutrient analysis. The nutrient data base was derived from the Dutch food composition tables (NEVO, 1986). The applicability of this method was verified prospectively in 57 patients. The patients completed 16 dietary records randomly spread over their 8 wks stay in the pulmonary rehabilitation center. The dietary records were compared with estimated dietary intake at the end of this period using the diet history method. Mean $\pm S D$ intake of 16 dietary records $(1814 \pm 108 \mathrm{kcal} / 24 \mathrm{~h})$ was not significantly different from the diet history (1899 $\pm 117 \mathrm{kcal} / 24 \mathrm{~h}$ ) (Schols, 1990).

Other relevant data regarding disease history, pattern and duration of weight loss, smoking behavior and medication were obtained by a standardized medicall questionnaire completed by the pulmonary physician. All measurements were performed one week after admission to the center, when medication was optimalized and therapeutic serum theophylline levels $(8-15 \mathrm{mg} / \mathrm{L})$ were attained.

\section{Statistics}

Two patients who refused measurement of REE and four patients who were on a selfimposed energy restricted diet were excluded from analysis. To determine the relative contribution of increased REE and decreased dietary intake to weight loss, the patients (n $=80$ ) were categorized in a weight stable and a weight losing group. The weight losing group consisted of patients with a history of significant continued weight loss within 12 months preceding admission. Weight loss was considered significant when the decrease in body weight amounted to $10 \%$ or more of usual stable body weight.

A second classification of the patients was done by degree of airflow obstruction and $\mathrm{P}_{\mathrm{B}} \mathrm{O}_{2}$. As cut off point for $\mathrm{FEV}_{1}$ the mean group value was taken Chronic hypoxemia was 


\section{Pant III: Pathogenesis}

defined as a $\mathrm{P}_{\mathrm{a}} \mathrm{O}_{2}<7.3 \mathrm{kPa}$ according to the criteria of the American Thoracic Society (1987). The total group of patients was then divided as follows:

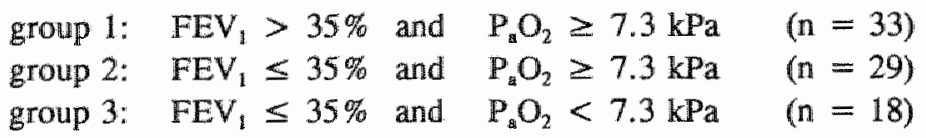

One way analysis of variance, and where appropriate the Mann-Whitney U test, were applied to test statistical significance of differences between groups. Significance was determined at the $5 \%$ level. All values are expressed as mean $\pm S D$.

\section{Results}

The study group represented elderly COPD patients (age: $65 \pm 7$ y) with a marked airflow obstruction $(\mathbb{E E V}: 35 \pm 18 \%)$. According to body weight expressed as percent of ideal weight $(93 \pm 11 \%)$ the patients were normal to underweight.

Table 1: Energy balance in weight losing and weight stable COPD patients.

\begin{tabular}{lrrrr}
\hline Energy balance & & \multicolumn{1}{c}{$\begin{array}{l}\text { weight losing } \\
\text { patients }(\mathrm{n}=39)\end{array}$} & $\begin{array}{l}\text { weight stable } \\
\text { patients }(\mathrm{n}=41)\end{array}$ \\
\hline Dietary intake & $(\mathrm{kcal} / \mathrm{day})$ & $1786 \pm 524 *$ & $1995 \pm 416$ \\
REE & $(\%$ HB) & $141 \pm 37$ & $146 \pm 32$ \\
& $(\mathrm{kcal} / \mathrm{day})$ & $1491 \pm 225$ & $1494 \pm 198$ \\
Dietary intake/REE & $(\%$ HB) & $117 \pm 19 \neq$ & $108 \pm 13$ \\
\hline
\end{tabular}

' mean \pm SD; $p<0.05 ; * \mathrm{p}<0.005$ significantly different from weight stable patients; $\mathrm{HB}=$ Harris Bendedict Bquations.

A considerable number of patients $(39 / 80 ; 49 \%)$ reported continued weight loss (table 1$)$. In 17 patients onset of weight loss was within 6 months before admission to the rehabilitation center. The average current body weight in the weight losing group was $8 \mathrm{~kg}(12 \%)$ below the initial stable body weight. Actual body weight was significantly different from the stable weight group $(57.0 \pm 1.6 \mathrm{~kg}$ and $66.5 \pm 1.5 \mathrm{~kg}$ respectively; $\mathrm{p}<0.001)$. Fat-free mass was also significantly lower in the weight losing group $(43.3 \pm 1.3 \mathrm{~kg}$ and $47.4 \pm 1.2$ $\mathrm{kg}$ respectively $(\mathrm{p}<0.05)$. Absolute values of dietary intake were significantly lower in the weight losing patients, whereas absolute values of REE were not different from the weight stable patients (table 1). However, when expressed as a percentage of predicted resting metabolic rate according to the Harris Benedict equations (REE/HB), REE was 
significantly higher in the weight losing patients whereas dietary intake was not different from the stable weight group.

Classification by $\mathrm{FEV}_{1}$ and $\mathrm{P}_{\mathrm{a}} \mathrm{O}_{2}$ revealed no differences in age between the groups (table 2), but a gradual decline in body mass and pulmonary function. In the most compromised group more patients suffered from weight loss and a more pronounced negative energy balance. Figure $\mathbb{f}$ further illustrates a decreased dietary intake $(p<0.05)$ in the hypoxemic patients relative to the normoxemic patients.

Table 2: Physical and pulmonary characteristics grouped by disease severity.

\begin{tabular}{|c|c|c|c|c|c|c|c|c|c|c|c|}
\hline \multirow{2}{*}{$\frac{\text { group }}{\text { Age }}$} & \multirow[b]{2}{*}{$(y)$} & \multicolumn{3}{|c|}{$\begin{array}{c}1 \\
\mathrm{FEV}_{1}>35 \%\end{array}$} & \multicolumn{3}{|c|}{$\mathrm{FEV}_{1}^{2} \leq 35 \%$} & \multicolumn{3}{|c|}{$\begin{array}{c}3 \\
\mathrm{P}_{\mathrm{z}} \mathrm{O}_{\mathrm{z}}<7.3 \mathrm{kPa} \\
\end{array}$} & \\
\hline & & 66 & \pm & 11 & 63 & 土 & 5 & 65 & \pm & 4 & \\
\hline Height & $(\mathrm{cm})$ & 167 & \pm & 11 & $17 \mathbb{1}$ & \pm & 5 & 171 & \pm & 4 & \\
\hline Weight & $(\mathrm{kg})$ & 65.3 & \pm & $13.8^{1}$ & 61.1 & \pm & 11 & 57.3 & \pm & 8.1 & * \\
\hline Fat-free mass & $(\mathrm{kg})$ & 46.7 & \pm & 7.5 & 45.1 & \pm & 8.6 & 43.6 & \pm & 7.2 & \\
\hline Wieight loss & & m & $=$ & 9 & $\mathbf{n}$ & $=$ & 16 & $n$ & $=$ & 14 & $H$ \\
\hline IVC & $(\%)$ & 79 & \pm & 29 & 66 & \pm & 5 & 52 & \pm & 12 & $\#$ \\
\hline$F E V_{1}$ & $(\%)$ & 51 & \pm & 6 & 25 & \pm & 5 & 20 & \pm & 4 & $\#$ \\
\hline $\mathrm{P}_{2} \mathrm{O}_{2}$ & $(\mathrm{kPa})$ & 9.7 & \pm & 1.7 & 9.2 & \pm & 1.0 & 6.8 & \pm & 0.4 & $\ddagger$ \\
\hline $\mathbb{P}_{4} \mathrm{CO}_{3}$ & (kPa) & 5.2 & \pm & 1.1 & 5.4 & \pm & 0.5 & 6.3 & \pm & 1.3 & + \\
\hline$P_{i}-\max$ & $(\mathrm{kPa})$ & 5.0 & \pm & 2.1 & 4.0 & \pm & 1.5 & 3.4 & \pm & 1.3 & + \\
\hline
\end{tabular}

Except for weight loss, all values are expressed as mean $\pm \mathrm{SD}$; ${ }^{*} \mathrm{p}<0.05 ; \sharp \mathrm{p}<0.005 ; \# \mathrm{p}<0.001$

\section{Discussion}

Several potential mechanisms have been suggested to explain weight loss in COPD. Weight loss can occur when the balance between energy intake and energy expenditure is disturbed. This implies that all suggested factors are interrelated and therefore must be studied concurrently. It further implies that it is not possible to investigate potential causative factors in one typical patient or even in a small group, particularly if a substantial measurement error is expected. We studied at a single time point the relative contribution of increased energy expenditure and decreased dietary intake to weight loss in a large number of patients with stable COPD.

Total energy expenditure comprises REE, diet induced thermogenesis and activity induced themogenesis. It is difficult to furnish a complete energy balance, because as a result of methodologic limitations, reliable data both on thermodymamic action of food (D'Alessio, 1988 ) and on spontaneous physical activity (Ravussin, 1986) cannot yet be reliable 


\section{Part III: Pathogenesis}

obtained. In this study we addressed REE, the major determinant of total energy expenditure. Corresponding to the study described in chapter 7, we established no difference between weight losing and weight stable patients in REE in absolute terms, but significantly higher values when expressed as a percentage of predicted resting metabolic rate.

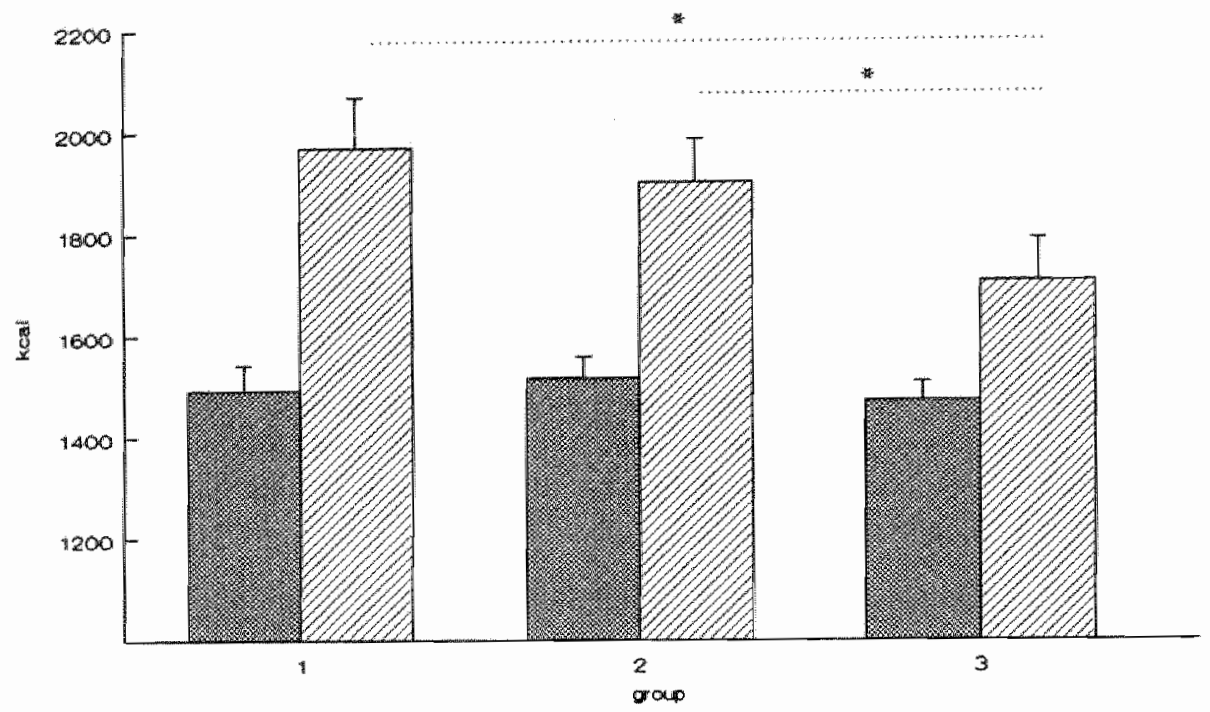

Figure 1: Energy indake (E-Intake; striped bars) and resting energy expenditure REE; cross-hatched bars) grouped by disease severity. " $p<0.05$.

We confirmed results by others (Hunter, 1981; Braun, 1984) that dietary intake in weight losing patients was normal or even high when compared to predicted energy requirements. Dietary intake in absolute terms, and expressed per measured REE, however were significantly lower in patients with recent weight loss compared to stable weight patients, Measurement of dietary intake is generally less precise than measurement of resting energy expenditure. Dietary intake in the first week of admission to the rehabilitation center is presumablly not representative of habitual intake. Dietary intake was therefore studied retrospectively using a diet history. All interviews were taken and coded by the same dietician. A possible systematic error was thus randomly distributed. We found that this group of elderly patients could very well quantitate dietary intake because dietary habits were often very stable. Generally these patients recall average dietary intake when feeling well however and do not quantitate reduced intake in periods of intermittent acute illness. Nevertheless REE in such periods also is considerably elevated, most likely even 
more than in stable disease. The contribution of superimposed acute disease to periodic weight loss must therefore be studied longitudinally.

When subgroups were distinguished according to disease severity a positive association was found between disease severity and energy depletion. In the less compromised group a moderate proportion of patients had an increased REE but this increase in REE was largely balanced by increased dietary intake so that very little weight loss occurred. When the degree of airflow obstruction increased, REE increased further with an associated increased intake but did not always balance REE so that more patients suffered weight loss. In the most severely compromised group, dietary intake dropped, leading to a more pronounced negative energy balance and pronounced weight loss.

The combined data suggest that two factors contribute to weight loss in COPD: Failure of an adaptive response to undernutrition and inadequate dietary intake for energy expenditure. 



\title{
Chapter 9
}

\section{Transcutaneous oxygen saturation and carbon dioxide tension during meals in patients with COPD}

\begin{abstract}
The effect on transcutaneous oxygen saturation $\left(\mathrm{S}_{2} \mathrm{O}_{2}\right)$ and carbon dioxide tension $\left(\mathrm{P}_{1} \mathrm{CO}_{2}\right)$ of eating was assessed in 44 patients with severe chronic obstructive pulmonary disease (COPD) $\left(\mathrm{FEV}_{1}<50 \%\right)$. The $\mathrm{S}_{2} \mathrm{O}_{2}, \mathrm{P}_{1} \mathrm{CO}_{2}$ and heart rate were measured every minute before, during and until 30 minutes after a standardized meal ( $445 \mathrm{kcal})$ was consumed. All patients were measured twice on the same day, while eating a meal with high (80\%) and low $(28 \%)$ carbohydrate content respectively. Mean meal desaturation was less than $1 \%$ in normoxemic patients but $-3.2 \pm 0.7 \%$ in hypoxemic $\left(\mathrm{P}_{3} \mathrm{O}_{2}<7.3 \mathrm{kPa}\right)$ patients. Significant differences between hypoxemic patients with a desaturation $>4 \%$ and $\leq 4 \%$ respectively were found in $\mathrm{FEV}_{1}(16 \pm 3 \%$ and $29 \pm 8 \%)$, maximal inspiratory $(3.9 \pm 1.2$ $\mathrm{kPa}$ and $5.9 \pm 1.2 \mathrm{kPa})$ and expiratory $(5.1 \pm 1.2 \mathrm{kPa}$ and $9.8 \pm 2.7 \mathrm{kPa})$ mouth pressures, heart rate ( $112 \pm 12$ beats per minute and $90 \pm 18$ beats per minute) body weight ( $54.9 \pm$ $7.5 \mathrm{~kg}$ and $74.7 \pm 10.4 \mathrm{~kg})$ and fat-free mass $(42.0 \pm 6.6 \mathrm{~kg}$ and $52.6 \pm 5.8 \mathrm{~kg})$ but not in baseline $\mathrm{S}_{\mathrm{a}} \mathrm{O}_{2}$ and $\mathrm{P}_{1} \mathrm{CO}_{2}$. The decrease in $\mathrm{S}_{\mathrm{a}} \mathrm{O}_{2}$ and the increase in heart rate were lower during the carbohydrate rich meal. No significant fluctuations in $\mathrm{P}_{t} \mathrm{CO}_{2}$ were found after either meal. Meal related oxygen desaturation cannot explain weight loss in normoxemic COPD patients, but may contribute to a limited dietary intake in a sub group of hypoxemic patients exhibiting marked oxygen desaturation during meals. A single carbohydrate rich meal does not have an immediate impact on $\mathrm{P}_{1} \mathrm{CO}_{2}$ in stable COPD.
\end{abstract}




\section{Introduction}

A negative energy balance commonly occurs in the course of chronic obstructive pulmonary disease (COPD) and can ultimately lead to cachexia. At present the cause of progressive weight loss in patients with COPD is not well understood. Results from chapter 7 and chapter 8 suggest that a failure of an adaptive response to undernutrition and an inadequate dietary intake for energy expenditure are two contributing factors to weight loss in COPD. Inadequate dietary intake for energy expenditure was most pronounced in patients suffering from chronic hypoxemia (chapter 8 ). In this study we addressed two factors related to dietary intake: The effect of eating on oxygen saturation $\left(\mathrm{S}_{4} \mathrm{O}_{2}\right)$ and the effect of the carbohydrate content of a meal on carbon dioxide tension.

Several studies have measured decreases in $\mathrm{S}_{\mathrm{n}} \mathrm{O}_{2}$ or in arterial oxygen tension $\left(\mathrm{P}_{\mathrm{n}} \mathrm{O}_{2}\right)$ during meals in patients with COPD (Brown, 1983; Castaldo, 1983; Nörregaard, 1988). However no systematic study on the relative contribution of meal related oxygen desaturation to a limited dietary intake has been reported.

The adverse effects of excessive carbohydrate calories in the intensive care unit have received considerable attention (Askanazi, 1980; Covelli, 1981). Carbohydrate oxidation yields more $\mathrm{CO}_{2}$ than fat oxidation. Carbohydrate oxidative capacity is limited. Too much carbohydrate $\left(>6 \mathrm{~g} / \mathrm{kg} /\right.$ day) leads to lipogenesis which also increases $\mathrm{CO}_{2}$ production resulting in a respiratory quotient (RQ) above 1.0. If the patient is incapable of responding to the increased $\mathrm{CO}_{2}$ production, respiratory failure may result (Covelli, 1981). It has therefore been suggested to shift from predominantly carbohydrate calories to high fat diets, resulting in a lower $\mathrm{RQ}$ and less $\mathrm{CO}_{2}$ production (Askanazi, 1981). Little is known about the effects of excessive carbohydrate intake in ambulatory patients with COPD.

\section{Methods}

\section{Patiens}

44 Patients with severe airflow obstruction (forced expiratory volume in one second (FEV $)<50 \%$ of predicted) participated in the study. All patients were in stable clinical condition and were not suffering from a lower respiratory tract infection.

\section{Merhods}

Body height $(\mathrm{Ht})$ was measured bare foot standing and determined to the nearest $0.5 \mathrm{~cm}$. Body weight was measured with a beam scale without shoes in light clothing to the nearest $0.1 \mathrm{~kg}$ (SECA, FRG). Body resistance (BIA 101, RJL systems, Detroit, USA) was measured as described by Lukaski (1985). Fat-free mass was calculated from height, body weight and resistance using a patient specific regression equation (chapter 3). 
Inspiratory vital capacity (IVC) and $\mathrm{FEV}_{1}$ were measured with a wet spirometer; the highest value from at least three spirometric measurements was used. FEV 1 and IVC were expressed as a percentage of the reference values (Quanjer, 1983). Blood was drawn in the end of the morning by puncture of the brachial artery at rest while breathing room air. Arterial oxygen tension $\left(\mathrm{P}_{8} \mathrm{O}_{2}\right)$ and carbon dioxide tension $\left(\mathrm{P}_{\mathrm{a}} \mathrm{CO}_{2}\right)$ were analyzed on a blood gas analyzer (Radiometer $A B L 330$, Copenhagen, Denmark). Inspiratory ( $P_{i}-\max$ ) and expiratory ( $\mathrm{P}_{\mathrm{e}}$-max) muscle strength were assessed by determining maximal inspiratory and expiratory mouth pressures according to the technique described by Black \& Hyatt (1969). The best of three determinations was used in subsequent calculations. $\mathrm{S}_{\mathrm{a}} \mathrm{O}_{2}$ was measured with a pulse oximeter. The electrode was placed around the left little finger and sealled with tape to prevent false light information from outside to reach the sensor. The $\mathrm{CO}_{2}$ sensor was attached to the patients' skin, at the right underarm, with a doublesided adhesive ring. The sensor was heated to $43^{\circ} \mathrm{C}$ to increase perfusion at the skin surface. A 2-point calibration for $\mathrm{CO}_{2}\left(5 \% / 10 \% \mathrm{CO}_{2}\right.$ in $\left.\mathrm{N}_{2}\right)$ was performed before every measurement. Measurements were done with a combined $\mathrm{S}_{\mathrm{a}} \mathrm{O}_{2}$ and $\mathrm{P}_{1} \mathrm{CO}_{2}$ monitor (Fastrac, Sensor Medics, Anaheim, USA) which is attached to a printer that automatically registers every minute the lowest measured $\mathrm{S}_{\mathrm{k}} \mathrm{O}_{2}$ value and the highest measured $\mathrm{P}_{\mathrm{t}} \mathrm{CO}_{2}$ value. Heart rate (HR) was registered with an ECG monitor (Servomed SMS 182, Hellige, Freiburg, Germany).

\section{Siudy design}

Three groups of patients were measured. The control group (group 1) consisted of 12 patients with a resting $\mathrm{P}_{\mathrm{a}} \mathrm{O}_{2} \geq 7.3 \mathrm{kPa}$ and a stable body weight. Group 2 consisted of 12 patients with a resting $\mathrm{P}_{\mathrm{a}} \mathrm{O}_{2} \geq 7.3 \mathrm{kPa}$ but $>10 \%$ weight loss in the previous year. Group 3 consisted of 20 patients with a resting $\mathrm{P}_{\mathrm{m}} \mathrm{O}_{2}<7.3 \mathrm{kPa}$ when breathing room air, 12 of whom used supplemental oxygen via nasal cannula when eating. $\mathrm{S}_{\mathrm{B}} \mathrm{O}_{2}, \mathrm{P}_{1} \mathrm{CO}_{2}$ and $\mathrm{HR}$ were measured before, during and until 30 minutes after a standardized meal was consumed.

To study the immediate effect of a carbohydrate load on $\mathrm{P}_{1} \mathrm{CO}_{2}$, the patients were measured at the same day in the early evening while eating an iso-caloric but carbohydraterich meal. Caloric content and nutrient composition of the meals is given in table 1. The patients were encouraged to eat the entire meal. The exact duration of the meal was recorded. When a patient could not complete the meal, the left-overs were weighed exactly using a digital scale (Soehnle). All patients tolerated the electrodes and the finger oximeter well and were able to eat in their usual manner. Immediately after completion of the meal the degree of dyspnea was rated $(1=$ no; $2=$ moderate; $3=$ severe). Medication was given $1 \mathrm{~h}$ before the beginning of the meal. Maintenance medication included theophylline, $\beta_{2}$-agonists, inhaled or oral corticosteroids and diuretics in most patients. Thirty minutes before the meal the patients were asked to sit relaxed at the dinner table at 
which time baseline values of $\mathrm{S}_{\mathrm{s}} \mathrm{O}_{2}, \mathrm{P}_{1} \mathrm{CO}_{2}$ and $\mathrm{HR}$ were recorded. During the meal, minute values were recorded continuously. Registration proceeded until 30 minutes after completion of the meal. The monitoring was completed in all patients and there were no complications or ontoward events during the study period.

Toble 1: Caloric content and mutrient compasition of experimental meals.

\begin{tabular}{llcc}
\hline & & meal 1 & meal 2 \\
\hline Time & p.m. & 0.30 & 5.30 \\
Energy & $(\mathrm{kcall})$ & 445 & 445 \\
Fat & $($ En\%) & 44.0 & 9.6 \\
Carbohydrates & (En\%) & 28.4 & 79.6 \\
Protein & (En\%) & 27.6 & 10.8 \\
\hline
\end{tabular}

meal 1: potatoes, cauliflower, meatballs, gravy.

meal 2: 3 slices of bread, 1 slice of lean meat, marmelade, banana, tea.

\section{Statistics}

The mean baseline $S_{\mathrm{R}} \mathrm{O}_{2}$ (base $\mathrm{S}_{\mathrm{g}} \mathrm{O}_{2}$ ) was the average saturation observed over a 10 min baseline period prior to eating. Meal saturation (meal $\mathrm{S}_{\mathrm{a}} \mathrm{O}_{2}$ ) was the average saturation observed throughout the meal. Mean meal desaturation $\left(\delta \mathrm{S}_{2} \mathrm{O}_{2}\right)$ was defined as (base $\mathrm{S}_{\mathrm{a}} \mathrm{O}_{2}-$ meal $\mathrm{S}_{\mathrm{B}} \mathrm{O}_{2}$ ). This index was used to ascertain the time weighed overall effect of eating on saturation. Mean 'after meal' saturation was calculated over a 30 minute interwal. Similarly baseline, meal and after meal values of $\mathrm{P}_{1} \mathrm{CO}_{2}$ and $\mathrm{HR}$ were defined.

Differences between two patient groups were tested with the Mann-Whitney $U$ test. Differences within the individual between the two meals were tested with the Wilcoxon Signed Rank test. Significance was determined at the $5 \%$ level. Except in figures all results are expressed as mean $\pm S D$.

\section{Results}

A description of the study group is given in table 2. The weight stable and weight losing group with a resting $\mathrm{P}_{\mathrm{s}} \mathrm{O} 2 \geq 7.3 \mathrm{kPa}$, were significantly different in age and pulmonary function measures. Even more compromised values for IVC, FEV and $\mathrm{P}_{\mathrm{i}}$-max were found in the hypoxemic patients. Mean values of base $\mathrm{S}_{4} \mathrm{O}_{2}$, meal $\mathrm{S}_{4} \mathrm{O}_{2}$ and after $\mathrm{S}_{4} \mathrm{O}_{2}$ of meal 1 for the 3 groups are graphically displayed in figure 1 . Base $\mathrm{S}_{8} \mathrm{O}_{2}$ was significantly lower in the hypoxemic relative to the normoxemic patients $(\mathrm{p}<0.001) . \mathrm{S}_{\mathrm{a}} \mathrm{O}_{2}$ was slightly decreased in weight stable $(-0.8 \pm 0.2 \%, p<0.05)$ and weight losing $(-0.6 \pm 0.2 \%$, $\mathrm{p}=0.05$ ) normoxemic patients. $0 \mathrm{~S}_{\mathrm{a}} \mathrm{O}_{2}$ in the hypoxemic patients was more pronounced 
meal related $\mathrm{S}_{4} \mathrm{O}_{2}$ and $\mathrm{P}_{8} \mathrm{CO}_{3}$ chilungex
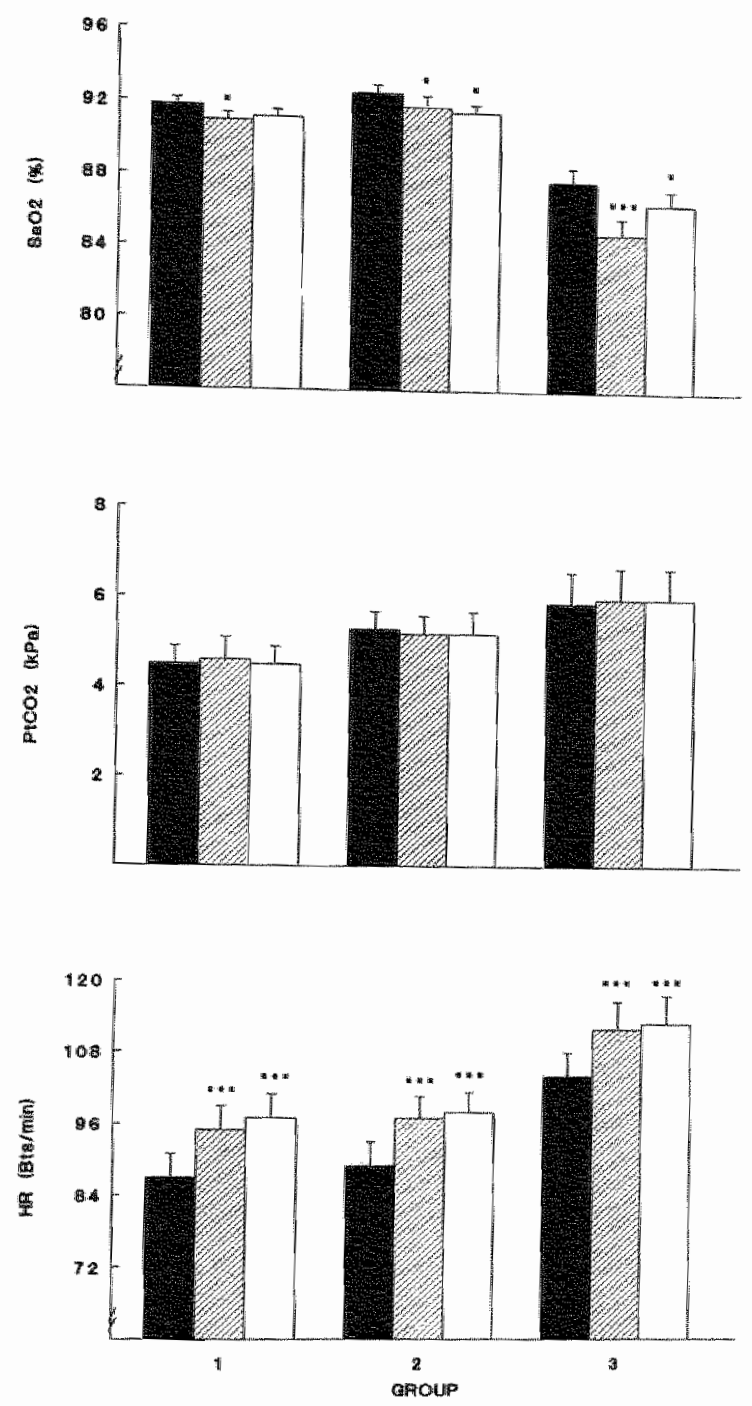

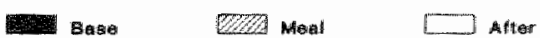

Figure 1: $S_{2} O_{2}, P_{1} C O_{2}$ and $H R$ (mean $+S E M$ ) before, during ep within 30 min after completion of meal 1. group $1=P_{n} O_{2} \geq 7.3 \mathrm{kPa}$, sable weigh; group $2=\mathrm{P}_{\mathrm{a}} \mathrm{O}_{2} \geq 7.3 \mathrm{kPa}$, weight losing; group $3=\mathrm{P}_{\mathrm{a}} \mathrm{O}_{2}<7.3 \mathrm{kPa}$. 
groups during the meal and remained elevated within $30 \mathrm{~min}$ after completion of the meal. Average meal 1 duration amounted to $12.2 \pm 2.1$ min and was not different between the 3 groups.

Because a high within group coefficient of variation of $23 \%$ was found in the hypoxemic patients, they were divided in two groups according to the criterion used by Brown and colleagues (1983) in an earlier study. Group 3a consisted of 8 patients exhibiting a significant drop in $\mathrm{S}_{\mathrm{a}} \mathrm{O}_{2}$ during the meal amounting to $4 \%$ or more; group $3 \mathrm{~b}$ consisted of 12 patients with a $\delta \mathrm{S}_{4} \mathrm{O}_{2}<4 \%$ (table 2). The groups did not differ in base $\mathrm{S}_{\mathrm{z}} \mathrm{O}_{2}$ or base $\mathrm{P}_{1} \mathrm{CO}_{2}$ but group $3 a$ had a more compromised pulmonary function as reflected in significantly lower values for FEV, $(p<0.001), P_{i}$-max $(p<0.01)$ and $P_{t}-\max (p<0.001)$ and a higher base HR $(p<0.001)$. Body weight $(p<0.001)$ and fat-free mass were significantly lower $(p<0.01)$ in group $3 a$ whereas in group $3 b$ body fat even tended to be relatively increased in relation to fat-free mass. Five out of 8 Patients of group 3 a experienced moderate to severe dyspnea while eating relative to 2 out of 12 patients of group $3 b$. To exclude a selection bias of patients using supplemental oxygen, an additional analysis was done only for the patients on oxygen therapy while eating. Results however were not different in this sub group.

Table 2: Physical and pulmonary characteristics of the study group

\begin{tabular}{|c|c|c|c|c|c|c|c|c|c|c|c|c|c|}
\hline \multirow[b]{2}{*}{ height } & \multirow[b]{2}{*}{$(\mathrm{cm})$} & \multicolumn{2}{|c|}{$\begin{array}{l}\text { group } 1 \\
(n=12)\end{array}$} & \multicolumn{5}{|c|}{$\begin{array}{l}\text { group } 2 \\
(n=12) \\
\end{array}$} & \multicolumn{3}{|c|}{$\begin{array}{l}\text { group 3a } \\
(n=8)\end{array}$} & \multicolumn{2}{|c|}{$\begin{array}{l}\text { group } 3 b \\
(n=12)\end{array}$} \\
\hline & & 168.8 & \pm 10.4 & & 174.7 & \pm & 8.4 & & 171.2 & \pm & 8.4 & 174.0 & $\pm 9.7^{1}$ \\
\hline weight & $(\mathrm{kg})$ & 67.7 & \pm 9.4 & & 63.0 & \pm & 9.0 & & 54.9 & \pm & 7.5 & 74.7 & \pm 10.4 \\
\hline FFM & $(\mathrm{kg})$ & 49.0 & \pm 7.9 & & 47.4 & \pm & 7.2 & & 42.0 & \pm & 6.6 & 52.6 & \pm 5.8 \\
\hline weight logs & & $\mathrm{n}$ & $=0$ & & $\mathrm{n}$ & $=$ & 12 & & $\mathrm{n}$ & $=$ & 5 & $\mathrm{n}$ & $=3$ \\
\hline IVC & (\%) & 81 & \pm 15 & * & 62 & \pm & 17 & $\#$ & 49 & \pm 1 & 2 & 61 & \pm 19 \\
\hline $\mathrm{FEV}_{1}$ & (\%) & 37 & $\pm s$ & $*$ & 29 & \pm & 10 & $*$ & 16 & \pm & 3 & * 29 & \pm 8 \\
\hline$p_{i}-\operatorname{mux}$ & $(\mathrm{KPa})$ & 7.0 & \pm 2.2 & + & 4.8 & \pm & 1.4 & $\dagger$ & 3.9 & \pm & 1.2 & 5.9 & \pm 1.2 \\
\hline$P_{6}-\max$ & $(\mathrm{kPa})$ & 10.2 & \pm 5.0 & & 7.0 & \pm & 3.0 & & 5.1 & \pm & 1.2 & 9.8 & \pm 2.7 \\
\hline $\mathrm{S}_{4} \mathrm{O}_{2}$ & $(\%)$ & 92 & \pm 1 & & 92 & \pm & 1 & H & 87 & \pm & 3 & 88 & \pm 4 \\
\hline $\mathrm{P}_{1} \mathrm{CO}_{2}$ & $(\mathrm{kPa})$ & 4.5 & it 0.7 & & 5.2 & \pm & 0.7 & * & 6.3 & \pm & 1.1 & 5.9 & \pm 1.0 \\
\hline $\mathrm{HR}$ & $(\mathrm{Bu} / \mathrm{min})$ & 90 & \pm 16 & & 88 & \pm & 13 & & 112 & \pm 1 & 12 & +90 & $\frac{4}{3} 18$ \\
\hline \multicolumn{2}{|c|}{ supplemental oxygen } & & & & & & & & n & $=$ & 6 & $n$ & $=6$ \\
\hline
\end{tabular}

' Unless otherwise stated all values are expressed as mean 4 SD;

* $p<0.05 ; 4<<0.01 ; \quad \mathrm{p}<0.001$ compared to the adjacent group. 
Figure 2 displays in more detail the pattern of desaturation for the subgroup 3a which exhibited a significant desaturation. The graph illustrates that the pattern of desaturation during and immediately after completion of the meal was comparable in all patients: $\mathrm{S}_{\mathfrak{k}} \mathrm{O}_{2}$ dropped within 5 min after the patients started their meal and remained at a low level throughout the meal, but was restored within a few minutes after the patients stopped eating. Mean $\mathrm{S}_{\mathrm{s}} \mathrm{O}_{2} 5$ to 30 minutes after completion of the meal $(85.3 \pm 1.0 \%)$ however was still lower than base $\mathrm{S}_{\mathrm{a}} \mathrm{O}_{2}(87.5 \pm 1.0 \%)$.

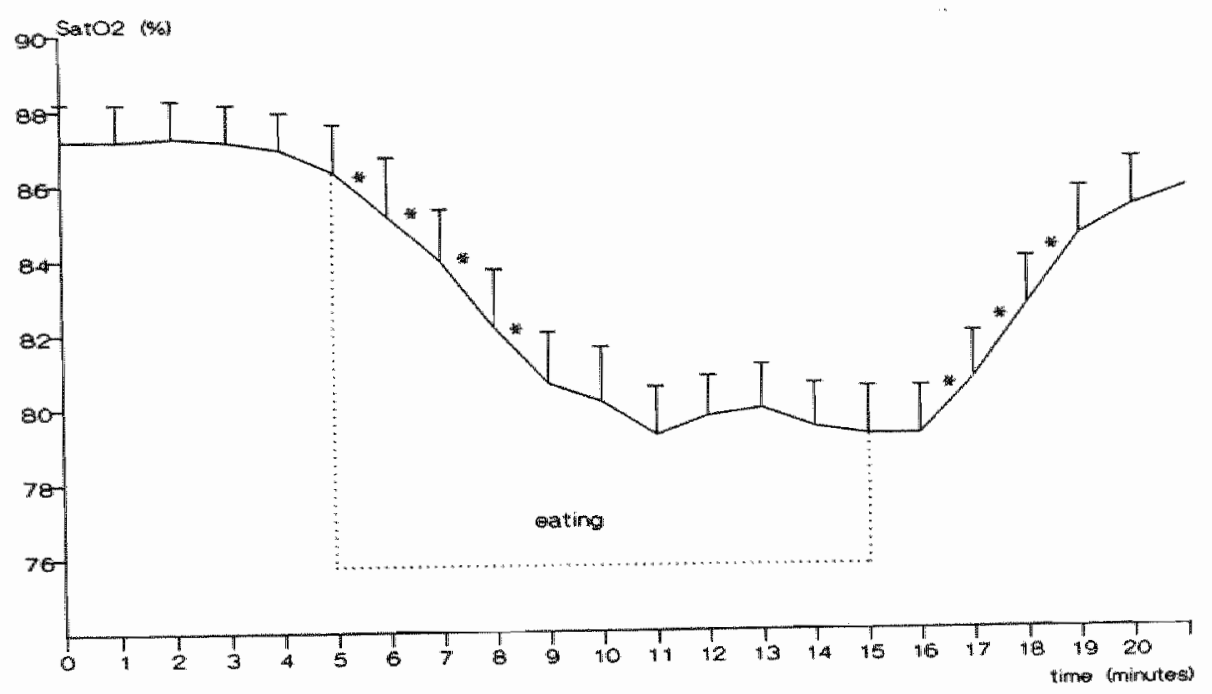

Figure 2: Fuctuations in $\mathrm{S}_{3} \mathrm{O}_{2}$ (mean $\left.+S E M\right)$ before, during and antil 5 minutes after completion of meal 1. for patients exhibiting $>4 \%$ desaturation; $* 0<0.05$

Table 3 reveals that the patients of group $3 a$ who had desaturation of $4 \%$ or more during meal 1 had less desaturation during meal 2 . The increase in HR during meal 1 was also greater than during meal 2 . The average duration for meal 2 amounted to $15.9 \pm 2.5 \mathrm{~min}$ and was significantly longer than meal 1 . Furthermore a shift in degree of dyspnea to a lower dyspneic sensation in meal 2 was found. No significant fluctuations in $\mathrm{P}_{1} \mathrm{CO}_{2}$ could be demonstrated for the total group as well as for the sub group of hypercapnic $\left(\mathrm{P}_{3} \mathrm{CO}_{2}>\right.$ $5.3 \mathrm{kPa}$ ) patients during or after completion of the carbohydrate rich meal 2. 
Table 3: Meal duration, $85_{\alpha} O_{2}$ \&HR and degree of dyspmeic sensation between meal I and meal 2 for 8 hypoxemic patienss exhibuting a $>4 \% 8 \mathrm{~S}_{\mathrm{a}} \mathrm{O}_{2}$ during meal $\mathrm{l}$.

\begin{tabular}{|c|c|c|c|c|c|}
\hline \multirow[b]{2}{*}{ durstion } & \multirow[b]{2}{*}{$(\min )$} & \multicolumn{2}{|r|}{ meal 1} & \multicolumn{2}{|c|}{ meal 2} \\
\hline & & 11.5 & $\pm 1.6 *$ & 15.9 & \pm 2.5 \\
\hline $8 \mathrm{SaO}_{2}$ & $(\%)$ & 5.7 & $\pm 1.2 *$ & 4.0 & \pm 1.8 \\
\hline $8 \mathrm{HR}$ & $(\mathrm{Bts} / \mathrm{min})$ & 8.7 & $\pm \quad 3.6 \dagger$ & 2.3 & \pm 1.7 \\
\hline $\mathrm{SP}_{1} \mathrm{CO}_{2}$ & $(\mathrm{kPa})$ & 0.08 & \pm 0.06 & 0.15 & \pm 1.1 \\
\hline \multirow[t]{3}{*}{ dyspnea } & no & $\mathrm{n}$ & $=3$ & $\mathrm{n}$ & $=6$ \\
\hline & moderate & n & $=3 *$ & $\mathrm{n}$ & $=2$ \\
\hline & sewere & n & $=3$ & a & $=0$ \\
\hline
\end{tabular}

Except for dyspnea all values are expressed as mean $\mathrm{ISD} ; \mathrm{p}<0.05 ; \mathrm{p}<0.01$ compared to meal 2 .

\section{Discussion}

Nutritional management of COPD is difficult and controversial. Several factors have been suggested in the literature that may interfere with dietary intake in COPD such as gastrointestinal disorders, psychosocial factors and meal related oxygen desaturation (Wilson, 1985). In this study we addressed the immediate effect of eating on $\mathrm{S}_{\mathrm{a}} \mathrm{O}_{2}$. Furthermore we were interested in the effect of the carbohydrate content of a meal on $\mathrm{P}_{\mathrm{a}} \mathrm{CO}_{2}$ because it has been suggested to patients with COPD to shift from predominantly carbohydrate calories to high fat diets.

$\mathrm{PCO}_{2}$ and $\mathrm{S}_{\mathrm{n}} \mathrm{O}_{2}$ were measured transcutaneously with a combined $\mathrm{S}_{\mathrm{a}} \mathrm{O}_{2}$ and $\mathrm{P}_{1} \mathrm{CO}_{2}$ monitor. Several studies demonstrated that transcutaneous $\mathrm{PCO}_{2}$ yields an excellent reflection of $\mathrm{P}_{\mathrm{a}} \mathrm{CO}_{2}$ as well as of fluctuations in $\mathrm{P}_{\mathrm{a}} \mathrm{CO}_{2}$ (Midgren, 1984; Mahutte, 1984; Everdy, 1988) if the measurement is preceded by a proper calibration. Pulse oximetry contrary to arterial blood sampling is a feasible means for long term monitoring of oxygenation during daily activities (Decker, 1989). However the method presents several limitations (Huch, 1988). Recent studies found for an $\mathrm{S}_{4} \mathrm{O}_{2}$ greater than $85 \%$ an absolute inaccuracy of $\pm 2.0-5.0 \%$ for the cutaneous measurement of $\mathrm{S}_{\mathrm{a}} \mathrm{O}_{2}$ when compared with arterial blood gas samples analyzed for $\mathrm{S}_{\mathrm{A}} \mathrm{O}_{2}$ (Cahan, 1990). Differences were larger for an $\mathrm{S}_{4} \mathrm{O}_{2}$ less than $80 \%$. Invalid measurements can also occur in conditions which result in decreased cutaneous blood flow, or elevated bilirubin, MetHb or COHb levels (Cariin, 1988). In this study patients were therefore grouped according to arterial $\mathrm{P}_{\mathrm{a}} \mathrm{O}_{2}$ whereas pullse oximetry was primarily used to identify trends in oxygenation while eating.

We did find a statistically significant decrease in oxygen saturation in patients with a $\mathrm{P}_{\mathrm{a}} \mathrm{O}_{2}$ $\geq 7.3 \mathrm{kPa}$, but a decrease of $1 \%$ can hardly be considered of clinical rellevance. No differences in $\delta \mathrm{S}_{\mathrm{a}} \mathrm{O}_{2}$ were found between weight stable and weight losing patients which 
suggests that weight loss in normoxemic COPD patients is not initiated by meal related $\mathrm{OS}_{\mathrm{O}} \mathrm{O}_{2}$.

A substantial amount of individual variability in desaturation was noticed in the hypoxemic patients. We therefore categorized them into two groups: (1) group 3a had a stable desaturation of more than $4 \%$ throughout the meal and (2) group $3 b$ had an overall meal desaturation less than $4 \%$. Variability in desaturation could not be explained by differences in baseline $\mathrm{S}_{\mathrm{s}} \mathrm{O}_{2}$ or $\mathrm{P}_{3} \mathrm{CO}_{2}$ but body weight, fat-free mass and respiratory muscle strength were lower in hypoxemic patients exhibiting more than $4 \%$ desaturation compared to hypoxemic patients with less desaturation when eating.

Several mechanisms are proposed to explain desaturation during meals. The pattern of desaturation was uniform. Despite the small number of patients involved, significant decreases in the first minutes after beginning of the meal and significant increases immediately after completion of the meal were found. The fact that desaturation occurs so early after the beginning of the meal excludes possible metabolic effects of food absorption and digestion on desaturation. This conclusion was confirmed by Brandstetter (1988) who could not establish a clinically significant effect of nasogastric feeding on arterial oxygen tension in a group of COPD patients receiving nasogastric bolus or contintous tube feeding.

A second hypothesis is a decrease in minute ventilation as a result of interrupted breathing while chewing and swallowing. A decrease in oxygen saturation however was not associated with a concomitant increase in $\mathrm{P}_{1} \mathrm{CO}_{2}$.

It has been speculated that alterations in ventilation-perfusion relationships may contribute to a fall in $\mathrm{S}_{\mathrm{a}} \mathrm{O}_{2}$ if tidal volume or respiratory frequency were altered (Brown, 1983). Smith (1989) recently studied the coordination of eating, drinking and breathing in 7 healthy adults using non invasive techniques. No change in tidal volume, inspiratory duration, expiratory duration or minute ventilation was found between the periods of normal breathing, eating and drinking. However, breathing became more irregular during eating and drinking.

Mean base $\mathrm{S}_{\mathrm{a}} \mathrm{O}_{2}$ in hypoxemic patients was substantially lower than in the normoxemic group. The higher percentage of oxygen desaturation in hypoxemic palients could therefore be attributed to the sigmoidal shape of the oxygen dissociation curve. However differences in the degree of desaturation within group 3 cannot be attributed to the shape of the oxygen dissociation curve. Base $\mathrm{S}_{8} \mathrm{O}_{2}$ was not lower in group 3a. The $\mathrm{HR}$ at rest was significantly higher in group $3 \mathrm{a}$ compared to group $3 \mathrm{~b}$. In accordance to findings in normal subjects a significant increase in $\mathrm{HR}$ was found in both groups while eating 


\section{Part III: Pathogenesis}

(Grollman, 1929); however if group 3a exhibits a limitation in stroke volume secondary to a more loss in pulmonary capillary bed, then the increased HR may have a limited effect in terms of contribution to the cardiac output; ventricular filling after eating may be further compromised by right ventricular preload reduction due to pooling of blood in the vascular intestinal bed. Careful haemodynamic evaluation of the patients will be necessary in further studies. Of interest is the observation that in the hypoxemic group exhibiting significant desaturation, a more modest decrease in $\mathrm{S}_{a} \mathrm{O}_{2}$ was found during the carbohydrate rich meal accompanied by a lower increase in $\mathrm{HR}$. This finding is in favor of a haemodynamic explanation for the differences in oxygen desaturation.

The meals did not differ only in carbohydrate content, but also in eating pattern and in protein content. Meal 2 consisted of sandwiches which the patients had to prepare themselves, whereas meal 1 was a hot meal ready for use. The time in between bites was therefore longer for meal 2 which was also reflected in a longer overall meal duration. In addition the dyspneic sensation was less during meal 2 which suggests that eating this meal constituted less exertion than eating meal 1. The thermic respons to protein is significantly greater than to isoenergetic amounts of carbohydrate or fat (Nair, 1983). This difference in thermogenetic stimuli of carbohydrate and protein is most pronounced approximately $1 \mathrm{~h}$ after the meal, but probably cannot explain the observed desaturation immediately after beginning of the meal.

Another objective was to see if there is evidence for beneficial effects of high fat supplements on $\mathrm{P}_{1} \mathrm{CO}_{2}$ for ambulatory patients with stable COPD. We found that a single carbohydrate rich meal did not influence $\mathrm{P}_{1} \mathrm{CO}_{2}$ during or immediately after the meal. This is probably not surprising since the concept that increasing fat intake aids in reducing the requirement for $\mathrm{CO}_{2}$ excretion assumed importance in case of sustained carbohydrate loading with a positive energy balance.

We conclude that meal related desaturation cannot explain weight loss in normoxemic patients with severe COPD but may contribute to a limited dietary intake in a sub group of hypoxemic patients exhibiting significant desaturation. Increasing oxygen supply in these patients when eating may be advocated. 
Part IV: Therapy 



\title{
Chapter 10
}

\section{The effect of supplemental nutrition alone or combined with anabolic steroids on body composition and physical performance in nutritionally depleted COPD patients}

\begin{abstract}
The effect of supplemental nutrition alone or combined with anabolic steroids on body composition and physical performance in COPD was investigated in a placebo controlled randomized trial. The trial was conducted as an integrated part of an 8 weeks pulmonary rehabilitation program. Underweight COPD patients as well as normal weight patients exhibiting a depleted fat-free mass, were included in the study. The interim analysis indicates that a daily nutritional supplement in combination with general physical training, is a successful and therapeutic feasible approach to gradually improve fat-free mass in depleted COPD patients. The results further suggest that supportive treatment with nandrolon decanoate may enhance an increase in muscle mass in stead of fat mass. The treated groups exhibited furthermore a significant increase in respiratory muscle strength, which was most pronounced in the group receiving anabolic steroids, but treatment contrasts with the group receiving placebo treatment were not yet statistically significant. No enhancing effect of the treatments on 12 minute walking distance could be demonstrated.
\end{abstract}




\section{Introduction}

Although the association between weight loss and COPD is well recognized, attention to the therapeutic implications of nutritional depletion in patients with COPD has gained only recent interest. Rationale for nutrition intervention is based on animal and human investigations supporting a direct relationship between body weight and diaphragm muscle thickness and area (Thurlbeck, 1978; Arora, 1982 1+11; Kelsen, 1985; Lewis 1986). Clinical investigations have further shown that undernutrition may be associated with altered contractility and increased fatiguabillity in both limb and respiratory muscles (Lopes, 1982; Fraser, 1986; Efthimiou, 1988).

Since 1986, seven nutrition intervention studies in patients with stable COPD have been reported, which are summarized in table 1. Comparison between these investigations is limited owing to the variety of study designs, characteristics of the study populations, nutritional markers and duration of patient follow-up.

Table 1: Summary of clinical investigations of nutritional pepletion in COPD

\begin{tabular}{|c|c|c|c|c|c|c|}
\hline \multirow[t]{2}{*}{ awithor } & \multirow{2}{*}{\multicolumn{2}{|c|}{ Designt }} & \multirow{2}{*}{$\begin{array}{l}\text { no of } \\
\text { patients }\end{array}$} & \multirow[t]{2}{*}{ duration } & \multicolumn{2}{|c|}{ outcome } \\
\hline & & & & & weight & other measures \\
\hline Wilson & NR & inpatient & 6 & $3 w k$ & $43.1 \mathrm{~kg}$ & + Pi-max / handgrip sitrength \\
\hline 1986 & $\mathrm{NC}$ & oral & & & & transdiaphragmatic pressure \\
\hline $\begin{array}{l}\text { Lewis } \\
1987\end{array}$ & $\mathrm{RC}$ & $\begin{array}{l}\text { outpatient } \\
\text { oral }\end{array}$ & 21 & $8 w k$ & $41.1 \mathrm{~kg}$ & $\begin{array}{l}\text { - Pl-max / Pe-max } \\
\text { - respiratory muscle endurance }\end{array}$ \\
\hline $\begin{array}{l}\text { Knowles } \\
1988\end{array}$ & $\mathrm{R} C$ & $\begin{array}{l}\text { outpatient } \\
\text { oral }\end{array}$ & 25 & $8 w k$ & $+1.1 \mathrm{~kg}$ & $\begin{array}{l}\text { - Pli-max / Pe-max } \\
\text { - respiratory muscle endurance }\end{array}$ \\
\hline $\begin{array}{l}\text { Efthimiou } \\
1988\end{array}$ & $\mathbf{R} \mathbf{C}$ & $\begin{array}{l}\text { outpatient } \\
\text { oral }\end{array}$ & 14 & 12 wh & $44.2 \mathrm{~kg}$ & $\begin{array}{l}\text { + Pi-max / Pe-max t stemo- } \\
\text { mastoid muscle function }\end{array}$ \\
\hline $\begin{array}{l}\text { Goldstein } \\
1989\end{array}$ & $\begin{array}{l}\text { NR } \\
\text { NC }\end{array}$ & $\begin{array}{l}\text { inpatient } \\
\text { (par)enteral }\end{array}$ & 10 & $2 w / k$ & $+2.0 \mathrm{~kg}$ & $\begin{array}{l}\text { 1 respiratory muscle strength } \\
\text { hamstring/endurance strength }\end{array}$ \\
\hline $\begin{array}{l}\text { Otte } \\
1989\end{array}$ & $\mathrm{R} / \mathrm{CAP}$ & $\begin{array}{l}\text { outpatient } \\
\text { oral }\end{array}$ & 28 & $13 w k$ & $\$ 1.5 \mathrm{~kg}$ & $\begin{array}{l}\text { - MVV; - immune response; } \\
\text { - } 12 \text { minute walking distance }\end{array}$ \\
\hline $\begin{array}{l}\text { Whittaker } \\
1990\end{array}$ & $\mathbb{R} \mathbf{C}$ & $\begin{array}{l}\text { inpatient } \\
\text { nasosnteral }\end{array}$ & 10 & $16 \mathrm{days}$ & $2.4 \mathrm{~kg}$ & $\begin{array}{l}\text { - respiratory muscle strength/ } \\
\text { endurance } \\
\text { - adductor pollicis function }\end{array}$ \\
\hline
\end{tabular}

\footnotetext{
$\mathrm{NR}=$ nonrandomized. $\mathrm{NC}=$ noncontrolled, $\mathrm{R}=$ randomized, $\mathrm{C}=$ controlled, $\mathrm{P}=$ placebo
} 
Definite conclusions are also limited in many cases by the small patient numbers. The conflicting results prompted a recent workshop of the National Institute of Health on 'Nutrition and the Respiratory System' to emphasize the need for 'carefully designed clinical trials of adequate sample size... to define whether augmented alimentation is potentially beneficial to those COPD patients who are cachectic and, if so, whether or not it is a practical therapeutic approach" (Edelman, 1986).

Treatment with anabolic steroids may be an additional mode of intervention leading to improvements in body composition and physical performance. One such anabolic steroid is nandrolon decanoate (deca durabolin ${ }^{3}$ ). Controlled studies in debility states associated with other chronic wasting diseases (liver cirrhosis, chronic renal failure, chronic infectious diseases and gastrointestinal disorders) have reported significant weight gain, improved sense of well being and improved appetite after supportive treatment with nandrolone decanoate (Johnson, 1962; Page, 1962; Vadas2, 1969; Rebora, 1971). No studies have been published yet concerning the effects of anabolic steroids in depleted COPD patients.

We conducted a placebo controlled randomized trial to investigate the effect of a 2 month period of supplemental oral nutrition alone or combined with anabolic steroids on body composition in depleted COPD patients. Since the study was conducted as an integrated part of an intensive clinical pulmonary rehabilitation program, it allowed us to study in addition the potentially enhancing effect of the 2 treatments on the outcome of general physical training. In this chapter results are presented of an interim analysis, performed after 75 patients had completed the study.

\section{Methods}

\section{Parients}

Nutritionally depleted patients who were suffering from COPD (defined by the criteria of the American Thoracic Society, 1987) and were admitted to the pulmonary rehabilitation center in the period January 1988-January 1990, were evaluated. The depleted group consisted of patients with a body weight less than $90 \%$ of ideal weight and/or a fat-free mass less than $67 \%$ (males) $163 \%$ (females) of ideal weight. Stratification was done bolh by body weight and fat-free mass since we demonstrated in an earlier study (chapter 5) that part of the normal weight COPD patients had a depleted fat-free mass. These pattients suffered from physical impaiment even to a greater degree than underweight patients with a relative preservation of fat-free mass.

Patients who demonstrated an increase in $\mathrm{FEV}_{1}$ of $>10 \%$ of the predicted baseline value after administration of a bronchodilator or who had unstable COPD were excluded from 
participation in the study. Other exclusion criteria were mild to moderate heart failure, unstable angina pectoris, severe cardiac rythm abnormalities, recent $(<3$ months) myocardial infarction, severe cardiac valve abnormalities or cardiomyopathy, severe abnormal liver function parameters (SGOT, SGPT, Gamma GT or alkaline phosphatase above the upper limit of the reference value $+50 \%$ ), active gastrointestinal abnormalities, severe endocrine abnormalities (insulin dependent diabetes mellitus, hyper/hypothyreoidism), a history of recent ( $<2$ months) surgery and malignant disease. The selected patients entered the study after they were fully informed about the aim and procedures of the study and after they had given written consent.

The first week after admission to the center several assessments were performed by the multidisciplinary team. Furthermore this period allowed familiarization with the various tests that could be influenced by effort and learning. After medication was optimalized and after theophylline levels were obtained within therapeutic range $(8-15 \mathrm{mg} / \mathrm{L})$ all patients entered a training program. The standard program (A) consisted of general physical training with particular attention to exercise in relation to daily activities, cycle ergometry, treadmill walking, walking circuits, swimming, sports and games. Patients requiring oxygen therapy (i.e. patients with a resting $\mathrm{P}_{\mathrm{a}} \mathrm{O}_{2}<7.3 \mathrm{kPa}$ while breathing room air) or suffering from prohibitive locomotor ailments, received an adapted less intensive reactivation program (= program $B$ ).

\section{Study design}

The intervention study was conducted as part of the rehabilitation program. The patients were randomly allocated to three sub-groups (G)

$\mathrm{G}_{1}$ The control group receiving nandrolone decanoate placebo;

$\mathrm{G}_{2}$ Patients receiving placebo nandrolone decanoate treatment and supplemental nutrition;

$\mathrm{G}_{3}$ Patients receiving nandrolone decanoate treatment and supplemental nutrition.

Since it was assumed that the distribution of patients who participated in exercise program A or B was equal over the three studied groups, no randomization to exercise program was performed.

The anabolic steroids or placebo were administered by intramuscular injection, in a double blind fashion on day $1,15,29$ and 43 . Males received $1 \mathrm{ml}$ containing $50 \mathrm{mg}$ and females received $0.5 \mathrm{ml}$ containing $25 \mathrm{mg}$ nandrolon decanoate. The placebo contained nanrolon decanoate vehicle (Arachis oil). Code lists with code numbers and coded medication were provided by the company. Daily nutritional supplementation could not be administered in a double blind fashion. The supplement consisted of a high caloric drink $(200 \mathrm{ml}=420 \mathrm{kcal} ; 51 \%$ fat; $35 \%$ carbohydrates; $14 \%$ protein; a mixture of Nutridrink $^{\$ \infty}$, Protifar and Fantomalt ${ }^{\infty}$, oill) in addition to the normal hospital diet. To avoid that administration of the supplement might lead to a decreased spontaneous dietary 
intake, the supplement was administered in the early evening between 7-9 p.m. To increase acceptability of the supplement, 7 mixtures of different favours were prepared. Nutritional intervention lasted at least until day 57. All groups were similarly monitored and encouraged to eat their regular meals.

Measurements of body weight, body composition, serum proteins, dietary intake, pulmonary function and exercise performance were performed on entry of the study, on day 29 and day 57. A record with possible side effects of the anabolic steroids was completed on day 29 and day 57. The assessment scheme is shown in figure 1 . The study was approved by the ethical comittee of the university and the procedures followed were in accord with the Helsinki declaration from 1977 as revised in 1983.

Figure 1: Assessment and treatment scheme.

\section{day}

$\begin{array}{llllllllll}\text { screening }^{4} & 1 & 8 & 15 & 22 & 29 & 36 & 43 & 50 & 57\end{array}$

treatment

nandrolom decanoatel

placebo i.m. injection

supplemental nutrition

\section{nssessments}

medical history

physical examination

body composition.

biochemistry

ind hrect calorimetry

lung function

exercise performance

dietary resords

diet history

emergent symptoms record

$\begin{array}{cccc}\mathrm{x} & \mathrm{x} & \mathrm{x} \\ < & \end{array}$

The maximum interval duration between screening and suart of treatment is 7 days.

\section{nutritional assessment}

Body composition was assessed using body weight, height, mid upper arm circumference, skinfold thicknesses and bioelectrical resistance. Ideal body weight was determined as the midpoint of the weight range for a given height and frame size (determined by wrist circumference) from the 1983 Metropolitan Life Insurance Tables. Circumference of the right upper arm was taken with a flexible measuring tape. Skinfolds were measured in 
triplicate with a skinfold caliper. Sub cutaneous body fat content was estimated from the sum of skinfold thicknesses at four sites: bicipital, tricipital, subscapular and suprailiac using the 'Durnin' tables. Fat-free mass (FFM) was assessed by bioelectrical resistance measurements (BIA 101, RJL Systems, Detroit, USA) in the supine position at the right site as described by Lukaski (1985). FFM was calculated from height ${ }^{2} /$ resistance and body weight using a patient specific regression equation derived from a study in our own center using deuterium dilution as a reference method (chapters $2+3$ ). Since no data are available on ideal FFM, FFM was expressed as a percentage of ideal weight. The values 63 and $67 \%$ corresponded to a body weight $90 \%$ of ideal weight on linear regression analysis (chapter 5). All measurements were performed by the same research assistent. Skeletal muscle mass was estimated from the creatinine height index, which was calculated by dividing the 24 hour urinary creatinine excretion of the patient by a reference value based on ideal body weight (Jensen, 1983). Serum concentrations of albumin, prealbumin and transferrin were analyzed by radial immunodiffusion on an automated system (Cobas Mira, Hofmann la Roche, Switzerland).

\section{Dietary intake}

Dietary intake of the period prior to admission and throughout the study period was assessed using the diet history method with cross check. The interviews were performed by the same trained dietician prior to entry of the study and in the week after completion of the treatment. A possible systematic error was thus randomly distributed. The information was coded for computer nutrient analysis using measured portion sizes and recepies from the hospital kitchen which uses an 8 week menu cycle. The nutrient data base was derived from the Dutci food composition tables (NEVO, 1986). Portion sizes were determined for each patient before entry of the study and possible changes were registered. In addition the patients completed 16 dietary records randomly distributed throughout the study period. The dietary records were compared with estimated dietary intake at the end of this period using the diet history method in 57 patients. Mean $\pm S D$ intake of 16 dietary records was not significantly different from the diet history (1814 and $1899 \mathrm{kcal}$ respectively). However it was evident that patients recalled average dietary intake when feeling well and could not quantitate reduced intake in periods of intermittent acute illness. Nevertheless we felt that asking the patients to record dietary intake daily, would be asking too much. The intake of the supplement was recorded daily.

\section{Resting energy expenditure}

Resting energy expenditure was measured by indirect calorimetry using a ventilated hood system as described in chapter 4 . Measurements were performed in the early morning in the fasting state (between 8.30 and $9.30 \mathrm{a} . \mathrm{m}$.) approximately $2 \mathrm{~h}$ after the patients had received their maintenance medication. 


\section{Lung function}

FEV, and inspiratory vital capacity (IVC) were measured with a wet spirometer; the highest value of at least three spirometric manoeuvres was used. FEV 1 and IVC were expressed as a percentage of the reference value (Quanjer, 1983). Arterial blood gases were drawn by puncture of the brachial artery at rest while breathing room air. Arterial oxygen tension $\left(\mathrm{P}_{\mathrm{a}} \mathrm{O}_{2}\right)$ and carbon dioxide tension $\left(\mathrm{P}_{\mathrm{a}} \mathrm{CO}_{2}\right)$ were analyzed on a blood gas analyzer (Radiometer, ABL 330, Copenhagen, Denmark). Respiratory muscle strength was determined by measuring maximal inspiratory and expiratory mouth pressures, according to the technique described by Black and Hyatt (1960). The best of three determinations was used in subsequent calculations.

\section{Exercise performance}

Exercise performance was evaluated with a 12 minute walk along an indoor corridor 100 $m$ long (McGavin, 1976). All tests were performed in the early afternoon and no encouragement was given. Walking distance was not evaluated in patients receiving the adapted training program $\mathbf{B}$.

\section{Side effects of anabolic steroids}

The following potential side effects of anabolic steroids were systematically checked on day 29 and 57: androgenic effects, disturbances in liver function, menstrual disorders and fluid retention. Acceptability and possible intolerance of the nutritional supplement were recorded daily.

\section{Statistics}

An interim analysis was scheduled after 75 patients had completed the study. If insufficient beneficial effects of nandrolon decanoate were demonstrated, the study would be stopped. Otherwise the study would be continued until the final recruitment of 150 patients. Statistical analysis was performed according to the "intention to treat principle", i.e. all patients that completed data collection until day 57, were analyzed. An analysis of covariance was done, taking the pre-treatment value as covariable, and considering treatment and exercise intensity as factors in the statistical model. Pairwise treatment contrasts "nutritional intervention + nandrolon decanoate" minus "nutritional intervention", "mutritional intervention minus control" and "nutritional intervention + nandrolon decanoate" minus "control" were calculated. Since the study comprised an interim analysis, a $97 \%$ confidence interval was chosen in order to set the experimentwise error $(\alpha)$ in the final analysis on $5 \%$. Pairwise testing within the treatment groups was done using Student's t-test. 
Part IV: Therapy

Results

68 Patients completed the study and were included in the interim analysis. Three patients dropped out because they were homesick. Four patients died because of reasons unrelated to the treatment. Patients who had an acute exacerbation during the study were effectively treated with a shori course of steroids and/or antibiotics, and remained in the study. The nutritional supplement and the injections were generally tolerated well. Three patients did not like the nutritional supplement and after a few days did not want any more. No side effects of anabolic steroids treatment were reported.

Dietary intake during the treatment period was significantly $(p<0.05)$ higher than prior to admission to the center. Dietary intake of the treated groups was $60 \%$ above resting metabolic rate and approximately $20 \%$ higher than the placebo group.

Table 2: Daily dietary intake in the 3 study groups.

\begin{tabular}{|c|c|c|c|c|}
\hline & & $G_{i}$ & $\mathrm{G}_{2}$ & $\mathrm{G}_{3}$ \\
\hline $\begin{array}{l}\text { habitual dictary } \\
\text { intake (at home) }\end{array}$ & $(\mathrm{kcal})$ & $1799 \pm 525$ & $1659 \pm 448$ & $1807 \pm 476$ \\
\hline $\begin{array}{l}\text { dietary intake } \\
\text { durimg treatment }\end{array}$ & (keal) & $1912 \pm 429$ & $1802 \pm 468$ & $1948 \pm 387$ \\
\hline $\begin{array}{l}\text { supplemental } \\
\text { nutrition }\end{array}$ & (kcal) & & 373 & 378 \\
\hline dietary intake/REE & $(\mathscr{w})$ & $144 \pm 34$ & $162 \pm 33$ & $160 \pm 26$ \\
\hline
\end{tabular}

$\mathrm{G}_{1}=$ group receiving nandrolone decanoate placebo

$\mathrm{G}_{2}=$ group receiving nandrolone decanoate placebo and supplemental nutriton

$\mathrm{G}_{3}=$ group receiving nandrolone decanoate and supplemental nutrition

The $97 \%$ confidence intervals of the estimated treatment contrasts indicated a significant improvement in body weight after supplemental nutrition alone $\left(\mathrm{G}_{2}\right)$ and supplemental nutrition + anabolic steroids $\left(\mathrm{G}_{3}\right)$. Furthermore in $\mathrm{G}_{2}$ a significant increase in FFM and midarm circumference was found compared to the placebo group, and a significant increase in fat-free mass and creatinine height index in $\mathrm{G}_{3}$. No significant difference could yet be established between $G_{2}$ and $G_{3}$ although the results indicate that the increase in FFM and creatinine height index relative to body weight was larger in $\mathrm{G}_{3}$. The anthropometric measures were generally less discriminative but the increase in both percent fat mass as well as in midarm circumference was larger in $G_{2}$ than in $G_{3}$. Average baseline values of the serum proteins were within the normal range and did not change significant 
lly after treatment. No significant differences between the groups were found in spirometry values post vs pre treatment, although inspiratory vital capacity increased significantly in $G_{2} \quad(p<0.05)$ and $G_{3} \quad(p<0.05)$. Within-group comparisons revealed significant improvements in 12 minute walking distance for all the groups, in $P_{i}$-max for $G_{3}$ $(p<0.001)$ and in $P_{c}-\max$ for $G_{2}(p<0.05)$ and $G_{3}(p<0.005)$. The treatment contrasts were not statistically significant.

A significant exercise $x$ treatment interaction was found for body weight $(p<0.005)$, fatfree mass $(p<0.01)$ and percentage of body fat estimated from skinfold measurements $(p<0.05)$. However it turned out that having chronic hypoxemia was the major reason $(68 \%)$ for placing patients in group B. Group B was furthermore characterized by significantly lower baseline values of inspiratory vital capacity ( 56 vs $68 \%, \mathrm{p}<0.05)$, creatinine height index ( 60 vs $76 \%, p<0.005), P_{i} \max (3.4$ vs $4.4 \mathrm{kPa}, \mathrm{p}<0.05)$, and a higher $\mathrm{P}_{\mathrm{a}} \mathrm{CO}_{2}(5.8$ vs $5.3 \mathrm{kPa}, \mathrm{p}<0.05)$ than group $\mathrm{A}$. 


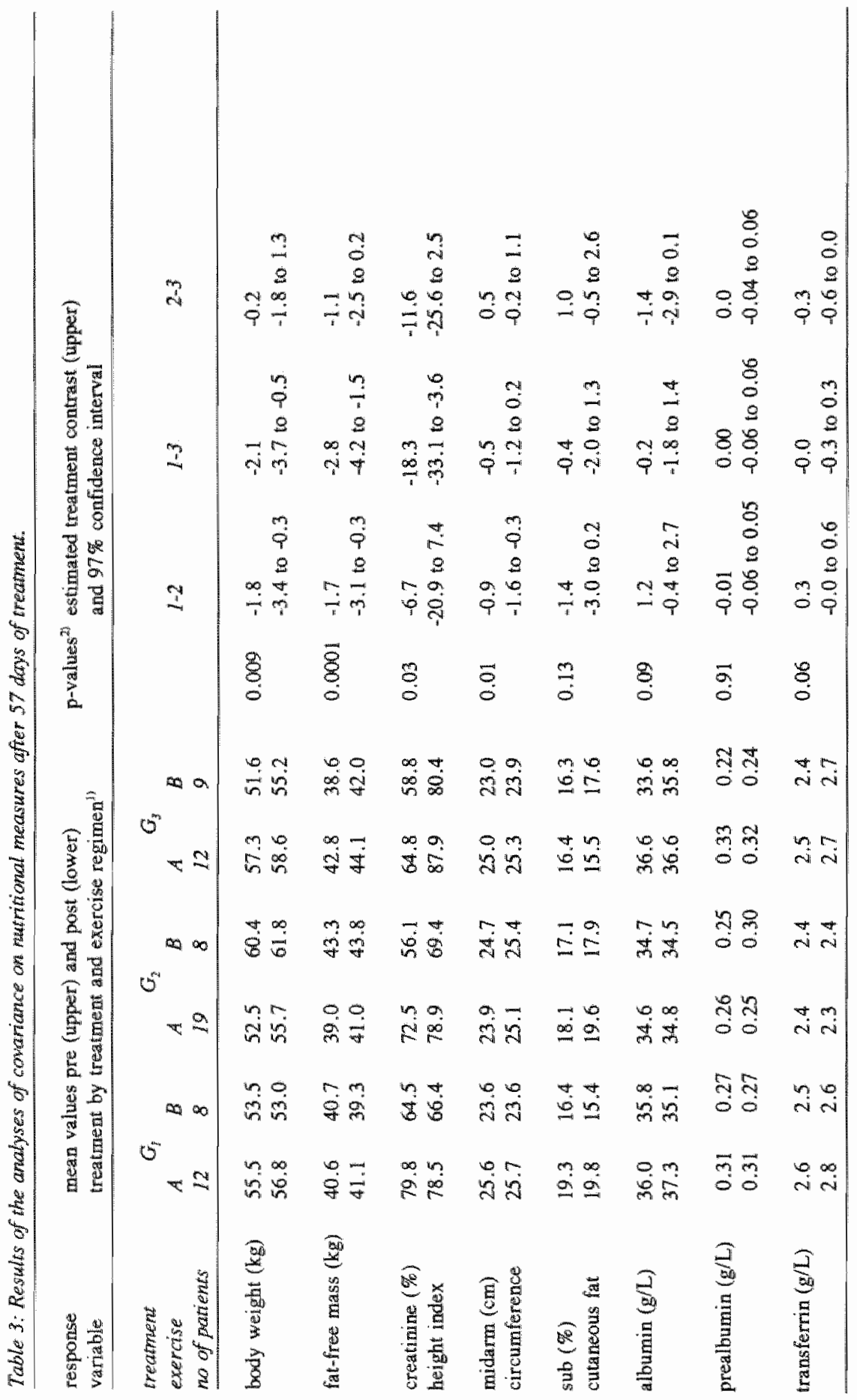




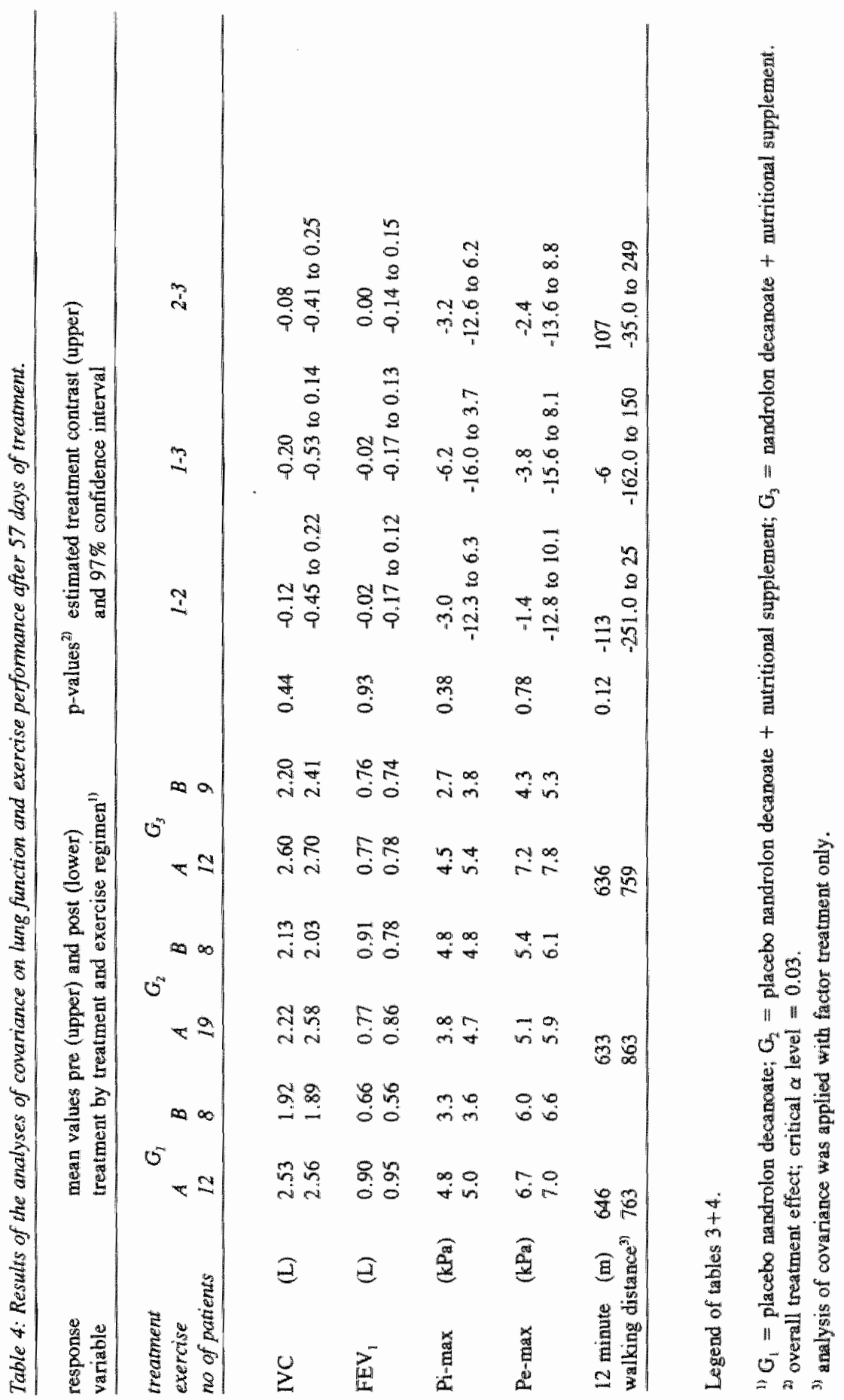




\section{Discussion}

An increased resting energy expenditure commonly occurs in COPD and has been associaled with markedly increased energy requirements for ventilation (chapter 7). A substantial number of COPD patients is not able to meet their metabolic requirements and suffers weight loss. Contrary to other conditions where metabolic rate is elevated such as injury and sepsis, Goldstein (1988) found that hypermetabolism, at least in normoxemic patients with stable COPD was not associated with hypercatabolism (i.e. a greater nitrogen breakdown than expected for a given energy expenditure). Consequently, when energy intake balances energy expenditure, depleted COPD patients are able to gain nitrogen and increase fat-free mass at a rate similar to that of other depleted patients who are not hypermetabolic.

The approach to outpatient nutritional support of COPD patients has focussed primarily on the use of oral nutrition support, since the majority of COPD patients have a normal gastrointestinal function. We reached a significant increase in body weight of $2.7 \mathrm{~kg}$ after a daily supplement of $420 \mathrm{kcal}$ during 8 weeks and a difference of $1.8 \mathrm{~kg}$ with the placebo group that exhibited an average weight gain of $0.6 \mathrm{~kg}$. In one other controlled study a substantial weight gain $(4.2 \mathrm{~kg}$ after 3 months oral support) was achieved (Efthimiou, 1988) but average weight gain in the studies of Lewis (1987), Knowles (1988) and Otte (1989) was less than $1.5 \mathrm{~kg}$ in 8 weeks. Failure to achieve weight gain may be explained by several factors: (1) The other studies were performed on an outpatient basis allowing relatively little control over daily caloric intake. (2) Lewis and Knowles aimed at a dramatic increase exceeding at least $50 \%$ of habitual dietary intake. In both studies a drop in normal intake was reported however in patients receiving the supplement. The net effect was therefore that the additional calories were taken in stead of rather than supplementary to the normal diet. Only in the study by Efthimiou caloric intake actually increased with $50 \%$, but baseline daily intake in their underweight group was very low, i.e. $65 \%$ of the intake of the normal weight control group. (3) Contrary to previous studies we administered supplemental nutrition in addition to a general physical training program. Reactivation may have positively influenced appetite and weight gain.

Although one extra supplement was therapeutically feasible and resulted on a group level in a significant weight gain, in some patients $420 \mathrm{kcal}$ may have been insufficient to induce weight gain. However when we started the intervention study, only limited information was available regarding the occurrence of an increased resting energy expenditure, and of the ratio total to resting energy expenditure in patients with advanced COPD. Recent prelininary results by Hugli (1990) indicate that in stable COPD patients total energy expenditure is approximately $10-40 \%$ above resting energy expenditure, comparable to healthy sedentary individuals. 
When a larger weight gain in a shorter period is aimed for, other ways of administrating calories should be employed. Goldstein (1989) and Whittaker (1990) were able to increase body weight by $\pm 2 \mathrm{~kg}$ after 2 weeks of nasoenteral or parenteral nutrition. However provision of excess calories places a metabolic demand on the respiratory system. Calorie administration of any type is associated with an increase in total $\mathrm{CO}_{2}$ production and $\mathrm{O}_{2}$ consumption, termed diet induced thermogenesis. The increase in $\mathrm{CO}_{2}$ production raises ventilatory requirements and may contribute to the dyspnea associated with meals in some COPD patients (Donahoe, 1990).

The ratio of $\mathrm{CO}_{2}$ produced and $\mathrm{O}_{2}$ consumed ( $=$ the respiratory quotient) depends on the substrate utilized. This value, approximately 0.7 for triglycerides, 0.8 for aminoacids, and 1.0 for glucose oxidation, is frequently used as the rationale for selecting substrates in pulmonary patients. It has been suggested that pulmonary patients benefit from a high lipid diet owing to a reduced respiratory quotient. Provision of caloric intake which exceeds metabolic requirements can lead to lipogenesis. Under these conditions the respiratory quotient can approach or exceed 1.0 and presumably this leads to clinical deterioration in patients with marginal ventilatory capacity. Because of the relationship between fuel source and $\mathrm{CO}_{2}$ production, and because we wanted a high caloric low volume drink, we administered a supplement consisting of $51 \%$ fat. However the benefit of altering fat-to-carbohydrate ratios in ambulatory COPD patients is not yet convincingly demonstrated. The marked increase in ventilatory demand attributed to carbohydrate administration by Askanazi (1980) was far in excess of estimated requirements (more than $200 \%$ of calculated resting energy expenditure). In a recent study we did not detect any change in transcutaneous carbon dioxide tension after ingestion of a single carbohydrate rich meal (chapter 9). Goldstein (1989) compared an isocaloric high carbohydrate formula (53\% of total calories) with a high fat formula ( $55 \%$ of total calories) during (par)enteral nutrition. No difference was noted in arterial blood gas values. Both diets were equally well tolerated and were associated with an equivalent level of nitrogen retention after 4 days.

Since oral nutritional support in COPD is limited, we studied the superimposing effect of anabolic steroid treatment on body weight and body composition. Weight gain was significantly larger in comparison with the placebo group, but an insignificant difference was found with the group receiving supplemental nutrition allone. On the other hand a substantially larger increase in fat-free mass and creatinine height index was found in the group receiving anabolic steroids, while the increase in sub cutaneous fat mass and midarm circumference tended to be larger in the 'nutrition' group. Despite the limitations of the individual body composition measures, the combination of these changes suggests a superimposing increase of metabolic active tissue in the group receiving anabolic steroids. According to the $97 \%$ confidence intervals it is expected that these differences will 
become statistically significant in the final analysis, when 150 patients have completed the study.

We also studied whether the treatments were reflected in improved physiologic function. A significant increase in $P_{i}$-max was found in the group receiving nandrolon decanoate, and a significant increase in $\mathrm{P}_{0}$ - $\max$ in both treatment groups. Treatment contrasts with the placebo group however were not statistically significant. No enhancing effect of the treatments on twelve minute walking distance could be demonstrated. A few other studies mentioned improved physiologic function associated with weight gain. However these studies were either uncontrolled or comprised small patient numbers. Whittaker and colleagues (1990) reported a significant improvement in $\mathrm{P}_{\mathrm{e}}$-max and in inspiratory muscle endurance after nutritional supplementation despite an unchanged $\mathbb{P}_{i}$-max. They related the improvement in respiratory muscle endurance to the demonstrated improvement in expiratory muscle strength. The improvement in $P_{0}-$ max was associated with a trend toward a decrease in residual volume. They hypothesized that the decreased residual volume leads to lengthening of the diaphragmatic muscle fibers when the expiratory muscles are recruited during the vigorous inspiratory manoeuvres of the endurance test. Martin and De Troyer (1982) indeed showed that the expiratory muscles are recruited during inspiratory resistive loading. Thus the expiratory muscles may assist inspiration and improve endurance. It is widely taken that the study by Efthimiou actually did demonstrate improvements in inspiratory muscle strength, 6 minute walking distance and sternomastoid muscle contractility and fatiguability properties. However careful examination of their statistical analyses reveals that the significant improvements involved a within group comparison and not a comparison with the placebo group.

A significant treatment $x$ exercise interaction was found for body weight and bodty composition, which at this point is difficult to interpret, owing to a limited number of patients in some sub groups. Comparison of baseline values between the exercise groups suggests that the interaction rather reflects a treatment $x$ disease severity interaction.

In conclusion the interim analysis indicates that a daily nutritional supplement in addition to a normal dietary intake, as part of a general physical training program is a succesful approach to gradually improve body weight in nutritionally depleted COPD patients. The results further suggest that supportive treatment with anabolic steroids enhances the incorporation of extra calories in muscle mass in stead of fat mass. The treatments did not exert an enhancing effect on exercise performance. This may be partly due to the small number of patients involved, which will be made clear after the final recruitment of 150 patients. The final analysis will also include an evaluation of the treatments after 4 weeks and a more detailed study of the effects of the treatments on spontaneous dietary intake using the dietary records. Furthermore the complete data will allow analysis of the 
interaction between depletion and disease severity on outcome as well as evaluation of the treatments on morbidity and mortality.

Additional studies are needed using tests for respiratory muscle strength and endurance and for skeletal muscle strength to investigate the effects of the treatments on physiologic function. Furthermore I would like to stress that our positive findings were obtained in a stable inpatient COPD population. The approach of nutritional intervention in an outpatient setting as well as during exacerbations of the disease requires further attention. 


\section{References}

- Anonymus. Metropolitan Life Insurance Company. New weight standards for men and women. Bull. Metropol. Life. Found. 1983;64:1-4.

- ATS. Standards for the diagnosis and care of patients with chronic obstructive pulmonary disease (COPD) and asthma. Am. Rev. Respir. Dis. 1987;134:239-43.

- Arora NS, Rochester DF. Respiratory muscle strength and maximal voluntary ventilation in undernourished patients. Am. Rev. Respir. Dis. 1982;126:5-8.

- Arora NS, Rochester DF. Effect of body weight and muscularity on human diaphragm muscle mass, thickness and area. J. Appl. Physiol. 1982;52:64-70

- Askanazi J, Elwyn DH, Silverberg PA, Rosenbaum SH, Kinney JM. Respiratory distress secondary to a high carbohydrate load:a case report. Surgery 1980;87:596-598.

- Askanazi J, Nordenstrom J, Rosenbaum SH, Elwyn DH, Hyman AI, Carpentier YA, Kinney JM. Nutrition for the patient with respiratory failure. Glucose vs fat. Anesthesiology 1981;54:373-377.

- Barrie A, Coward WA. A rapid analytical technique for the determination of energy expenditure by the double labelled water method. Biomed. Mass. Spectrom. 1985;12$: 535-41$.

- Beaumont A, Cockroft A, Guz A. A self paced tredmill walking test for breathless patients. Thorax 1985;40:459-464.

- Benedict FG. Factors affecting basal metabolism. J. Biol. Chem. 1915;20:263-299.

- Bishop $\mathrm{ChW}$, Bowen PhT, Ritchey SJ. Norms for nutritional assessment of American adults by upperarm anthropometry. Am. J. Clin. Nutr. 1981;34:2530-2539.

- Black G. A review of validations of dietary assessment methods. Am. J. Epidemiol. 1982;115:492-505.

- Black LF, Hyatt RE. Maximal respiratory pressures: normal values and relationship to age and sex. Am. Rev. Resp. Dis. 1969;99:696-702. 


\section{References}

- Bland JM, Altman DG. Statistical methods for assessing agreement between two methods of clinical measurement. The Lancet 1986;i:307-310.

- Bleiberg-Daniel F, Wade S, Labarre C, Ballagny D, Fichelle A, Bory I, Desmonts JM, Lemonnier D. Variations in plasma thyroxine-binding prealbumin (TBPA) in relation to other circulating proteins in post-operative patients during rapid oral refeeding. Human Nutrition: Clinical Nutrition 1985;39C:55-62.

- Boothby WM, Berkson J, Dunn HL. Studies on the energy of metabolism of normal individuals: A standard for basal metabolism with a nomogram for clinical application. Am. J. Physiol. 1936;3:468-483.

- Boushy SF, Adhikan PK, Sakamoto A, Lewis B. Factors affecting prognosis in emphysema. Dis. Chest 1964;45:402-11.

- Brandstetter RD, Zakkay Y, Gutherz Ph, Goldberg RJ. Effect of nasogastric feedings on arterial oxygen tension in patients with symptomatic chronic obstructive pulmonary disease. Heart Lung 1988;17:170-172.

- Brater DC. Resistance to loop diuretics. Why it happens and what to do about it. Drugs $1985 ; 30 ; 427-443$.

- Braun ShR, Keim NL, Dixon RL, Clagnaz P, Anderegg A, Shrago ES. The prevalence and determinants of nutritional changes in Chronic Obstructive Pulmonary Disease. Chest $1984 ; 86: 558-563$.

- Brennan MF. Uncomplicated starvation versus cancer cachexia. Cancer 1977;37:23592364.

- Brown SE, Casciari RJ, Light RW. Arterial oxygen saturation during meals in patients with severe chronic obstructive pulmonary disease. Southern Medical Journal 1983;76:194-198.

- Bye PRP, Farkas GA, Roussos C. Respiratory factors limiting exercise. In: Gosselink 1983; fysiotherapie by CARA. Utrecht, Bunge, The Netherlands.

- Cahan C, Decker MJ, Hoekje PL, Strohl KP. Agreement between noninvasive oximetric values for oxygen saturation. Chest 1990;97:814-19. 
- Carlin BW, Clausen JL, Ries AL. The use of cutaneous oximetry in the prescription of long-term oxygen therapy. Chest 1988;94:239-241.

- Castaldo WA, DeGregario $\mathrm{B}$, Brandstetter RD. Mealtime arterial $\mathrm{O}_{2}$ saturation in COPD. (letter to the editor) Southern Medical Journal 1983;76:1347.

- Christensen CC, Frey HMM, Foenstelien E, Aadiand E, Refsum HER. A critical evaluation of energy expenditure estimates based on individual $\mathrm{O}_{3}$ consumption/heart rate curves and average daily heart rate. Am. J. Clin. Nutr. 1983;37:468-72.

- Chumlea WMC, Rache A, Guo S, Woynarowska B. The influence of physiological variables and oral contraceptives on bioelectrical impedance. Human Biology 1987;59:257-259.

- Chumlea WMC, Baumgartner RN. Status of anthropometry and body composition data in elderly subjects. Am. J. Clin. Nutr. 1989;50:1158-66.

- Cohn SH. How valid are bioelectricall impedance measurements in body composition studies? Am. J. Clin. Nutr. 1985;42:889-90.

- Cotes JE, Zejda J, King B. Lung function impairment as a guide to exercise limitation in work-related lung disorders. Am. Rev. Respir. Dis. 1988;137:1089-93.

- Covelli HD, Black JW, Olsen MS, Beekman JF. Respiratory failure precipitated by high carbohydrate loads. Ann. Intern Mied. 1981;95:579-581.

- D'Alessio DA, Kavle EC, Mozzoli MA et al. Thermic effect of food in lean and obese men. J. Clin. Invest. 1988;81:1781-91.

- Decker MJ, Hoekje PL, Strohl KP. Ambulatory monitoring of arterial oxygen saturation. Chest 1989;95:717-22.

- Derenne JP, Macklem PT, Roussos C: State of the art: The respiratory muscles: Mechanics, control, and pathofysiology. Parts I, II, III. Am. Rev. Respir. 1978;118:$119-133,373-389,581-601$.

- Deurenberg P, Westrate J A, Paymans I, Kooy van der K. Factors affecting bioelectrical impedance measurements in humans. Eur. J. Clin. Nutr. 1988;42: 1017-1022. 


\section{References}

- Diaz EO, Villar J, Immink M, Gonzalez T. Bioimpedance or anthropometry? Eur. J. Clin. Nutr. $1989 ; 43: 129-37$.

- Donahoe M, Rogers RM. Nutritional assessment and support in chronic obstructive lung disease. Clinics in Chest Medecine 1990;11:487-504.

- Donahoe M, Rogers RM, Wilson DO, Pennock BE. Oxygen consumption of the respiratory muscles in normal and in malnourished patients with Chronic Obstructive Pulmonary Disease. Am. Rev. Respir. Dis. 1989;94:1260-1263.

- Domhorst A. Respiratory insufficiency. Lancet 1955;268:1185-7.

- Driver AG, Mc Alevy MT, Smith JL. Nutritional assessment of patients with Chronic Obstructive Pulmonary Disease and acute respiratory failure. Chest 1982;82:568-71.

- Dullo $\mathrm{AG}$, Miller DS. The thermogenic properties of epinephridine/methylxanthine mixtures: human studies. Int. J. Obes. 1986;10:162.

- Dumin JVGA, Rahaman MM. The assessment of the amount of fat in the human from measurement of skinfold thickness. Br. J. Nutr. 1967;21:681-689.

- Dumin JVGA, Womersley K. Body fat assessed from total body density and its estimation from skinfold thickness: measurements on 481 men and women aged 16 to 72 years. Br. I. Nutr. 1974;32:77-97.

- Edelman NH, Rucker RB, Peady HH. Nutrition and the respiratory system. NIH workshop summary. Am. Rev. Respir. Dis. 1986;134:134-52.

- Edmonds CJ, Jasani HB, Smith T. Total body potassium and body fat estimation in relationship to height, sex, age, malnutrition and obesity. Clin. Sci. Mol. Med. $1975 ; 48: 431-440$.

- Efthimiou $J$, Fleming $J$, Gomes $C$, Spiro SG. The effect of supplementary oral nutrition in poorly nourished patients with Chronic Obstructive Pulmonary Disease. Am. Rev. Respir. Dis. 1988;137:1075-1082.

- Everdy BAB, McLeod ME, Mulera M, Kirpalani H. End-tidal, transcutaneous and arterial $\mathrm{PCO}_{2}$ measurements in critically ill neonates: a comparative study. Anesthesiology $1988 ; 69: 112-116$. 
- Falciglia G, O'Conner J, Gedling E. Upper arm anthropometric norms in elderly white subjects. J. Am. Diet. Assoc. 1988;88:569-574.

- Faulkner JA, Maxwell LC, Ruff GL, White TP. The diaphragm as muscle. Am. Rev. of Respir. Dis. 1979;119:89-92.

- Fiaccadori E, DelCanale S, Coffrini E, Vitali P, Antonucci C, Cacciani G, Mazzola I, Guariglia A. Hypercapnic-hypoxemic chronic obstructive pulmonary disease (COPD): influence of severity of COPD on nutritional status. Am. J. Clin. Nutr. 1988;48:680-5.

- Fitting JW, Frascarolo Ph, Jéquier E, Leuenberger Ph. Energy expenditure and rib cage-abdominal motion in chronic obstructive pulmonary disease. Eur. Respir. J. $1989 ; 2: 840-845$.

- Forse RA, Shixgal HM. Serum albumin and nutritional status.. J.P.E.N. 1980;450-454.

- Fraser IM. The effects of refeeding on respiration and skeletal muscle function. Clin. Chest Med. 1986;7:131-9.

- Fredrix EWHM, Soeters PB, von Meyenfeldt MF, Saris WHM. Measurement of resting energy expenditure in a clinical setting. Clinical Nutrition, 1990;9:229-304.

- Fuller NJ, Elia M. Potential use of bioelectrical impedance of the whole body and of body segments for the assessment of body composition: comparison with densitometry and anthropometry. Eur. J. Clin. Nutr. 1989;43:779-91.

- Garby L, Lammert $O$. Within-subjects between-days-and-weeks variation in energy expenditure at rest. Hum. Nutr: Clin. Nutr. 1986;40C:365-369.

- Goldstein S, Askanazi J, Weissman C, Thomashow B, Kinney J. Energy expenditure in patients with Chronic Obstructive Pulmonary Disease. Chest 1987;91:222-224.

- Goldstein SA, Thomashow BM, Kvetan V et al. Nitrogen and energy relationships in malnourished patients with emphysema. Am. Rev. Respir. Dis. 1988;138:636-44.

- Goldstein SA, Askanazi J, Elwyn DH, Thomashow B, Millic-Emili J, Kvetan V, Weissman Ch, Kinney JM. Submaximal exercise in emphysema and malnutrition at two levels of carbohydrate and fat intake. J. Appl. Physiol. 1989;67:1048-55. 


\section{References}

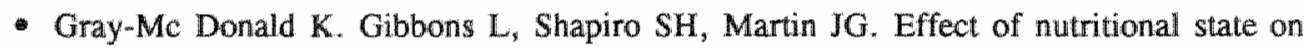
exercise performance in patients with chronic obstructive pulmonary disease. Am. Rev. Respir. Dis. 1989; 140:1544-1548.

- Grollman A. Physiological variations in the cardiac output of man. The Am. J. of Physiol. 1929;89:366-370.

- Harris JA, Benedict EG. A biometric study of basal metabolism. Washington:Carnegie Institution of Washington, 1919.

- Heymsfield SB, Artega C, McManus C, Smith J, Moffit S. Measurement of muscle mass: validity of the 24-hour urinary creatinine method. Am. J. Clin. Nutr. 1983;37:478-494.

- Hoffer EC, Meador CK, Simpson DC. Correlation of whole body impedance with total body water. J. Appl. Physiol. 1969;27:531-534

- Hofstetter A, Schutz Y, Jequier E. Increased $24 \mathrm{~h}$ energy expenditure in cigarette smokers. N. Eng. J. Med. 1986;314,79-82.

- Huch A, Huch R, Konig V, Neuman MR, Parker D, Yount J, Lubbers D. Limitations of pulse oximetry. The Lancet 1988;357-358.

- Hugli O, Schutz Y, Leuenberger Ph, Fitting JW. Twenty four hour energy expenditure in COPD (Abstr). Am. Rev. Respir. Dis. 1990;141:4 A 35.

- Hunter AMB, Carey MA, Larsh HW. The nutritional status of patients with Chronic Obstructive Pulmonary Disease. Am. Rev. Respir. Dis. 1981;124:376-81.

- Jackson AS, Pollock ML, Graves JE, Makar MT. Reliability and valididty of bioelectrical impedance in determining body composition J. Appl. Physiol. 1988;64:529-534.

- Jensen TG, Engbert DM, Dudrick SJ. Nutritional assessment. A manual for practitioners. Ed: Appleton-Century-Crofts, Connecticut, 1983.

- Jequier E. Measurement of energy expenditure in clinical nutritional assessment. JPEN 1987;11:86S-89S.

- Johnson PC. Weight gain in geriatric patients. Proceedings of symposium on anabolic therapy. Detroit, 1962;85-95. 
- Katch FI, Solomon RT, Shayevitz B. Validity of bioelectrical impedance to estimate body composition in cardiac and pulmonary patients. Am. J. Clin. Nutr. 1986;43:97278 .

- Kelly AM, Rosa A, Field S, Coughlin M, Shizgal HM, Mackiem PT. Respiratory muscle strength and body composition in patients receiving totall parenteral nutrition therapy. Am. Rev. Respir. Dis. 1984;130:33-37.

- Kelsen SG, Ference M, Kapoor S. Effects of prolonged undernutrition on structure and function of the diapragm. J. Appl. Physiol. 1985;58:1354-1359.

- Kemper MS. Indirect calorimetry. Equipment and practical considerations. Problems in respiratory care $1989 ; 2: 479-490$.

- Keys A, Brozek J, Henschel A. The biology of human starvation. The University of Minnesota Press, 1950.

- Killian KJ, Jones NL. Respiratory muscles and dyspnea. Clinics in Chest medicine $1988 ; 9: 237-248$.

- Kleinbaum $\mathrm{DG}$, Kupper L.L. Muller KE. Applied regression analysis and other multivariate methods. PWS-Kent Publishing Company, Boston, 1988.

- Knowles JB, Farbarne MS, Wiggs DJ, et al. Dietary supplementation and respiratory muscle performance in patients with COPD. Chest $1988 ; 93: 977-83,1988$.

- Kushner P F, Schoeller DA. Estimation of total body water by bioelectrical impedance analysis. Am. J. Clin. Nutr. 1986;44:417-444

- Lanigan C, Moxham J, Ponte J. Effect of airflow limitation on resting oxygen consumption. Thorax 1990;45:388-390.

- Lewis MI, Sieck GC, Fournier M: Effect of nutritional deprivation on diaphragm contractility and muscle size. J. Appl. Physiol. 1986;60:596-603.

- Lewis MI, Belman MI, Dorr-Uyemura L. Nutritional supplementation of ambulatory patients with chronic obstructive pulmonary disease. Am. Rev. Respir. Dis. 1987; 135:1062-68. 


\section{References}

- Lopes J, Russell DMcR, Whitwell J, Jeejeebhoy KN. Skeletal muscle function in malnutrition. Am. J. Clin. Nutr. 1982;36:602-610.

- Lopes I. Prognostic and therapeutic implications of deranged pulmonary function. Proc. R. Soc. Med. 1962;55:454-7.

- Lukaski HC, Johnson PE, Bolonchuk WW, Lykken GI. Assessment of fat-free mass using bioelectrical impedance measurements of the human body. Am. J. Clin Nutr. $1985 ; 41: 810-817$.

- Lukaski HC, Bolunchuk WW, Hall CB, Siders WA. Validation of tetrapolar bioelectrical impedance method to assess human body composition. J. Appl. Physiol. 1986;60:1327-1332.

- Lukaski HC. Methods for the assessment of human body composition: traditional and new. Am. J. Clin. Nutr. 1987;46:537-56.

- Mahutte CK, Michiels TM, Hassell KT, Trueblood DM. Evaluation of a single transcutaneous $\mathrm{PO}_{2}-\mathrm{PCO}_{2}$ sensor in adult patients. Critical Care Medicine 1984; 12 :$1063-1066$.

- Martin $J_{G}$, De Troyer $A$. The behavior of the abdominal muscles during inspiratory mechanical loading. Respir. Physiol 1982;50:63-73.

- Mc Gavin CR, Gupta SP, Mc Hardy GJR. Twelve minute walking tests for assessing disability in chronic bronchitis. Br. Med. J. 1976; 1:822-823.

- Midgren B, Airikkala P, Rijding E. Transcutaneous $\mathrm{CO}_{2}$ monitoring and disordered breathing during sleep. Eur. J. Respir. Dis. 1984;65:521-528.

- Moore JA, Angelillo VA. Equations for the prediction of resting energy expenditure in Chronic Obstructive Lung Disease. Chest 1988;94:1260-1263.

- Morton RE, Hutchings J, Halliday D, Rennie MJ, Wolman SL. Protein metabolism during treatment of chest infection in patients with cystic fibrosis. Am. J. Clin. Nutr. $1988 ; 47: 214-19$.

- Munro HN. Mammalian protein metabolism. Chapter 10, vol 1. ed H.N. Munro and JB Allison. 1964; New York and London. Academic press. 
- Murgatroyd PR, Davies HL, Prentice AM. Intra-individual variability and measurement noise in estimates of energy expenditure by whole body indirect calorimetry. Br.J. Nutr. 1987;58:347-56.

- Nair KS, Halliday D, Garrow JS. Thermic response to isoenergetic protein, carbohydrate or fat meals in lean and obese subjects. Clinical Science 1983;65:307-312.

- NEVO tabel. Stichting Nederlands Voedingsstoffenbestand.s'Gravenhage: Voorlichtingsbureau voor de Voeding, 1986.

- Nörregaard $O$, Larsen BO, Dahl $R$. Meal related changes in dyspnea and arterial blood gases in patients suffering from chronic obstructive pulmonary disease. (abstract) Eur. J.Respir. Dis. 1988;68 s.

- O'Keefe SID, Dicker J. Is plasma albumin concentration useful in the assessment of nutritional status of hospital patients? Eur. J. Clin. Nutr. 1988;42:41-45.

- Openbrier DR, Irwin MM, Rogers MM et al. Nutritional status and lung function in patients with emphysema and chronic bronchitis. Chest 1983;83:17-22.

- Otte KE, Ahlburg $\mathbb{P}$, D'Amore F. et al. Nutritional repletion in malnourished patients with emphysema. J.P.E.N. 1984;13:152-6.

- Page CW. The treatment of debility: a controlled experience. Proceedings of symposium on anabolic therapy. Detroit 1962;85-95.

- Passmore R, Eastwood MA. Human Nutrition and Dietetics 8th ed. Churchill Livinstone, Edinburgh, London, Melbourne, New York 1986,93-102

- Pethig $\mathbb{R}$. Dieelectrical and electronic properties of biological materials. John Willey \& Sons, Chicester 1969.

- Quanjer Ph ed. Standardized lung function testing. Bulletin Europ. Physiopath. Resp. $1983 ; 19: 7-44$.

- Ravussin E, Lillioja $S$, Anderson TE, Christin L, Bogardus C. Determinants of 24 hour energy expenditure in man: methods and results using a respiration chamber. $I$. Clin. Invest. 1986;78:1568-78. 


\section{References}

- Ravussin E, Burnard B, Schutz Y. Twenty four hour energy expenditure and resting metabolic rate in obese, moderately obese and control subjects. Am. J. Clin. Nutr. 1981;35:566.

- Ravussin E, Bogardus C. Relationship of genetics, age and physical fitness to daily energy expenditure and fuel utilization. Am. J. Clin. Nutr. 1989;49:968-75.

- Rebora Togno F. El decanoato do nondrolona com coadyuvante del tratamiento medico o quirurgico de la tuberculosis pulmonar. Sem. Med. Mex. 1971;67:146-50.

- Renzetto AD, Mc Clement JH, Litt BD. The veterans administration cooperative study of pulmonary function. Mortality in relation to respiratory function in chronic obstructive pulmonary disease. Am. J. Med. 1966;41:115-129.

- Renzi GD, Renzi PM, Feustel PJ, Dutton RE. The influence of weight on exercise limitation in chronic obstructive lung disease (abstract). Am. Rev. Respir. Dis. 1985; 131:A353).

- Rochester DF, Braun NMT. Determinants of maximal inspiratory pressure in chronic obstructive pulmonary disease. Am. Rev. Respir. Dis. 1985;132:42-47.

- Rochester DF. Body weight and respiratory muscle function in chronic obstructive pulmonary disease. Am. Rev. Respir. Dis. 1986;134:646-648.

- Roussos CH, Macklem PT. The respiratory muscles. N. Eng. J. Med. 1982;307:786.

- Russell D Mc R, Prendergast P J, Darby P L 1983 A comparison between muscle function and body composition in anorexia nervosa: the effects of refeeding. Am. J. Clin. Nutr. 1979;38:229-237

- Schoeller DA, Van Santen E. Total body water measurement in humans with ${ }^{18} \mathrm{O}$ and ${ }^{2}$ H labeled water. Am. J. Clin. Nutr. 1980;33:2686-93.

- Schoeller DA. Changes in total body water with age. Am. J. Clin. Nutr. 1989;50:1176-81.

- Schols AMWI, Mostert R, Soeters PB, Greve LH, Wouters EFM. Inventory of nutritional status in chronic obstructive pulmonary disease. Chest 1989;96:247-249. 
- Schols AMWJ, Mostert R, Soeters PB, Greve LH, Wouters EFM. Nutritional state and exercise performance in patients with chronic lung disease. Thorax 1989;44: 937941.

- Schols AMWJ, Hoogeveen CEM, Wouters EFM. Assessment of dietary intake in COPD. Eur. Respir. J. 1990;3:148s.

- Segal KR, Gutin B, Presta E, Wang J, Italie v TB. Estimation of human body composition by electrical impedance methods. A comparitive study. Joumal of Applied Physiology 1985;58:1565-71.

- Segal KR. Comparison of indirect calorimetric measurements of resting energy expenditure with a ventilated hood, face mask and mouth piece. Am. J. Clin. Nutr. $1987 ; 45: 1420-3$.

- Seideli JC, Oosterlee A, Thyssen MAO, Burema J, Deurenberg P, Hautvast JGAJ, Ruys JHJ. Assessment of intraabdominal and subcutaneous fat: relation between anthropometry and computed tomography. Am. J. Clin. Nutr. 1987;45:7-13.

- Sheng HP, Higgins RA. A review of body composition studies with emphasis on total body water and fat. Am. J. Clin. Nutr. 1979;32:630-647.

- Siech GC, Lewis MI, Blanco CE. Effects of undernutrition on diaphragm fiber size, SDH activity and fatigue resistance. J. Appl. Physiol. 1989;66(5): 2196-2205.

- Smith J, Wolkove $\mathrm{N}$, Colacone A, Kreisman H. Coordination of eating, drinking and breathing in adults. Chest 1989;96:578-582.

- Soares MJ, Shetty PS. Intra-individual variations in resting metabolic rates of human subjects. Hum. Nutr: Clin. Nutr. 1986;40C:365-369.

- Soeters PB, Von Meyenfeldt MF, Meyerink WJHJ, Fredrix EWHM, Wouters EFM, Schols AMWJ. Serum albumin and mortality. (letter to the editor) The Lancet 1990; i: 348

- Swerts PJM, Mostert R, Wouters EFM. Comparison of corridor and treadmill walking in patients with severe chronic obstructive pulmonary disease. Physical Therapy $1990 ; 70: 439-442$ 
- Swinburn CR, Cooper BG, Mould H, Corris PA, Gibson GJ. Adverse effects of additional weight on exercise against gravity in patients with Chronic Obstructive Alirways Disease. Thorax 1989;44:716-20.

- Thurlbeck WM. Diaphragm and body weight in emphysema. Thorax 1978;33:483-7.

- Tuten MB, Wogt S, Dasse F, Leider Z. Utilization of prealbumin as nutritional parameter. J.P.E.N. 1985;9:709*11.

- Vadasz 1. Nandrolone decanoate on some forms of pulmonary tuberculosis. Arzneimittel-Forsch. 1969;19:100-103.

- Vaisman N, Levy LD, Pencharz P.B. et al. Effect of salbutamol on resting energy expenditure in patients with cystic fibrosis. J. Pediatr. 1987;111:137.

- Vandenbergh E, Van de Woestijne $\mathrm{K}$, Gyselen A. Weight changes in the terminal stages of chronic obstructive lung disease. Am. Rev. Respir. Dis. 1967;95:556-566.

- Weir JB. New methods for calculating metabolic rate with special reference to protein metabolism. J. Physiol. 1949;109:1-9.

- Weits T, Van der Beek EJ, Wedel M, Ter Haar-Rhomeny BM. Computed tomography measurement of abdominal fat deposition in relation to anthropometry. International Journal of Obesity $1988 ; 12: 217-225$

- Whittaker JS, Ryan F, Buckley PA, Road JD. The effects of refeeding on peripheral and respiratory muscle function in malnourished Chronic Obstructive Pulmonary Disease patients Am. Rev. Respir. Dis. 1990;142:283-88.

- Wilson DO, Donahoe M, Rogers RM, Pennock BE. Metabolic rate and weight loss in Chronic Obstructive Lung Disease. J.P.E.N. 1990;14:7-11.

- Wilson DO, Rogers RM, Hoffman RM. Nutrition in chronic lung disease. Am. Rev. Respir. Dis. 1985;132:1347-1365.

- Wilson DO, Rogers RM, Sanders MH, Pennock BE, Reilly JJ. Nutritional intervention in malnourished patients with emphysema. Am. Rev. Respir. Dis. 1986; 134: 672-677.

- Wilson DO, Rogers RM, Wright E, Anthonisen NR. Body weight in Chronic Obstructive Pulnonary Disease. Am. Rev. Respir. Disease 1989;139:1435-1438. 


\section{Summary}

Although the association between weight loss and chronic obstructive pulmonary disease (COPD) is well-known, pathophysiological and therapeutic implications of nutritional depletion in COPD patients have received little attention. The major part of this thesis is devoted to providing a conceptual framework for treating nutritional depletion in COPD patients. The thesis ends with preliminary results of a study in which it was attempted to improve body composition and physical performance in nutritionally depleted COPD patients. The studies were conducted in a pulmonary rehabilitation center, to which patients with moderate to severe COPD, in a stable clinical condition, are referred by their pulmonary physician, to participate in an intensive pulmonary rehabilitation program.

To identify patients who may benefit from nutritional support, above all it is necessary that nutritional depletion is defined clearly. Furthermore reliable and reproducible measures are required for assessing and the follow-up of nutritionally depleted patients.

Body weight or body weight corrected for height is often used as an indicator of mutritional status. However, when nutritional depletion is investigated, additional information on body composition and specifically on the size of the 'metabolicaliy active mass' is needed. A direct measure of this so-called body cell mass is not yet available in clinical practice, but it is generally acknowledged that, in the absence of excess fluid shifts, a useful estimate is given by the fat-free mass. Numerous methods are available for assessing fatfree mass, most of which are cumbersome and unfit for clinical use. Recent years saw the introduction of the bioelectrical impedance method, which allows quick, easy and reliable assessment of body composition in healthy subjects. In chapters 2 and 3 the reliability and reproducibility of this method is investigated when fat-free mass in patients with COPD is assessed. A regression model for bioelectrical impedance was generated, in which total body water (assessed by deuterium dilution) was used as a reference method in a sample of COPD patients in a stable pulmonary and cardiac condition. Height squared divided by resistance, and body weight were included in a model that explained $89 \%$ of the variation in total bodly water. Predicted total body water was then used to estimate fat-free mass. Subsequently, this fat-free mass was compared with skinfold-based fat-free mass predictions. The findings indicate that bioelectrical resistance is a reliable measure to assess fatfree mass in patients with stable COPD. The suggestion made by other authors that skinfold anthropometry tends to overestimate fat-free mass in elderly people, is confirmed.

Since in biological systems electric conduction is related to water and ionic distribution in the conductor, it can be deduced that changes in body water and/or electrolyte balance influence total body resistance. Therefore the within-day and between-day variation of 
bioelectrical resistance in patients with severe COPD was investigated. In addition, the relative influence of a meal, exercise and diuretic maintenance treatment to the within-day variation was investigated. The results indicate that in patients with stable COPD, withinday variation only has a slight impact on the estimation of fat-free mass for patient comparison, but should be considered during follow-up studies.

In chapter 4 a computerized open-circuit ventilated hood is described, constructed to assess resting energy expenditure in a clinical setting. The measurement error of the device, tested by ethanol combustion, was less than $5 \%$. Since few data exist with respect to the within-patient variability of resting energy expenditure measurements that are performed in a daily clinical routine, we investigated, for several groups of COPD patients, (1) reproducibility (2) the influence of routine physical activity prior to measurement and (3) measurement duration. Short-term and long-term reproducibility of the measurement was good. Variation because of limited activity and different measurement duration (between 10 and 30 minutes) was small and not significant. The results indicate that resting energy expenditure can be reliably assessed in COPD patients on an outpatient basis.

Prevalence and characteristics of nutritional depletion were investigated in $255 \mathrm{COPD}$ patients consecutively admitted to a pulmonary rehabilitation center. Depletion of body weight, fat-free mass and muscle mass is most pronounced (40-50\%) in patients suffering from chronic hypoxemia and in normoxemic patients with severe airflow obstruction. However, depletion was also found in about $25 \%$ of COPD patients with moderate airflow obstruction. Classification of the patients into four groups by body weight and fatfree mass revealed that depletion of fat-free mass may occur in normal-weight COPD patients. These patients suffered from physical impairment to an even greater extent than underweight patients showing preservation of fat-free mass. No systematic differences in serum protein concentrations were found in the four groups.

Chapter 6 systematically deals with the relation between nutritional depletion and exercise performance in COPD patients with severe airflow obstruction. Exercise performance was evaluated with a 12-minute walking test. A relation between walking distance and spirometic measures was not found. A good correlation was found between walking distance and fat-free mass both in the entire group and in the subgroup of underweight patients, whereas body weight correlated with walking distance in the entire group only. On stepwise regression analysis fat-free mass, maximal inspiratory mouth pressure and arterial oxygen tension explained a major part of the variation in the distance walked in 12 minutes. These results indicate that fat-free mass, independent of airflow obstruction is an important determinant of exercise performance in patients with severe COPD. 
Information concerning the pathogenesis of depletion is required to design intervention programs and to interpret outcome. A major cause of weight loss is an imbalance between energy intake and energy expenditure. In chapter 7 resting energy expenditure, the major determinant of total energy expenditure, is studied. Resting energy expenditure was measured by indirect calorimetry using a 'wentilated hood' system, in a group of COPD patients and in a healthy age-matched control group. Fat-free mass explained the major part of the variation in resting energy expenditure in the control group, but only $34 \%$ of the variation in resting energy expenditure in the COPD patients. Resting energy expenditure in the COPD patients could not reliably be predicted from regression equations either developed in healthy subjects or in COPD patients. Resting energy expenditure adjusted for fat-free mass was slightly higher in COPD patients losing weight compared to weightstable COPD patients, and significantly higher in weight-stable patients compared to the weight-stable control group. These results indicate that COPD patients develop a diseaserelated increase in resting energy expenditure.

In chapter 8 resting energy expenditure is compared to energy intake assessed using a diet history. Patients who have recently suffered weight loss exhibit lower dietary intake both in absolute terms and expressed as a percentage of measured resting energy expenditure. A positive relation is established between disease severity and energy depletion, with a pronounced drop in energy intake in patients suffering from chronic hypoxemia. The combined data of chapters 7 and 8 suggest that two factors cause weight loss in COPD: (1) the absence of an adaptive metabolic response to undernutrition and (2) inadequate dietary intake.

In chapter 9 two factors that may interfere with dietary intake in COPD are systematically investigated: the effect of eating on transcutaneous oxygen saturation and the effect of the carbohydrate content of a meal on transcutaneous carbon dioxide tension. It was found that meal-related oxygen desaturation cannot explain weight loss in normoxemic COPD patients. However, it may cause limited dietary intake in a subgroup of hypoxemic patients. Contrary to suggestions of other authors, a single carbohydrate rich meall does not have an immediate impact on transcutaneous carbon dioxide tension.

The effect of supplemental nutrition, alone or combined with anabolic steroids, on body composition and physical performance was investigated in a controlled, randomized trial, conducted as an integrated part of an eight-week pulmonary rehabilitation program. Both underweight and normal-weight patients exhibiting fat-free mass depletion were considered depleted. The interim analysis indicates that daily supplemental nutrition combined with general physical training is a successful and therapeutically feasible approach to gradually increase fat-free mass in depleted COPD patients. Furthermore the results suggest that supportive treatment with anabolic steroids may enhance an increase in 
muscle mass instead of fat mass. The treated groups also exhibited a significant increase in respiratory muscle strength, which was most pronounced in the group receiving anabolic steroids. Treatment contrasts with the group receiving placebo treatment were not significant, however. Preliminary conclusions as to exercise performance cannot yet be drawn from this interim analysis, due to the small number of patients involved. 


\section{Samenvatting}

Gewichtsverlies komt frequent voor bij patiënten met een chronisch obstructief longlijden (Engelstalige afkorting: COPD). Reeds in de zestiger jaren werd aangetoond dat gewichtsverlies prognostisch een ongunstig teken is voor de COPD-patient. Het duurde echter tot de tachtiger jaren voordat er bij de behandeling van COPD-patiënten aandacht aan werd besteed. Deze was gebaseerd op dierexperimenten en op studies bij mensen, waarin werd aangetoond dat ondervoeding niet alleen leidt tot depletie van skeletspiermassa, maar dat ze ook de ademhalingsspieren aantast. Desondanks is er nog slechts weinig onderzoek verricht naar de oorzaken, de consequenties en de behandeling van gewichtsverlies en spiermassa-depletie bij patiënten met COPD.

Een groot gedeelte van het in dit proefschrift beschreven onderzoek behelst een raamwerk voor de behandeling van depletie bij COPD-patiënten. Aan het einde ervan worden de voorlopige resultaten besproken van een studie waarin werd getracht de lichamelijke conditie van deze patiënten te verbeteren; dit door middel van voedingssuppletie allén, of in combinatie met anabole steroiden. Het onderzoek is uitgevoerd bij COPD-patiënten, opgenomen in het astmacentrum Hornerheide, alwaar ze deelnamen aan een intensief longrevalidatie-programma.

Om patiënten te selecteren die baat kunnen hebben van voedingsondersteuning, dient het begrip 'ondervoeding.' of, beter gezegd, 'depletie' te worden gedefinieerd. Tevens zijn betrouwbare en reproduceerbare meetinstrumenten nodig. Lichaamsgewicht, gerelateerd aan de lichaamslengte is een gangbaar meetinstrument, maar heeft als nadeel dat het geen rekening houdt met de lichaamssamenstelling van de mens. Het lichaam is opgebouwd uit vetmassa en vetvrije massa. De vetvrije massa bestaat uit lichaamscelmassa en water. De lichaamscelmassa is de 'metabool actieve' massa en bestaat voor het grootste deel uit spiermassa. Voor het vaststellen van depletie is informatie over de onvang van de lichaamscelmassa nodig. Er is momenteel nog geen klinisch bruikbare methode beschikbaar voor het bepalen van deze omvang, maar algemeen wordt aangenomen dat hiervoor de hoeveelheid vetvrije massa als maat kan dienen, tenzij er sprake is van verstoring in de vochtbalans. Onlangs werd de zogenoemde bio-electrische impedantiemethode geïntroduceerd voor een snelle, voor de patiënt niet belastende bepaling van de vetvrije massa. Het principe van deze meting berust op de geleidbaarheid van een zwakke wisselstroom door het lichaam. De geleiding wordt bij bepaalde frequenties grotendeels bepaald door het lichaamswater en de electrolyteninhoud van de weefsels. De geleidbaarheid van de vetvrije massa, die de lichaamsvloeistoffen en electrolyten bevat, is groter dan die van de vetmassa. Theoretisch bestaat er een lineair verband tussen de vetvrije massa of de totale hoeveelheid lichaamswater enerzijds en de lichaamslengte in het kwadraat, gedeeld door de impedantie, anderzijds. In hoofdstuk 2 kijken we of dit verband ook geldt voor COPD- 
patienten, waarbij de totale hoeveelheid lichamswater wordt bepaald door middel van de deuterium verdunningsmethode. Er wordt, net als bij gezonde vrijwilligers, inderdaad een relatie tussen de twee meetinstrumenten gevonden. De totale hoeveelheid lichaamswater wordt gebruikt om de vetvrije massa te bepalen. Deze wordt vervolgens vergeleken met de hoeveelheid veturije massa op basis van huidplooimetingen. De bevindingen tonen auan dat meting van de impedantie een betrouwbare methode is voor het bepalen van de vetvije massa bij COPD-patienten, mits ze zich in een klinisch stabiele toestand bevinden. We zien tevens de resultaten van andere auteurs bevestigd, dat meting van huidplooidikten tot een owerschatting leidt van de vetvrije massa bij oudere personen.

Omdat in biologische systemen de electrische geleiding afhankelijk is van de water- en ioneiverdeling van de geleider, kan worden gesteld, dat veranderingen in lichaamswater en/of electrolyten van invloed zijn op de lichaamsimpedantie. Daartoe bestuderen we in hoofdstuk 3 de binnen- en tussendagsvariatie van de lichaamsimpedantie bij ernstige COPD-patiënten. Speciaal kijken we daarbij nog naar de effecten van een maaltijd, van lichamelijke inspanning en van diuretica, als onderhoudsmedicatie op de binnendagswariatie. De resultaten tonen aan dat bij klinisch stabiele patiënten de binnendagsvariatie slechts een beperkte invloed heeft op de meting van de vetvrije massa, die verwaarloosbaar is bij vergelijking tussen patiënten onderling, maar waarmee wel degelijk rekening moet worden gehouden bij vervolgstudies.

Volgens de principes van de indirecte calorimetrie is het mogelijk om het energieverbruik bij mensen in rust (de ruststofwisseling) te meten. In hoofdstuk 4 wordt het 'ventilated hood-systeem' beschreven, dat ontworpen is on de ruststofwisseling van patiënten te meten in de klinische praktijk. De patiënten liggen onder een kap van plexiglas, waar een constante stroom kamerlucht doorheen wordt geleid. Die mengt zich met de uitademingslucht van de patiènt. Het energieverbruik kan worden berekend uit de hoeveellheid lucht die door de kap stroomt en uit de concentraties zuurstof en koolzuur van de inkomende en uitgaande lucht. Omdat er slechts weinig gegevens beschikbaar zijn aangalande de condities waaronder stofwisselingsmetingen in rust moeten worden uitgevoerd, bestuderen we bij verschillende groepen COPD-patiënten de reproduceerbaar. heid, de invloed van dagelijkse lichamelijke activiteiten, voorafgaande aan de meting en de meetduur. Er blijkt dat de reproduceerbaarheid wan de meting met een interval van 2 manden, bij patiënten met een stabiel lichaamsgewicht goed is, terwijl variaties door beperkte lichamelijke activiteit of een variabele meetduur (tussen 1.0 en 30 minuten) klein en statistisch niet significant zijn. Deze bevindingen tonen dus aan dat de ruststofwisseling bij COPD-patiënten ook poliklinisch gemeten kan worden.

De prevalentie en de kenmerken van depletie bij COPD zijn vastgesteld bij 255 patiënten die achtereenvolgens opgenomen waren in het astmacentrum. Depletie van lichaams- 
gewicht, van vetvrije massa en van spiermassa blijkt het duidelijkst (40-50\%) bij patienten met een chronische hypoxemie (= te lage zuurstofspanning in het arterièle bloed), en bij patiènten met een ernstige luchtwegobstructie. Maar ze wordt ook geconstateerd bij ongeveer $25 \%$ van de COPD-patiënten met een minder emstige luchtwegobstructie. Opmerkelijk is dat depletie van vetwrije massa niet alleen optreedt bij sterk vermagerde patiënten, maar ook kan voorkomen bij patiënten met een normaal lichamamsgewicht. De inspanningstolerantie en de kracht van de ademhalingsspieren van deze patienten zijn zelfs lager dan die van patiënten met verlies van lichaamsgewicht, maar wier hoeveelheid vetvrije massa verhoudingsgewijs minder is afgenomen.

In hoofdstuk 6 nemen we systematisch de relatie tussen depletie van vetvrije massa en de inspanningstolerantie bij COPD-patiënten onder de loep. De inspanningstolerantie wordt geëvalueerd met een "12 minuten-looptest". COPD-patiënten met een ernstige luchtwegobstructie worden bestudeerd. Patiënten met een chronische hypoxemie, en/of patiẽnten die niet in staat zijn deze test zonder tussenstops te volbrengen, worden uitgesloten van de studie. Er wordt geen verband gevonden tussen loopafstand en luchtwegobstructie, maar wel een positieve correlatie tussen loopafstand en vetvrije massa. Dit geldt zowel voor alle proefpersonen als specifiek voor de vermagerde patienten. 60 Procent van de variatie in de 12 minuten-Loopafstand is via regressie-analyse te verklaren uit de hoeveelheid vetvrije massa, de arteriële zuurstofspanning en de maximale inspiratoire spierkracht. Uit. dit als volgt dat bij COPD-patiênten met een ernstige luchtwegobstructie de vetvrije massa, onafhankelijk van de luchtwegobstructie, een belangrijke determinant is van de inspanningstolerantie.

Voor de behandeling van depletie bij COPD-patiënten is het nodig inzicht te verwerven in de oorzaken ervan. Gewichtsverlies wordt voornamelijk veroorzaakt door verstoring van de balans tussen energie-inmame en energieverbruik. De belangrijkste determinant van het dagelijkse energieverbruik is de ruststofwisseling. In hoofdstuk 7 wordt deze vergeleken tussen een groep COPD-patiënten en een gezonde controle-groep. Terwijl de vetvrije massa normaliter grotendeels de variatie in ruststofwisseling tussen individuen verklaart, blijkt dit niet het geval te zijn bij COPD patienten. Na correctie van de verschillen in vetvrije massa blijkt de groep COPD-patienten een significant hogere ruststofwisseling te hebben dan de gezonde controle-groep. De ruststofwisseling van patiënten met recent gewichtsverlies is daarbij nog jets hoger dan dat van patiènten met een stabiel lichaamsge-wicht. Dit is een opvallende bevinding, aangezien de ruststofwisseling normaliter daalt bij ondervoeding. Deze resultaten wijzen erop dat er bij COPD-patienten sprake is van een aan de ziekte inherente toename wan de ruststofwisseling.

In hoofdstuk 8 vergelijken we de ruststofwisseling van COPD-patiënten met de voedselinname. De voedselinname is lager bij patiënten met recent gewichtsverlies, zowel in 
absolute zin als uitgedrukt in een percentage van de gemeten ruststofwisseling. Er wordt een positief verband aangetoond tussen energiebalans en de ernst van de ziekte. Een duidelijke daling van de voedselinname treedt op bij patiënten met een chronische hypoxemie. De bevindingen in de hoofdstukken 7 en 8 geven aan dat zowel cen verminderde voedselinname, als het ontbreken van een adaptieve daling van de ruststofwisseling bij ondervoeding bijdragen tot gewichtsverlies bij COPD-patiënten.

In hoofdstuk 9 worden vervolgens 2 factoren bestudeerd die mogelijk een verminderde voedselinname bij deze patiënten kunnen verklaren, namelijk het effect van het eten op de zuurstof-saturatie en het effect van de hoeveelheid koolhydraten van de maaltijd op de koolzuurspanning. Desaturatie tijdens de maaltijd blijkt echter geen verklaring te zijn voor het gewichtsverlies bij COPD-patiënten met normale bloedgassen in rust. De resultaten wijzen erop dat, bij een deel van de hypoxemische COPD-patiënten, desaturatie wel de voedselinname kan beperken. In tegenstelling tot suggesties van andere auteurs, hebben wij geen stijging van de koolzuurspanning tijdens, of direct na het eten van een koolhydraatrijke maaltijd gevonden.

Het effect van voedingssuppletie, alleén of in combinatie met anabole steroïden, op de lichaamssamenstelling en de lichamelijke conditie van COPD-patiënten komt in hoofdstuk 10 aan de orde. De interventie is geintegreerd in een 8 weken durend longrevalidatieprogramma. Van de gepresenteerde interim-analyse tonen de resultaten aan dat een dagelijks voedingssupplement, in combinatie met training, een succesvolle benadering is om een geleidelijke toename van de vetvrije massa bij COPD-patiënten te bewerkstelligen. De resultaten geven verder aan dat een ondersteunde behandeling met anabole steroïden, de inbouw van calorieèn in vetvrije massa vergroot. De kracht van de ademhalingsspieren neemt bij de behandelde patiënten eveneens toe en is zelfs iets groter bij de patiënten die anabole steroiden hebben ontvangen. Deze toename blijkt bij vergelijking met de controlegroep echter nog niet statistisch significant. Voorlopige conclusies met betrekking tot toename wan de inspanningstolerantie kunnen in deze interim-analyse nog moeilijk worden getrokken. 


\section{List of abbreviations}

\begin{tabular}{|c|c|}
\hline $\mathrm{ALB}$ & albumin \\
\hline anthr & anthropometry \\
\hline $\mathrm{BCM}$ & body cell mass \\
\hline bi & bioelectrical impedance \\
\hline BMI & body mass index \\
\hline $\mathrm{CHI}$ & creatinine height index \\
\hline COPD & chronic obstructive pulmonary disease \\
\hline$\delta$ & delta \\
\hline $\mathrm{EE}$ & energy expenditure \\
\hline $\mathrm{FEV}_{\mathrm{a}}$ & forced expiratory volume in $1 \mathrm{~s}$ \\
\hline FFM & fat-free mass \\
\hline FFMPIBW & fat-free mass expressed as percentage of ideal body weight \\
\hline${ }^{2} \mathrm{H}_{2} \mathrm{O}$ & deuterium dilution technique \\
\hline $\mathrm{Ht}$ & height \\
\hline IVC & inspiratory vital capacity \\
\hline MAC & midar circumference \\
\hline $\mathrm{MMC}$ & midarm muscle circumference \\
\hline MVV & maximal voluntary ventilation \\
\hline $\mathrm{P}_{\mathrm{a}} \mathrm{CO}_{2}$ & arterial carbon dioxide tension \\
\hline PALB & preallbumin \\
\hline $\mathrm{P}_{\mathrm{n}} \mathrm{O}_{2}$ & arterial oxygen concentration \\
\hline$P_{c}-\max$ & maximal expiratory mouth pressure \\
\hline$P_{i}-\max$ & maximal inspiratory mouth pressure \\
\hline PIBW & percent ideal body weight \\
\hline $\mathrm{P}_{1} \mathrm{CO}_{2}$ & transcutaneous carbon dioxide tenstion \\
\hline $\mathrm{R}$ & resistance \\
\hline REE & resting energy expenditure \\
\hline $\mathrm{RQ}$ & respiratory quotient \\
\hline $\mathrm{S}_{8} \mathrm{O}_{2}$ & arterial oxygen saturation \\
\hline $\mathrm{SD}$ & standard deviation \\
\hline SEE & standard error of estimation \\
\hline SEM & standard error of mean \\
\hline STPD & standard temperature pressure dry \\
\hline TBW & total body water \\
\hline TRF & transferrin \\
\hline
\end{tabular}




\section{List of publications}

Schols AMWJ, Mostert R, Soeters PB, Greve LH, Wouters EFM. Inventory of nutritional status in chronic obstructive pulmonary disease. Chest 1989;96:247-249.

Schols AMWJ, Mostert R, Soeters PB, Greve LH, Wouters EFM. Nutritional state and exercise performance in patients with chronic obstructive lung disease. Thorax 1989;44:937. 41.

Schols AMWJ, Dingemans ANC, Soeters PB, Wouters EFM. Within day variation of bioelectrical resistance measurements in patients with chronic obstructive pulmonary disease. Clinical Nutrition 1990;9:266-271.

Schols AMWJ, Wouters EFM, Soeters PB, Westerterp KR. Body composition by bioelectrical impedance analysis compared to deuterium dilution and skinfold anthropometry in patients with chronic obstructive pulmonary disease. "The American Journal of Clinical Nutrition 1991;53:421-424.

Schols AMWJ, Mostert R, Soeters PB, Saris WHM, Wouters EFM. Energy balance in patients with chronic obstructive pulmonary disease. The American Review of Respiratory Disease $1991 ; 143: 1248-1252$.

Schols AMWJ, Schoffelen P, Ceulemans H, Wouters EFM, Saris WHM. Measurement of resting energy expenditure in patients with COPD in a clinical setting. Accepted in the Journal of Parenteral and Enteral nutrition.

Schols AMWJ, Soeters PB, Dingemans ANC, Mostert R, Frantzen PJ, Wouters EFM. Prevalence and characteristics of nutritional depletion in patients with COPD eligible for pulmonary rehabilitation. Accepted in the American Review of Respiratory Disease.

Schols AMWJ, Mostert R, Soeters PB, Wouters EFM. Body composition and exercise performance in chronic obstructive pulmonary disease. Accepted in Thorax.

Schols AMWJ, Fredrix EWHM, Soeters PB, Westerterp KP, Wouters EFM. Resting energy expenditure in patients with chromic obstructive pulmonary disease. Accepted in the American Journal of Clinical Nutrition.

Schols AMWJ, Cobben N, Mostert R, Soeters PB, Wouters EFM. Transcutaneous oxygen saturation and carbon dioxide tension during meals in COPD. Accepted in Chest. 

De huidige klinische voedingsproblemen vergen een interdisciplinaire wetenschappelijke aanpak. Dit proefschrift is een vrucht van kruisbestuiving tussen de vakgroepen Pulmonologie, Heelkunde en Humane Biologie aan de Rijksuniversiteil Limburg. Het daarvoor benodigde onderzoek vond plaats in het astmacentrum Hornerheide. Wat aanvankelijk een uitdaging leek, bleek al spoedig een voorrecht deze in de genoemde setting te kunnen realiseren.

Bijzonder veel dank ben ik verschuldigd aan mijn co-promotor en promotor die mij de nodige ruimte gaven bij het uitvoeren van het onderzoek en op wie ik altijd een beroep kon doen. Dr. Miel Wouters droeg de probleemstelling voor dit proefschrift aan en was vervolgens op een prettige en efficiënte wijze intensief betrokken bij de concretisering ervan. De visie van Prof. Peter Soeters op de klinische voeding heeft mijn wetenschappelijke vorming in hoge mate beïnvloed. Door stimulerende discussies en waardevolle suggesties wist hij het onderzoek verder uit te diepen.

Veel waardering heb ik voor de medewerkers van het astmacentrum Hornerheide, die flexibel en gemotiveerd wisten in te spelen op de toenemende onderzoeksactiviteiten in hun afdeling, zonder daarbij de patiëntenzorg tekort te doen. De longartsen, de verpleging, de diëtiste, de voedingsassistentes, de longfunctielaborantes, de fysiotherapeuten, de klinische laborantes, de secretaresse en het personeel van de centrale keuken hebben bijgedragen aan een nauwgezette gegevenswerzameling. Problemen werden alert gesignaleerd en zonodig opgelost. In het bijzonder wil ik Drs. Rob Mostert, hoofd astmacentrum, bedanken voor zijn rol als intermediair tussen medewerkers en onderzoeksteam. Onder zijn enthousiaste leiding heb ik het centrum in korte tijd een enorme ontwikkeling zien doormaken. Ook Clarie Weling wil ik graag persoonlijk bedanken voor het vele werk dat zij, als diëtiste, opgeruimd en meelevend, verrichtte ten behoeve van de interventiestudie.

Prof. Wim Saris, Dr. Klaas Westerterp, Ing. Paul Schoffelen en Ing. Loek Wouters ben ik erkentelijk voor hun substantiële bijdragen aan de ontwikkeling en de evaluatie van onderzoeksmethoden op het gebied van energiewisseling en lichaamssamenstelling. Dr. Lily Fredrix bedank ik voor haar bijdrage aan hoofdstuk 7 .

De stagaires Hilde Ceulemans, Nicolle Cobben, Annemarie Dingemans, Angela Finke, Conny Hoogeveen, Bianca Kreuk en Kris Rens dank ik voor hun hulp en gezellige samenwerking. 
De interventiestudie is opgezet en uitgevoerd in naww overleg met de industrie. De heren G. wan de Laar, Drs. R. Pluymers en Drs. S. Stulemeyer dank ik voor hun gewaardeerde bijdragen.

Dit onderzoek was onuitvoerbaar geweest zonder de deelname van veel patiènten. Ik wil hen hartelijk bedanken voor hun inzet, me daarbij realiserend dat confrontatie met onderzoek, gevoegd bij hun aandoening, wel eens belastend zal zijn geweest. Rest mij de hoop uit te spreken dat de invalshoek voeding/metabolisme ook daadwerkelijk geïntegreerd zal worden in de behandeling wan chronisch obstructieve longpatiënten. 




\section{Curriculum vitae}

Annemie, M.W.J. Schols werd op 26-7-1961 geboren in Beek (L). Na het behallen van het V.W.O.-diploma aan het Rythoviuscollege te Eersel (N.Br.) in 1979 begon zij haar studie aan de Landbouwuniversiteit te Wageningen. In 1985 studeerde zij af als landbouwkundig ingenieur in de studierichting Humane Voeding, met als hoofdvakken Voedingsleer, Klinische Voeding (afgelegd aan de Rijksuniversiteit Limburg) en als bijvak Wiskundige Statistiek.

Gedurende het studiejaar 1983 vervulde zij een stage bij het Klinisch Voedingsinstituut in Gotenburg, Zweden. Van oktober 1985 tot november 1986 werd zij door middel van een onderzoeksbeurs van de Canadese regening in de gelegenheid gesteld om bij de Unite de récherche en Nutrition Humaine, aan de medische faculteit van de Universiteit van Sherbrooke, Québec, Canada, onderzoek te doen naar voedingsaspecten bij de ziekte van Crohn. Vanaf mei 1987 is zij werkzaam als onderzoeker bij de vakgroep Pulmonologite aan de medische faculteit van de Rijksuniversiteit Limburg, alwaar het in dit proefschrift beschreven onderzoek werd verricht. 